\title{
International Union of Crystallography Seventeenth General Assembly and International Congress of Crystallography Seattle, Washington, USA, 8-17 August 1996
}

Table of Contents

Introduction and Opening Ceremony

Seventeenth International Congress

Minutes of the Seventeenth General Assembly

Introduction and list of delegates

First Session, Saturday 10 August 1996, 7.05 p.m.

(1) Introductory remarks by the President

(2) Procedural matters .... 694

(3) Approval of Agenda . . . . . . . . . . . . . . 694

(4) Amendments to Statutes and By-Laws affecting adherence to the Union

(5) Applications for membership of the Union . .

(6) Changes in names of Adhering Bodies . . .

(7) Approval of Minutes of Sixteenth General Assembly

(8) Amendments to Statutes and By-Laws not affecting adherence to the Union

(9) Report of Executive Committee

(10) Financial Report . . . . . . . . . . . . . 695

(11) Ewald Prize . . . . . . . . . . . . . . 695

(12) Commission on Journals. Report by Chairmen and review of activities . . . . . . . . 695

(13) Commission on International Tables. Report by Chairman and review of activities

(14) Committee on Electronic Publishing, Dissemination and Storage of Information

(15) Non-publishing Commissions. Reports by Chairmen and review of activities .

(18) Determination of number of elected members of each Commission . . . . . . . . . . . . 696

(19) Proposal to change name of Commission on Small Molecules . . . . . . . . . . . . .

(20) Sponsorship of meetings: Sub-committee on the Union Calendar . . . . . . . . . . . .

(21) IUCr/Oxford University Press Book Series . .

Second Session, Sunday 11 August 1996, 7.05 p.m.

(22) Confirmation of date and place of Eighteenth General Assembly

(23) Preliminary consideration of date and place of Nineteenth General Assembly . . . . . . .

(24) Reports of Representatives on Regional and Scientific Associates

(25) Reports of Representatives on bodies not belonging to the Union
694

693

693

693

694

694

694

694

694
Third Session, Wednesday 14 August 1996, 7.05 p.m.

(26) Amendments to Statutes and By-Laws not affecting adherence to the Union (continued)

(27) Preliminary consideration of date and place of Nineteenth General Assembly (continued)

(28) Determination of general policy and timetable for period to Eighteenth General Assembly

(29) Preliminary consideration of activities for period 1999-2002

(30) Budget estimates for period to Eighteenth General Assembly: determination of unit contribution .

(31) Confirmation of appointments of Editors of publications of the Union

(32) Election of Chairmen and members of Commissions

(33) Election of Representatives on bodies not belonging to the Union and on Regional and Scientific Associates . . . . . . . . . . . . . 697

(34) Election of Officers of the Union . . . . . . 697

(35) Any other business . . . . . . . . . . . . 698

Closing Ceremony, Saturday 17 August 1996

Annex I: Appendices to the Agenda of the Seventeenth General Assembly

(A) Report of the Executive Committee . . . . . 699

(B) Financial Report . . . . . . . . . . . . . 700

(C) Ewald Prize . . . . . . . . . . . . . . . . 708

(D) Reports of Commissions of the Union . . . . 708

(E) Committee on Electronic Publishing, Dissemination and Storage of Information . . . . . . 722

(F) Reports of Representatives on Regional and Scientific Associates . . . . . . . . . . . .

(G) Reports of Representatives on bodies not belonging to the Union

(H) Sponsorship of meetings: Sub-committee on the Union Calendar . . . . . . . . . . . . . . . 728

(1) IUCr/Oxford University Press Book Series . . 729

(J) Budget estimates for period to Eighteenth General Assembly: determination of unit contribution

Annex II: Statutes and By-Laws of the International Union of Crystallography

Annex III: Committees, Commissions and representatives on Regional and Scientific Associates and bodies not belonging to the Union .

Annex IV: Adhering Bodies and National Committees for Crystallography 


\section{Introduction and Opening Ceremony}

By invitation of the US National Committee for Crystallography, in collaboration with the American Crystallographic Association, and the US National Academy of Sciences-National Research Council, the Seventeenth General Assembly and International Congress of Crystallography were held at the Washington State Trade and Convention Center, Seattle, USA, 8-17 August 1996.

The meetings were attended by 2311 scientists, 252 accompanying members and 150 exhibitors from 51 countries.

The General Assembly and Congress were opened on the afternoon of 8 August at the Fifth Avenue Theatre. Professor R. F BRYAN, Chairman of the Organizing Committee, chaired the ceremony. The welcoming addresses and the opening address by Professor P. COPPENS, President of the IUCr, were followed by the presentation of the Ewald Prize to Professor M. G. ROSSMANN and the Ewald Address entitled Crystallographic Studies of Virus Structures. There then followed A Musical Entertainment by the Flying Karamazov Brothers. The evening ended with a welcoming reception at the Bell Harbor International Conference Center.

\section{Seventeeth International Congress}

Scientific programme

24 Keynote Lectures and 104 Microsymposia and Open Commission Meetings were held during the morning and late afternoon sessions. Nobel laureate talks were presented at lunch times and the early afternoons were reserved for poster sessions. There were two evening sessions and three Workshops. The abstracts in the published book of Collected Abstracts were prepared from hard copy and electronic submissions and these abstracts also appeared as a Supplement to Acta Crystallographica, Volume A52, dated 1 September 1996.

\section{Exhibitions}

A commercial exhibition comprising 33 companies, booksellers and software demonstrations was organized.

\section{Social events}

In addition to the opening reception, there was a young scientist mixer, a banquet and a visit to the Pacific Science Center. A variety of excursions were also arranged.

\section{Minutes of the Seventeenth General Assembly}

These Minutes have been prepared by M. H. Dacombe, Executive Secretary, under the authority of S. Larsen, General Secretary and Treasurer of the IUCr and Secretary of the General Assembly. Words importing the male sex in these Minutes shall include the female sex.

\section{Introduction and list of delegates}

Sessions of the General Assembly were held on the evenings of Saturday 10 August, Sunday 11 August and Wednesday 14 August. It was not found necessary to meet on Friday 16 August, as originally planned. The following attendance list gives the names of official delegates appointed by the Adhering Bodies and of the alternates who substituted at one or more sessions. Dates of attendance are given in parentheses for those who were not present at every session. The names are listed by the countries to which the respective Adhering Bodies belong, and the number of votes of the Adhering Body is given in parentheses after the name of the country. The names of the Chairmen of the delegations are printed in bold type where they are known; those of alternates are marked by an asterisk. There were no delegates from Serbia, Ukraine or Venezuela.

Argentina (1): G. Punte

Australia (3): E. N. Maslen, M. A. Spackman, J. W. White

Austria (1): A. Preisinger

Belgium (2): G. H. Evrard, K. H. Michel

Brazil (3): E. E. Castellano (10 and 11 August), A. Craievich, Y. Mascarenhas

Bulgaria (1): O. Angelova

Canada (3): I. C. Bassignana. S. Fortier, R. J. Read

Chile (1): J. Garin

China, People's Republic (4): X.-l. Jin, Z.-h. Mai (11 and 14 August), N.-b. Ming (11 and 14 August), Z. Zhang

China, The Academy of Sciences Located in Taipei (2): S. L. Chang, Y. Wang

Croatia (1): B. K. Prodić

Czech/Slovak Republics (1): Z. Zak

Denmark (1): N. Thorup

Egypt (1): M. S. Ahmed

Finland (1): T. L. P. Paakkari

France (4): B. Capelle, Y. Epelboin, R. Fourme, C. Lecomte

Germany (4): H. Fuess, W. Jeitschko, P. Paufler, W. Schmahl

Hungary (1): A. Kálmán

India (2): K. Lal, D. Pandey

Israel (1): F. H. Herbstein

Italy (3): S. Candeloro, G. Filippini, F. Zanazzi

Japan (4): Y. Mitsui, O. Nittono ( 10 and 11 August), Y. Ohashi, M. Ohmasa* (14 August), M. Tanaka (10 and 11 August), H. Toraya* (14 August)

Korea (1): S. J. Chung

Mexico (1): D. Romeu-Casajuana (10 and 11 August), $\mathrm{H}$. Terrones-Maldonado* (14 August)

The Netherlands (2): D. Feil, P. Gros

New Zealand (1): B. F. Anderson

Norway (1): B. Fjaertoft-Pedersen

Poland (1): A. Pietraszko

Portugal (1): M. A. Carrondo (11 and 14 August), M. T. Duarte (10 August)

Russia (4): E. V. Antipov, L. A. Aslanov, A. A. Chemov, V. I. Simonov

Slovenia (1): I. Leban

South Africa (2): G. J. Kruger, L. R. Nassimbeni

Spain (3): F. J. Lahoz, C. Miravitlles, J. Rius

Sweden (2): R. Norrestam, I. Olovsson

Switzerland (2): G. C. Chapuis, W. B. Schweizer

$U K$ (5): J. B. Forsyth, A. M. Glazer, J. A. K. Howard, S. J. Maginn, M. Moore

USA (5): R. F. Bryan, C. E. Bugg, W. L. Duax, D. S. Eggleston, J. Flippen-Anderson

Present as members of the Executive Committee: P. Coppens (President), R. Chidambaram (Vice-President), S. Larsen (General Secretary and Treasurer), A. Authier (Immediate Past President), E. N. Baker, P. W. Codding, J. Harada, M. Hart and H. Schenk (Ordinary Members). M. H. Dacombe was in attendance as Executive Secretary. 
First Session, Saturday 10 August 1996, 7.05 p.m

\section{(1) Introductory remarks by the President}

Professor COPPENS welcomed the delegates and observers. The President began by recalling the sad losses of Professor A. I. HORDVIK (General Secretary and Treasurer) and Professor Yu. T. STRUCHKOV (Vice-President) who had both died in 1995 and who had both contributed so much to the Union. He thanked Professor S. LARSEN who had energetically taken over as General Secretary and Treasurer at very short notice and Dr R. CHIDAMBARAM who had agreed to serve as Vice-President.

\section{(2) Procedural matters}

In order to verify the list of voting delegates, the President requested the General Secretary to read this list, and asked delegates to indicate their presence when their names were called. (This procedure was repeated at the beginning of each session of the General Assembly.)

Two delegates, one from the Czech/Slovak Republics and one from South Africa, were appointed to act as tellers when votes had to be counted during the Assembly.

\section{(3) Approval of Agenda}

The Agenda and the Appendices to the Agenda had been distributed to Secretaries of National Committees in May 1996. The Agenda were approved.

(4) Amendments to Statutes and By-Laws affecting adherence to the Union

At the end of the Beijing Congress, the Executive Committee had established a Sub-committee with the charge to present proposals for changes in the IUCr Statutes and By-Laws, to be voted on at the time of the Seventeenth General Assembly in Seattle in 1996. The membership was the Immediate Past President of the IUCr (A. Authier) as Chairman, Th. Hahn, A. I Hordvik, J. Karle and K. V. J. Kurki-Suonio. The Sub-committee submitted recommendations to the Executive Committee for consideration at its meeting in June 1994. The subsequent report of the Sub-committee was circulated to Secretaries of National Committees for Crystallography in January 1995. The Executive Committee considered the report at its meeting in August 1995 and was grateful to those National Committees which had sent suggestions or comments. The Executive Committee endorsed the recommendations made. In accordance with Statute 13.1, the amendments to the Statutes and By-Laws proposed by the Executive Committee were sent to National Committees and Commissions in March 1996.

The proposed modifications to Statutes 3.2 and 3.3 to allow the admission of The Academy of Sciences Located in Taipei were adopted without discussion. The revised Statutes are included as Annex II.

Proposed changes to the Statutes and By-Laws not affecting adherence to the Union were considered under Minute (8).

\section{(5) Applications for membership of the Union}

Applications for membership of the IUCr had been received from The Academy of Sciences Located in Taipei (Category II) and the Korean Federation of Science and Technology Societies (Category I) and the Executive Committee recommended to the General Assembly that these be accepted. Both applications were accepted by the General Assembly and the delegates from these countries took their seats. Y. WANG (Taipei) thanked the Executive Committee, delegates and the Academia Sinica (Beijing) for agreeing to the changes in the Statutes which had made their admission possible. S. J. CHUNG thanked the Executive Committee and delegates on behalf of the Korean Crystallographic Association.

\section{(6) Changes in names of Adhering Bodies}

No request for a change in name of Adhering Body had been received.

\section{(7) Approval of Minutes of Sixteenth General Assembly}

The Minutes were contained in the published Report of the Sixteenth General Assembly and International Congress of Crystallography [Acta Cryst. (1995), A51, 596-648]. It was noted that in Annex IV (Adhering Bodies) Israel should have been listed as adhering in Category I. The modified Minutes were approved and two copies were signed by the President and the General Secretary, in accordance with By-Law 1.13. There were no matters arising from the Minutes.

(8) Amendments to Statutes and By-Laws not affecting adherence to the Union

In accordance with Statute 13.1, the amendments to the Statutes and By-Laws proposed by the Executive Committee had been sent to National Committees and Commissions in March 1996 [see Minute (4)].

(a) On behalf of the Executive Committee, the President explained the proposed modifications to Statutes 5.4 and 5.5 to allow postal ballots of the General Assembly. In the ensuing debate, several delegates expressed concern about the interpretation of 'postal' and the problems of verifying safe delivery and receipt of information, including ballots. It was agreed that the term 'postal' should be defined to include all verifiable means of communication including fax. C. E. BUGG felt that any call for an Extraordinary General Assembly must also allow for postal balloting. Following further discussion, it was agreed that postal balloting would be allowed at an Extraordinary General Assembly. The proposed modifications to Statutes 5.4 and 5.5 were then adopted (see Annex II).

(b) The President reported that the proposed changes to the By-Laws to incorporate the existence of the Finance Committee, to establish officially the position of Convener and to incorporate the existence of the Sub-committee on the Union Calendar were in part contradictory. A revised version had been notified to delegates on 9 August and discussion would be deferred until the third session of the General Assembly in accordance with By-Law 9.1 [see Minute (26)]

The President reported that he had received a letter from the US National Committee for Crystallography in which their proposed amendments to the Statutes and By-Laws to establish the position of President-Elect on the Executive Committee, replacing the position of Vice-President (as circulated to National Committees and Commissions in March 1996), had been withdrawn.

\section{(9) Report of Executive Committee}

The Report of the Executive Committee on the activities of the IUCr since the Sixteenth General Assembly had been submitted to the National Committees and the Commissions in May 1996, in accordance with Statute 6.8 and follows these Minutes as Annex I, Appendix A. The report was accepted without discussion. 


\section{(10) Financial Report}

A Financial Report, covering the calendar years 1993, 1994 and 1995, had been prepared by the Treasurer and had been submitted to the National Committees and the Commissions in May 1996. The Report, with a subsequent correction, follows these Minutes as Annex I, Appendix B.

The Treasurer recalled the circumstances which had led to her appointment following the sad loss of Professor A. I. Hordvik. As she had been Treasurer for only a few months, she gave her personal view of the present financial situation. She presented plots showing effects of exchange-rate fluctuations on the assets of the Union. Over the triennium 1993-1995, the assets of the Union had increased by $4.9 \%$ if exchange-rate fluctuations were excluded, but decreased by $1.9 \%$ if exchange-rate fluctuations were included. The return on the investments had been about $10 \%$ per annum for the triennium. She presented a plot showing income versus expenditure for the Acta Crystallographica Fund, the main income-generating fund, in Swiss francs and US dollars. She highlighted the problem of falling numbers of subscriptions to the journal (a problem common to all journals) accompanied by increasing numbers of submissions and resulting increased costs of printing more pages. Delegates were asked to encourage libraries to subscribe to the Union's journals. Despite the rise in number of pages printed, the editorial costs had remained constant thanks to the efficiency of the Chester staff. The editorial costs included in-house typesetting and numerical checking of structural papers.

The General Assembly accepted the Financial Report (with a modified Table 4 which had been notified to the delegates on 9 August) with applause.

\section{(11) Ewald Prize}

Details of the Prize, awarded to Professor M. G. Rossmann at the Opening Ceremony, and the citation are given in Annex I, Appendix C.

The Selection Committee was thanked for its work.

(12) Commission on Journals. Report by Chairmen and review of activities

The report of the Commission on Journals had been distributed to the National Committees and the commissions in May 1996 and is reprinted in Annex I, Appendix D. The Chairman of the Commission, C. E. BUGG, summarized the report and highlighted the growth of Section D of Acta Crystallographica, the progress of Journal of Synchrotron Radiation and the success of having individual Editorial Boards for the different sections of the journals. He noted that he would be retiring as Chairman and Editor-in-Chief at the Seattle Congress.

The report was accepted by the General Assembly and Professor Bugg was thanked for his dedicated work over nine years - under his guidance the journals had flourished.

(13) Commission on International Tables. Report by Chairman and review of activities

The report of the Commission on International Tables had been distributed to the National Committees and the Commissions in May 1996 and is reprinted in Annex I, Appendix D.

The President reported that the Executive Committee had decided that all volumes in the International Tables series should be numbered alphabetically from $A$ to $Z$ (i.e. labels such as Al would not be used). He also reported that the Executive Committee had approved two new volumes: Volume
F Macromolecular Crystallography edited by M. G. Rossmann and E. Arnold and Volume G Crystallographic Information edited by S. R. Hall and B. McMahon. He was delighted that Professor Rossmann and Professor Arnold had agreed to take on the important task of Volume $F$ with great enthusiasm and felt that Volume $G$ would set the standards for the various implementations of CIF (Crystallographic Information File).

The report was accepted by the General Assembly.

\section{(14) Committee on Electronic Publishing, Dissemination and Storage of Information}

The report of the Chairman of the Committee on Electronic Publishing, Dissemination and Storage of Information had been distributed to the National Committees and the Commissions in May 1996 and is reprinted in Annex I, Appendix E.

D. S. EGGLESTON commented that the provision of offprints had not been addressed by the Committee and the Chairman of the Committee, E. N. MASLEN, replied that this was something which would be addressed.

The Managing Editor, P. R. STRICKLAND, reported on the present status of SGML implementation in the IUCr journals and on plans to make electronic submission easier for authors by the provision of templates for standard word-processing packages.

The report was accepted by the General Assembly.

\section{(15) Non-publishing Commissions. Reports by Chairmen and review of activities}

The reports of the Commissions on their activities since the Sixteenth General Assembly had been distributed to the National Committees and Commissions in May 1996. The reports are reprinted in Annex I, Appendix D. The reports were taken as read, but the Chairman of each Commission, or his alternate, was invited to say a few words about any further developments and to answer any questions.

The General Assembly accepted all the reports that had been received on the activities of the non-publishing Commissions.

\section{(16) Proposals for new Commissions}

The President reported that formal proposals had been received to form two new Commissions: (a) a Commission on XAFS (X-ray Absorption Fine Structure) and (b) a Commission on Small-Angle Scattering. The Executive Committee had considered the terms of reference and proposed memberships and recommended that both Commissions be established.

After a short discussion the General Assembly approved the formation of a Commission on XAFS and of a Commission on Small-Angle Scattering.

\section{(17) Review of existing Commissions}

The President reported that the Executive Committee had decided to recommend to the General Assembly that $(a)$ the Commission on Crystallographic Data should be terminated and replaced by a Committee on Crystallographic Databases with representatives from the major databases and $(b)$ the Commission on Crystallographic Apparatus should be renamed the Commission on High Pressure.

He noted that the although the Commission on Crystallographic Apparatus had been very important in the early years of the Union, the tasks had to a large extent been taken over by the other Commissions of the Union. The present Commission on Crystallographic Apparatus had a High Pressure sub-group which 
had become increasingly important. The Executive Committee wished to recognize this change of emphasis.

The General Assembly approved both recommendations.

(18) Determination of number of elected members of each Commission

In accordance with Statute $5 \cdot 10(d)$, the Assembly had to determine the number of persons to be elected on the Commissions until the Eighteenth General Assembly; these numbers did not include Chairmen, Co-editors or ex officio members.

The Executive Committee now proposed that the membership of the Commission on Aperiodic Crystals be increased from seven to eight members.

The numbers of elected members approved by the General Assembly (Chairmen not included) are set out below:

1. Commission on Journals

2. Commission on International Tables

3. Commission on Aperiodic Crystals

4. Commission on Biological Macromolecules

5. Commission on Charge, Spin and Momentum Densities

6. Commission on Crystal Growth and Characterization of Materials

7. Commission on Crystallographic Computing

8. Commission on Crystallographic Nomenclature

9. Commission on Crystallographic Teaching

10. Commission on Electron Diffraction

11. Commission on High Pressure

12. Commission on Neutron Scattering

13. Commission on Powder Diffraction

14. Commission on Small-Angle Scattering

15. Commission on Structural Chemistry

16. Commission on Synchrotron Radiation

17. Commission on XAFS

(19) Proposal to change name of Commission on Small Molecules

Members of the Commission on Small Molecules felt that the word 'small' was indefinite and that the use of 'molecules' would appear to remove most of inorganic and intermetallic crystallography from the remit of the Commission. The Commission on Small Molecules therefore proposed that its name be changed to Commission on Structural Chemistry.

The General Assembly approved the change.

(20) Sponsorship of meetings: Sub-committee on the Union Calendar

Since this is a Sub-committee of the Executive Committee, the Assembly is not formally required to approve its report, which is reprinted as Annex I, Appendix H. The Chairman of the Subcommittee (P. W. CODDING) thanked the members for working so efficiently. E. N. MASLEN asked whether any thought had been given to encouraging the use of teleconferencing. The Chairman replied that this had not been considered but this was something for the next Chairman to consider in the next triennium. The President noted that the ability to provide financial support for meetings depended on the success of the journals. He fully supported the Treasurer's request that delegates should encourage libraries to subscribe to the journals.

\section{(21) IUCr/Oxford University Press Book Series}

The Chairman (J. H. ROBERTSON) reported that he was particularly pleased with some of the texts in this Book Series. He was thanked by the Assembly with acclamation for his work.

The report on this Book Series was accepted by the Assembly and is reprinted as Annex I, Appendix I.

The President then adjourned the session at 8.55 p.m.

\section{Second Session, Sunday 11 August 1996, 7.05 p.m.}

\section{(22) Confirmation of date and place of Eighteenth General Assembly}

The invitation from the British Crystallographic Association, on behalf of the Royal Society, to hold the Eighteenth General Assembly in Glasgow, Scotland, which had been preliminarily accepted in 1993, was formally accepted.

\section{(23) Preliminary consideration of date and place of Nineteenth General Assembly}

In accordance with By-Law 1.3, the General Assembly could give preliminary consideration to the place of the next but one General Assembly, namely the Nineteenth General Assembly to be held in 2002. The President announced that invitations had been received from the Israel Crystallographic Society to hold the Congress in Jerusalem, Israel, from the Science Council of Japan and the Crystallographic Society of Japan to hold the Congress in Yokohama, Japan, from the South African National Committee to hold the Congress in Durban, South Africa, and from the Spanish National Committee to hold the Congress in Barcelona, Spain. He reported that the Executive Committee had considered all the applications and found them to be in order. J. BERNSTEIN presented the formal invitation for Israel, $Y$. OHASHI and two convention representatives presented the formal invitation for Japan, J. C. A. BOEYENS presented the formal invitation from South Africa and C. MIRAVITLLES and a convention representative presented the formal invitation from Spain. A decision on which invitation to accept was delayed until the next session to give the delegates time to consider the choice [see Minute (27)]. At the request of A. A. CHERNOV, it was agreed that a table comparing the facilities offered at each site would be prepared and distributed to delegates before the next session. This was subsequently done by H. SCHENK.

(24) Reports of Representatives on Regional and Scientific Associates

In accordance with Statute $8 \cdot 5$, the reports of the Representatives on Regional and Scientific Associates had been circulated with the Agenda papers in May 1996. These reports are reprinted as Annex I, Appendix F. It was noted that the Representative on the European Crystallographic Committee (ECC), Professor Yu. T. Struchkov, had sadly died in 1995 and so there was no mention of the successful Sixteenth European Crystallographic Meeting (ECM-16) held in Lund, Sweden, in that year. The reports were accepted by the General Assembly.

(25) Reports of Representatives on bodies not belonging to the Union

In accordance with Statute 8.5 , the reports of the Representatives had been circulated with the Agenda papers. These reports are reprinted as Annex I, Appendix G. E. N. MASLEN 
noted that the Intemational Council for Scientific and Technical Information (ICSTI) had undergone a profound transformation in the last three years and that its activities were now more relevant for the Union. The reports were accepted by the General Assembly.

The President adjourned the session at 9.35 p.m.

\section{Third Session, Wednesday 14 August 1996, 7.05 p.m.}

(26) Amendments to Statutes and By-Laws not affecting adherence to the Union (continued)

Further to Minute $8(b)$, the revised version of the proposed changes to the By-Laws to incorporate the existence of the Finance Committee, to establish officially the position of Convener and to incorporate the existence of the Sub-committee on the Union Calendar had been notified to delegates on 9 August. The President confirmed that the wording of the proposed ByLaw 6.2 should be interpreted to mean that the Chairman of the Calendar Sub-committee should come from the Executive Committee. The proposed new By-Law 6 was adopted (see Annex II).

\section{(27) Preliminary consideration of date and place of Nineteenth General Assembly (continued)}

Before voting took place, W. L. DUAX addressed the General Assembly to give details of his experience on the use of the World-Wide Web and the IUCr Newsletter in preparation for the Seattle Congress.

The General Assembly gave preliminary acceptance to the invitation to hold the Nineteenth General Assembly in 2002 in Israel.

(28) Determination of general policy and timetable for the period to Eighteenth General Assembly

There was some discussion as to the scope, size and duration of IUCr Congresses. It was agreed that a questionnaire addressing these points should be prepared and distributed to those attending the present Congress. [This was subsequently done by the Executive Secretary.] The results would be useful for future Congress organizers.

\section{(29) Preliminary consideration of activities for 1999-2002}

There were no comments on this item.

(30) Budget estimates for the period to the Eighteenth General Assembly: determination of unit contribution

These budget estimates had been distributed with the Agenda papers and are printed as Annex I, Appendix J to these Minutes.

The General Assembly accepted the budget estimates and approved the recommendation of the Executive Committee to continue the unit contribution unchanged, as CHF 1000 , for the years 1997, 1998 and 1999.

\section{(31) Confirmation of appointments of Editors of publications of the Union}

In accordance with Statute $7 \cdot 1$, the initial appointments and the reappointments of the Editors of the publications of the Union were made by the Executive Committee and were subject to confirmation by the General Assembly.
In addition to the appointments and reappointments notified to the delegates in the Agenda papers, the Executive Committee had appointed the following Editors for International Tables: M. G. Rossmann and E. Amold for Volume F and S. R. Hall and B. McMahon for Volume G.

The Assembly unanimously confirmed the following appointments and reappointments for the period of three years:

Editor-in-Chief of Acta Crystallographica: J. R. Helliwell (UK)

Editor of Section A of Acta Crystallographica: A. Authier (France)

Editor of Section B of Acta Crystallographica: F. H. Allen (UK)

Editor of Section C of Acta Crystallographica: S. R. Hall (Australia)

Editor of Section D of Acta Crystallographica: J. P. Glusker (USA)

Editor of Journal of Applied Crystallography: A. M. Glazer (UK)

Editors of Journal of Synchrotron Radiation: S. S. Hasnain (UK), J. R. Helliwell (UK) and H. Kamitsubo (Japan)

General Editor of International Tables and Editor of Volume A: Th. Hahn (Germany)

Editor of Volume B: U. Shmueli (Israel)

Editor of Volume C: E. Prince (USA)

Editor of Volume D: A. Authier (France)

Editors of Volume E: V. Kopsky (Czech Republic) and D. B. Litvin (USA)

Editors of Volume F: M. G. Rossmann (USA) and E. Arnold (USA)

Editors of Volume G: S. R. Hall (Australia) and B. McMahon (UK)

Editor of Volume H (formerly Volume A1): H. Wondratschek (Germany)

\section{(32) Election of Chairmen and members of Commissions}

The nominations made by the Executive Committee for the Chairmen and members of Commissions, after consultation with the Commissions through their Chairmen, had been notified to delegates. It was noted that it had not been possible to contact one of the proposed members of the new Commission on High Pressure and so his name was removed.

Since no other nominations had been made by the delegates, the persons recommended by the Executive Committee were considered elected.

The current full memberships of all the Commissions, including the ex officio members, together with the addresses of the Chairmen, are given as Annex III.

(33) Election of Representatives on bodies not belonging to the Union and on Regional and Scientific Associates

The nominations made by the Executive Committee for those Representatives to be elected by the General Assembly had been notified to delegates. As no other nominations were made, these persons were considered elected.

The names and addresses of the Representatives of the Union, including those appointed ex officio, are given in Annex III.

\section{(34) Election of Officers of the Union}

The nominations made by the Executive Committee for Officers of the Union had been included in the Agenda papers distributed in May 1996. E. N. Baker was nominated for President, R. Chidambaram for Vice-President and S. Larsen for 
General Secretary and Treasurer. Seven nominations were made for the three or four vacancies for Ordinary Members: L. A. Aslanov (Russia), J. C. A. Boeyens (South Africa), H. Fuess (Germany), P. F. Lindley (UK), D. Louër (France), G. M. Punte (Argentina) and M. Tanaka (Japan). No other nominations were made by the delegates. Elections for the three Ordinary Members for the normal six-year term and for one Ordinary Member for a three-year term (to fill the unexpired term of office of the newly elected President) were held by secret ballot. The following nominees were elected:

President:

E. N. Baker (New Zealand)

Vice-President:

R. Chidambaram (India)

General Secretary and Treasurer:

S. Larsen (Denmark)

Ordinary Members (six years):

L. A. Aslanov (Russia)

H. Fuess (Germany)

M. Tanaka (Japan)

Ordinary Member (three years):

J. C. A. Boeyens (South Africa)

The newly elected President congratulated the new members of the Executive Committee and invited delegates to participate fully in activities during the next triennium. He thanked the retiring members of the Executive Committee for all that they had done.

(35) Any other business

W. L. DUAX commented that the present Congress had overlapped with the Congress of the International Union of
Pure and Applied Biology (IUPAB) which had been held in Amsterdam. The President reported that he had been in contact with IUPAB and the periodicity of the IUPAB meetings may be changed to avoid undesirable overlaps of this sort.

There being no further business, and therefore no need for the final session of the General Assembly which had been scheduled for Friday 16 August, the President declared the Seventeenth General Assembly closed at 9.30 p.m.

\section{Closing Ceremony, Saturday 17 August 1996}

R. F. BRYAN (Chairman of the Congress Organizing Committee) and W. L. DUAX (Chairman of the Congress Programme Committee) thanked everyone involved with making the Congress a success; it had been a rich and rewarding experience.

P. COPPENS, the retiring President, said that this had been a successful and well organized Congress and thanked the organizers for their hard work. He found it a great pleasure to be handing over the Presidency to someone from the large and important community of macromolecular crystallographers and to someone who would be the first President from the Southern Hemisphere.

The new President, E. N. BAKER, paid tribute to the retiring President for his guidance, his concem for people and science and the wisdom he had brought to the Presidency. He said that this had been a large but wonderful Congress. It was important to keep all aspects of crystallography together at the one Congress. This was a marvellous time to be carrying out science and he was looking forward to the next three years. He then declared the Seventeenth General Assembly and Congress closed. 


\section{ANNEX I}

\section{Appendices to the Agenda of the Seventeenth General Assembly}

\section{Appendix A: Report of the Executive Committee}

\section{Executive Committee and Finance Committee meetings}

The Executive Committee met in Beijing, China, in August 1993 before and during the General Assembly, in Chester, England, in June 1994 and in Lund, Sweden, in August 1995 at the time of the European Crystallographic Committee annual meeting. The Finance Committee met in March 1993, August 1993, March 1994, April 1995 and August 1995, to prepare its advice and recommendations on finances, establishment and staff matters.

The most important items of business dealt with by the Executive Committee during the triennium at these meetings, and in postal ballots between meetings, were:

(1) Editorial policy, pricing policy and subscription rates, approval of appointments of Co-editors, separate editorial boards for Sections $A, B, C$ and $D$ of Acta Crystallographica, electronic publishing, Special Issues, and other matters concerning the IUCr journals.

(2) Appointment of new staff in the IUCr office in Chester.

(3) Upgrading of office technology in the $\mathrm{IUCr}$ office in Chester and expansion of this office; provision of an IUCr home page on the World-Wide Web.

(4) Publication of the new Section D of Acta Crystallographica.

(5) Publication of the new Journal of Synchrotron Radiation.

(6) Cooperation with databases, including relations between the IUCr and the Cambridge Crystallographic Data Centre, between the IUCr and the International Centre for Diffraction Data and between the IUCr and the Gmelin Institut/Fachinformationszentrum Karlsruhe.

(7) The implementation of the Crystallographic Information File (CIF) for Acta Crystallographica papers and other uses of CIF, patent application and adoption of the STAR file and CIF by other bodies.

(8) Progress with Volumes B, C, D and E of International Tables for Crystallography and consideration of possible further volumes.

(9) Establishment of an international crystallographic newsletter, the $\mathrm{IUCr}$ Newsletter.

(10) Approval of publications, jointly with the Oxford University Press, in the IUCr/OUP Book Series.

(11) World Directory of Crystallographers.

(12) Approval of the audited accounts.

(13) The General Fund estimates and the level of the unit contribution.

(14) Investment policy.

(15) UK taxation considerations.

(16) Funding and uses of the Publications and Journals Development Fund and the Research and Education Fund.

(17) Consolidation of the Ewald Fund and appointment of the Selection Committee for the fourth Ewald Prize.

(18) Sponsorship of meetings and possible financial support for meetings.

(19) Young scientists' support to meetings.

(20) Free circulation of scientists.

(21) Report of the Sub-committee on the IUCr Statutes and By-Laws.

(22) Applications for membership of the IUCr.
(23) Approval of the membership of the Programme Committee for the Seattle Congress.

(24) Discussion of the arrangements for the Seattle General Assembly and Congress.

(25) Level of financial support for the Seattle Congress and its satellite meetings.

(26) Review of the activities of the Commissions.

(27) Proposals to establish new Commissions.

(28) Nominations for Officers of the IUCr and for Chairmen and members of Commissions, and proposals from the National Committees for these positions.

\section{Publications}

The subscription prices (in Danish kroner) of Acta Crystallographica and the Journal of Applied Crystallography were increased each year during the triennium. The new Section $D$ of Acta Crystallographica was supplied free of charge in 1993 to all subscribers to Acta Crystallographica (except those taking only Section C). The new Journal of Synchrotron Radiation was supplied free of charge in 1994/1995 to all subscribers to the Journal of Applied Crystallography, Section D of Acta Crystallographica and to a further 420 principal investigators at the major synchrotron radiation centres.

The total annual number of pages published in 1993, 1994 and 1995 were:

$\begin{array}{lrrr} & 1993 & 1994 & 1995 \\ \text { Acta Cryst. Section A } & 901 & 798 & 952 \\ \text { Acta Cryst. Section B } & 1075 & 782 & 1104 \\ \text { Acta Cryst. Section C } & 2186 & 2102 & 2726 \\ \text { Acta Cryst. Section D } & 604 & 920 & 1106 \\ \text { J. Appl. Cryst. } & 848 & 1078 & 860 \\ \text { J. Synchrotron Rad. } & - & 106 & 319 \\ \text { Total } & 5614 & 5786 & 7067\end{array}$

In addition, in 1993 Acta Cryst. Section A included a Supplement of 515 pages of abstracts communicated to the Beijing Congress. The January 1993 issue of Acta Cryst. Section D contained 222 pages of papers presented at the meeting on Direct Methods of Phasing in Macromolecular Crystallography, Panama City Beach, Florida, USA, 24-27 April 1992. The July 1994 issue of Acta Cryst. Section D contained 336 pages of papers contributed to the Fifth International Conference on Crystallization of Biological Macromolecules, San Diego, California, USA, 8-13 August 1993. The July 1995 issue of Acta Cryst. Section D contained 204 pages of papers presented at the meeting on Structure-Based Drug Design, Panama City Beach, Florida, USA, 22-25 April 1994. The August 1995 issue of Acta Cryst. Section B contained 256 pages of papers presented at the meeting on New Trends in Small Moiety Crystallography, Atlanta, Georgia, USA, 26 June-1 July 1994.

The transition to fully electronic submission of papers to Acta Cryst. Section $C$ in CIF format has been completed successfully and good progress towards having the other journals available in electronic SGML format is being made.

An IUCr home page on the World-Wide Web has been established and this contains information on the titles, synopses, structural schemes and contents of the IUCr journals. Numerical information in CIFs may be downloaded. 
Full details on the publication of volumes of International Tables for Crystallography are given in the Report of this Commission.

The Ninth Edition of the World Directory of Crystallographers, edited by Y. Epelboin, was published in 1995. This is held as an electronic database in STAR file format and this also allows the automated typesetting of the Directory. The database may be accessed via the World-Wide Web and mirror sites have been established in North America and South Africa.

The IUCr/OUP Book Series continues to be successful. Details are given in the relevant Appendix to the Agenda.

The IUCr Newsletter was launched in January 1993 and has achieved great popularity. It is distributed free of charge to 587 libraries and 15000 crystallographers and other interested individuals in 39 countries. W. L. Duax is the Editor with the editorial office at the Hauptman-Woodward Medical Research Institute at Buffalo, New York, USA, which also handles the distribution. The Newsletter is printed by the American Institute of Physics. Four issues appeared in 1993, four in 1994 and three in 1995. Three issues are planned for 1996 .

\section{Sponsorship of meetings}

The Executive Committee has a Sub-committee on the Union Calendar to consider and to advise the Executive Committee on requests for IUCr sponsorship and financial support of meetings. The Chairman of the Sub-committee has been P. W. Codding in this triennium. Because of its healthy financial status, the IUCr has been able to increase its support for young scientists attending meetings. A list of IUCr-sponsored meetings is given in the Report of this Sub-committee.

Applications for sponsorship and financial support are considered if they are submitted at least nine months in advance of the date of the meeting. Requests from satellite meetings must be submitted, and possible financial support requested, through the organizing committee of the main meeting. Meetings (other than satellite meetings) scheduled to be held within two months before or after an IUCr Congress will not be considered for sponsorship. For any meetings scheduled to be held between two and three months before or after a Congress, the application for sponsorship requires the approval of the Chairman of the Congress Programme Committee.

The IUCr continues to support and uphold ICSU's policy of non-discrimination and adheres to its decisions and procedures concerning free circulation of scientists. Organizers of any meetings seeking IUCr sponsorship or support must assure the Calendar Sub-committee that the authorities of the country in which the meeting is to take place guarantee free entrance of bona fide scientists from all countries.

\section{Commissions of the $\mathrm{IUCr}$}

Each Commission Chairman is required to provide a written triennial report to the General Assembly. These reports are included as Appendices to the Agenda. Financial assistance has again been offered to the Commission Chairmen, to enable them to attend the General Assembly for the presentation and discussion of their reports and to meet the Executive Committee prior to the General Assembly.

\section{Regional Associates, Scientific Associates, and other bodies}

The reports of the Representatives on these bodies are given as separate Appendices to the Agenda.

\section{IUCr staff}

There have been some staff changes during the triennium. The present members of staff in the IUCr offices in Chester are: $\mathrm{Mr}$ M. H. Dacombe (Executive Secretary), Mrs A. Cawley (Part-time Administrative Assistant to the Executive Secretary), Mrs M. J. Robinson (Part-time Secretary to the Executive Secretary), Mr P. R. Strickland (Managing Editor), Mrs S. E. King (Technical Editor), Mr B. McMahon (Research and Development Officer), Dr A. S. Berry (Assistant Technical Editor), Mr S. P. Westrip, Dr G. F. Holmes, Mrs L. E. Clark-Jones, Miss J. K. Stoddard and Miss C. A. Moore (Senior Editorial Assistants), Mr S. Conway, Miss A. M. K. Monahan, Dr N. J. Stedman and Dr A. Weight (Editorial Assistants), Dr M. A. Hoyland, Mr M. Geselle and Mr D. Holden (Research and Development Assistants), Mrs L. Rathbone (Secretary) and Mrs C. Cook (Part-time Keyboard Operator).

The additions to the editorial staff have been made to handle the increased workload resulting from (1) the transfer of the consistency and duplication checking from the journals' Co-editors to the Chester office, (2) the increased number of manuscripts being submitted for publication, (3) the introduction of the new Journal of Synchrotron Radiation, (4) the move towards in-house typesetting $(58 \%$ of the total pages were typeset in-house in 1995) and provision of final output in SGML format, and (5) the setting up and maintenance of databases and the World-Wide Web home page.

\section{Acknowledgements}

On behalf of the IUCr, the Executive Committee wishes to express its deep gratitude to the US National Committee for Crystallography, in collaboration with the American Crystallographic Association, and the National Academy of Sciences of the United States for the invitation to hold the Seventeenth General Assembly and International Congress of Crystallography in Seattle. It particularly wishes to thank the Chairman of the Programme Committee, Dr W. L. Duax, and the Chairman of the Organizing Committee, Professor R. F. Bryan.

The continuing support shown by UNESCO in the form of its annual subvention received by the IUCr through ICSU, and the support of ICSU itself, is gratefully acknowledged.

Finally, the Executive Committee wishes to thank all crystallographers who have assisted in the work of the IUCr in so many ways. This cooperation between crystallographers of different nationalities constitutes a most valuable aspect of the IUCr's activities.

\section{Appendix B: Financial Report}

\section{The Funds' structure}

The accounts of the IUCr for the calendar years 1993 and 1994 have already been published [Acta Cryst. (1995), A51, 204-233 and (1996), A52, 91-124]. The accounts for 1995 have been audited and will be published in due course in Acta Crystallographica Section A [Acta Cryst. (1996), A52, 958-999]. The accounts for the three years 1993, 1994 and 1995 are summarized in Tables 1-15. All amounts are expressed in Swiss Francs. The notations used in this report for the various currencies of the IUCr's activities are CHF $=$ Swiss Franc, GBP = Pound Sterling, USD = US Dollar, NLG = Netherlands Guilder, DKK = Danish Krone. 
Table 1. Balance Sheet, Fund Accounts (Swiss Francs)

General Fund

President's Fund

Acta Crystallographica Fund

Journal of Applied Crystallography Fund

Journal of Synchrotron Radiation Fund

Structure Reports Fund

International Tables Fund

Book Fund

Publications and Journals Development Fund

Research and Education Fund

Ewald Fund

Newsletter Fund

TOTAL ACCUMULATED BALANCE
31 December 1992

1053301

36114

1783370

435705

134055

164550

11435

745264

700989

261126

$5 \longdiv { 3 2 5 9 0 9 }$
Fluctuations in rates

of exchange

$-237110$

$-10030$

$-411365$

$-88560$

$-10188$

$-21847$

$-56293$

$-2598$

$-135117$

$-183477$

$-68743$

$-13358$

$-1238686$
31 December 1995

1190554

48386

1544696

342556

71534

85979

264045

12522

579275

739304

294048

51741

5224690

\section{General financial development}

Table 1 shows a comparison of the fund accounts at the beginning and the end of the triennium. Two new funds, the Journal of Synchrotron Radiation Fund and the Newsletter Fund, were established in this period. The total assets have decreased by CHF 101219 from CHF 5325909 to CHF 5224690 , or $1.9 \%$, over the triennium. It should be noted that these figures include the fluctuations in exchange rates. If the exchangerate fluctuations are disregarded, the total assets increased by CHF 281476 from CHF 5687219 to CHF 5968695 , or $4.9 \%$, over the triennium.

Table 2 shows the distribution of the assets. The amount of CHF 194071 for debtors at 31 December 1995 is normal. It includes, in part, the IUCr's funding of the Seattle General Assembly and Congress paid in advance. The great majority of the other amounts under debtors and creditors have since been settled.

The total investments at 31 December 1995 are CHF 4882698 at market value, as shown in Table 2 , of which $32.4 \%$ is held by Merrill Lynch, $53.6 \%$ by Foreign \& Colonial and $14.0 \%$ is held in UK Treasury Gilts. It should be noted that in 1994 it was decided to list the investments of the IUCr at market value, rather than at revalued cost as had been done previously. It was felt that this would better reflect the financial position. The IUCr bank accounts and short-term deposits are held with the Union Bank of Switzerland, the National Westminster Bank and Merrill Lynch, involving the currencies CHF, GBP and USD.

As an association incorporated in Switzerland, the IUCr is exempt from Swiss Federal and Geneva Cantonal Tax. Under the terms of the United Kingdom/Switzerland Double Taxation Agreement dated 8 December 1977, investment income arising within the UK under present circumstances is not subject to United Kingdom tax. Investment income received from other countries with which Switzerland has a Double Taxation Agreement is also exempt from tax. In October 1985, a recognition of tax-exempt status in the USA was received from the Internal Revenue Service, Department of the US Treasury.

\section{General Fund}

Table 3 shows the accounts for the General Fund (GF) and Table 4 compares these accounts for the triennium with the budget approved by the Beijing General Assembly. This
Table 2. Balance Sheet, Assets (Swiss Francs)

31 December 199231 December 1995

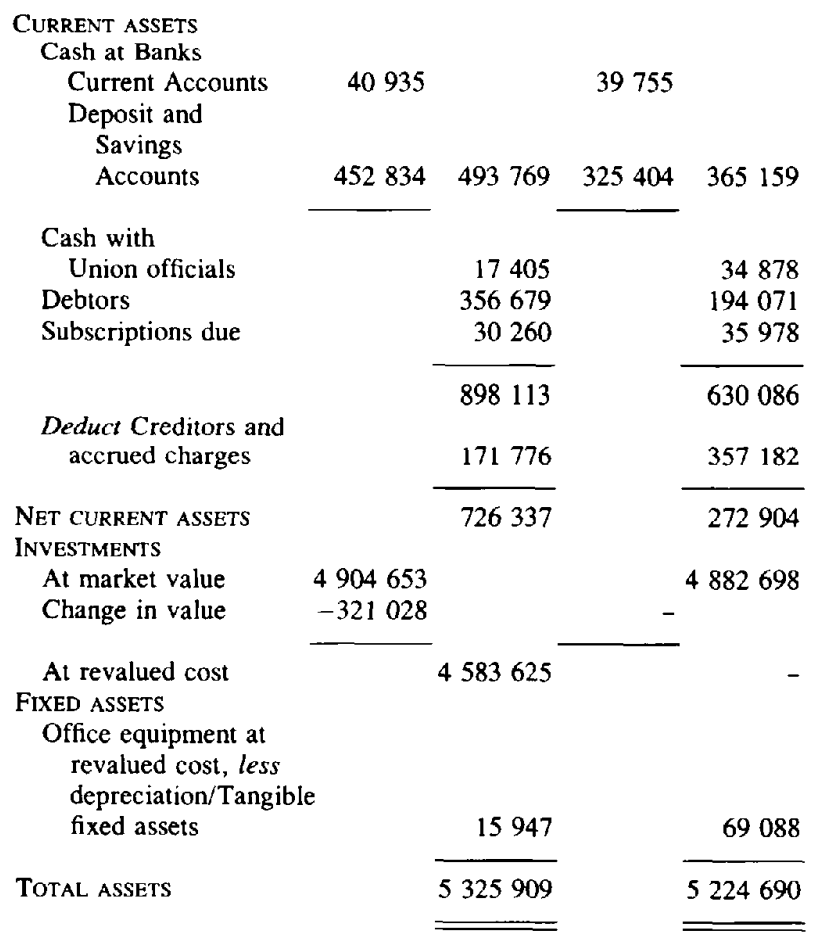

fund carries the income and expenditure related to the IUCr's administration and its regular scientific activities other than publications. The income has two main sources, the subscriptions from Adhering Bodies and the interest income from investments and bank accounts. The subscriptions from Adhering Bodies are based on the unit contribution, which was CHF 890 for 1993 and CHF 1000 for 1994 and for 1995. The total number of membership units was 148 for each year, while the budget was based on 138 for 1993,140 for 1994 and 142 for 1995 . The yield from investments exceeds the budgeted amount by CHF 319601 . The yield from investments includes the release from valuation 
Table 3. General Fund (Swiss Francs)

1993

INCOME

Subscriptions from Adhering Bodies

Yield from investments and bank accounts

Grants from UNESCO to ICSU and from ICSU

Amount charged to other Funds:

Acta Crystallographica Fund

Joumal of Applied Crystallography Fund

Joumal of Synchrotron Radiation Fund

EXPENDITURE

Administration

Subscriptions to ICSU/ICSU bodies

Executive Committee

Finance Committee

XVI General Assembly \& Congress:

Expenses

XVII General Assembly \& Congress:

Programme Committee

Expenses

IUCr Representatives on other bodies

Newsletter

STAR/CIF

Expenses of Commissions

Sponsorship of meetings

President's secretary

IUCr/FIZ Agreement

Transfers to other Funds:

President's Fund

Publications and Journals Development Fund

Ewald Fund

Newsletter Fund

EXCESS OF INCOME OVER EXPENDITURE

FluCtuATIONS IN RATES OF EXCHANGE

RELEASE FROM VALUATION

RESERVE/MOVEMENT IN MARKET VALUE

ACCUMULATED BALANCE AT END OF YEAR
131720

207063

18522

59281

19760

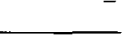

263472

5059

68131

12220

62151

183

3605

47561

11596

41050

9956

7590

25000

1500

.

1994

1995

148000
121088
15750
55889
13110
-

217980

7340

21520

7924

2797

9368

9940

16028

27866

20778

778
-

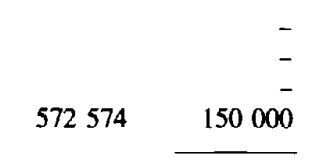

$-13622$

11976
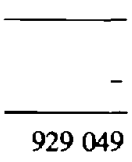

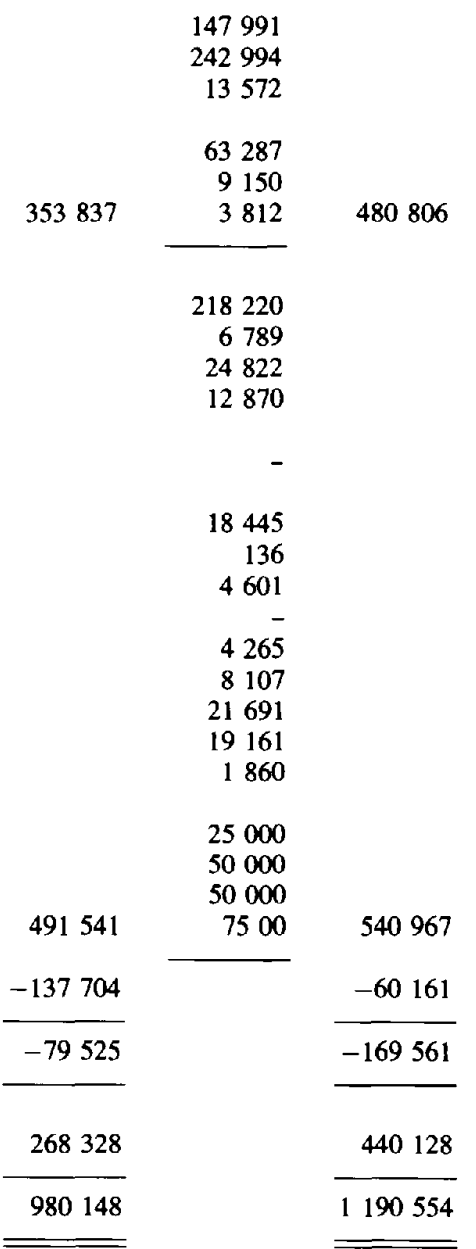

Table 4. General Fund. Comparison of budget and accounts for the years 1993-1995 inclusive (Swiss Francs)

\author{
INCOME \\ Subscriptions from Adhering Bodies \\ Yield from investments and bank accounts \\ Grants from UNESCO, ICSU and COSTED \\ EXPENDITURE \\ Administration (net) \\ Subscriptions to ICSU/ICSU bodies \\ Administrative meetings \\ Scientific meetings \\ Transfers to other Funds
}

FAVOURABLE YARIANT FROM BUDGET

ESTIMATED PROFTT

EXCESS OF INCOME OVER EXPENDITURE
Budget

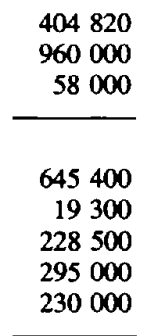

960000

58000

1422820

427711

1279601

47844

522912

19188

165061

283632

1418200

390000

Accounts

Difference

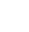

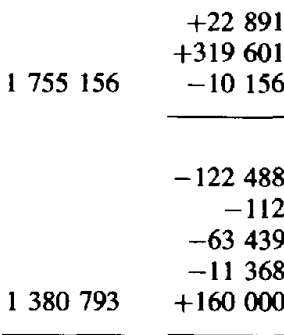

$+332336$

$-37407$

369743

4620

374363 
reserve in 1994 and movement in market value in 1995 which resulted from the change to stating investments at market value from 1994 mentioned above.

The administration expenses for the journals are calculated as $30 \%$ of the general administration costs of the IUCr, including the work of the Executive Secretary and his office and of the General Secretary and Treasurer. The Executive Committee met annually, while the Finance Committee held two meetings in 1993, one in 1994 and two in 1995. The cost of these meetings varies, as seen from Table 3 , depending on the location and the circumstances. In Table 4, they are included in the expenses of administrative meetings, together with the costs of the IUCr representatives on other bodies. The expenses of scientific meetings in Table 4 include the travel grants and other expenses for the Beijing Congress in 1993, the cost of the 1995 meeting of the Programme Committee for the Seattle Congress, the expenses of the non-publishing Commissions and in connection with STAR/CIF, Newsletter expenses in 1993, financial support to meetings and schools and expenses incurred in connection with the IUCr/FIZ Agreement. The financial support for young scientists attending meetings and schools is charged to the Research and Education Fund, see Table 13.

\section{President's Fund}

Table 5 gives the account for the President's Fund. It is intended mainly for use in emergencies and under special or difficult circumstances to help crystallographers from countries with currency problems to take part in the activities of the IUCr.
Table 5. President's Fund (Swiss Francs)

1993

1994

1995

INCOME

Donations, transfers and interest

EXPENDITURE

Grants

EXCESS OF INCOME OVER EXPENDITURE

FLuctuations IN RATES OF EXCHANGE

ACCUMulate balance AT END OF YEAR

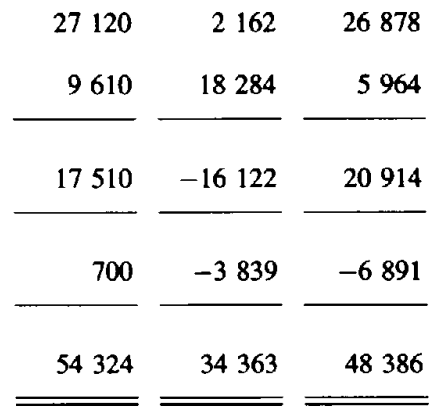

\section{The Journals Funds}

Tables 6, 7 and 8 give the accounts for Acta Crystallographica (AC), the Journal of Applied Crystallography (JAC) and the Journal of Synchrotron Radiation (JSR). For AC and JAC, the profit for both journals has stayed rather constant during the triennium, if the transfers to other funds are taken into account. The total number of pages printed for $\mathrm{AC}$ and JAC were 5614,5680 and 6748 in 1993, 1994 and 1995, respectively. This represents an increase of $20 \%$ over the triennium. The Finance Committee (FC) and the Executive Committee (EC)

Table 6. Acta Crystallographica (Swiss Francs)

INCOME

Subscriptions

Sale of back numbers and single copies

Airfreight charged to subscribers

Profit/loss on reprints

Royalties, copyright fees

Less Publisher's commission

Yield from advertisements

EXPENDITURE

Printing and binding

Distribution and postage

Airfreight costs

Annual Index

Acta Supplement

Microfiche costs

Editorial expenses

Administration expenses

Transfers to other Funds:

Publications and Journals Development Fund

Research and Education Fund

Journal of Synchrotron Radiation Fund

EXCESS OF INCOME OVER EXPENDITURE

FluCtuAtions IN RATES OF EXCHANGE

ACCUMULATED BALANCE AT END OF YEAR
1993

1994

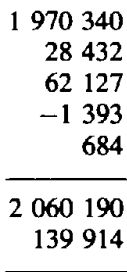

970340

62127

$-1393$

684

1920276

1921146

32325

55316

11045

1806

$\begin{array}{r}1920276 \\ 1850 \\ \hline\end{array}$

1922126

633342

120286

25364

14259

31440

89

751142

59281

60000

40000

-

2021638

136751

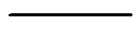

613783

90978

41739

2356

6427

85

710873

55889

100000

100000

1735203
1995

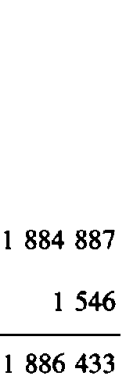

1892514

15545

53271

$-15127$

5338

1951541

1886433

133952

1817589

521

1818110

1722130

164303

186923

$-217098$

25730

1943228

1996023
60000

200000

1996645

$-178535$

$-219997$

92158

40460

2380

88

716415

63287

1544696 
Table 7. Journal of Applied Crystallography (Swiss Francs)

INCOME

Subscriptions

Sale of back numbers and single copies

Airfreight charged to subscribers

Royalties, copyright fees

Less Publisher's commission

Yield from advertisements

\section{EXPENDITURE}

Printing and binding

Distribution and postage

Airfreight costs

Loss on reprints

Editorial expenses

Administration expenses

Transfers to other Funds:

Publications and Journals Development Fund

Research and Education Fund

EXCESS OF INCOME OVER EXPENDITURE

Fluctuations in Rates of exchange

ACCUMULATED BALANCE AT END OF YEAR
1993

$\begin{array}{r}351586 \\ 7148 \\ 7714 \\ 1038 \\ \hline 367486 \\ 25111 \\ \hline\end{array}$

(1)

$\begin{array}{r}324442 \\ 3784 \\ 6575 \\ \\ 1662 \\ \quad 22975 \\ \hline\end{array}$

1994

1995

\begin{tabular}{|c|c|c|}
\hline & $\begin{array}{r}325547 \\
4306 \\
8241 \\
1096\end{array}$ & \\
\hline 313488 & $\begin{array}{rr}339 & 190 \\
23 & 159\end{array}$ & 316031 \\
\hline 494 & & 825 \\
\hline 313982 & & 316856 \\
\hline & $\begin{array}{r}94911 \\
13377 \\
5514 \\
7524 \\
108637 \\
9150\end{array}$ & \\
\hline 353340 & $\begin{array}{l}50000 \\
50000\end{array}$ & 339113 \\
\hline-39358 & & -22257 \\
\hline-46208 & & -48787 \\
\hline 413600 & & 342556 \\
\hline
\end{tabular}

Table 8. Journal of Synchrotron Radiation (Swiss Francs)

1994

INCOME

Subscriptions

Airfreight charged to subscribers

Less Publisher's commission

Yield from advertisements

Transfers from other Funds:

Acta Crystallographic Fund

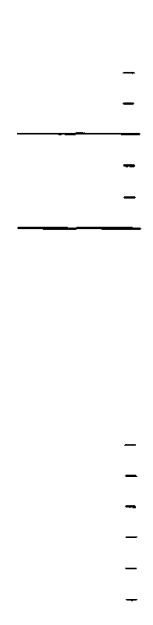

EXPENDITURE

Printing and binding

Distribution and postage

Airfreight costs

Loss on reprints

Editorial expenses

Administration expenses

1993

EXCESS OF INCOME OVER EXPENDITURE

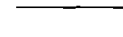

Fluctuations in RATES OF EXCHANGE

ACCUMULATED BALANCE AT END OF YEAR

have monitored the financial development for both journals very closely and, taking account of the predicted increase in the number of pages printed, the prices were increased by $7 \%$ for 1993 , by $5 \%$ for 1994 and by $5 \%$ for 1995 . In 1993, the first volume of Section $D$ of $A C$ was distributed free of charge.

10031

613

10644

1770

8874

14312

200000

223186

62622

12306

8977

108

53639

3812

141464

81722

$-10188$

71534

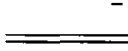

JSR was launched in 1995 (with an Inaugural Issue at the end of 1994) and was distributed free of charge to existing subscribers to JAC and AC Section $D$.

The number of subscriptions decreased by about $10 \%$ for $\mathrm{AC}$ and $7 \%$ for JAC over the triennium. This figure for $\mathrm{AC}$ excludes 
Table 9. Structure Reports (Swiss Francs)

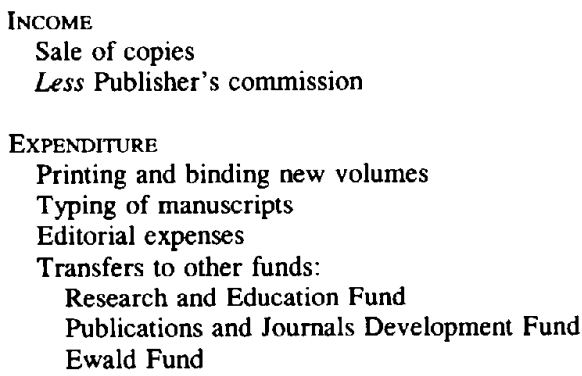

EXCESS OF INCOME OVER EXPENDITURE

Fluctuations in RATES OF EXChANGE

ACCUMULATED BALANCE AT END OF YEAR
1993

\begin{tabular}{r}
326432 \\
84872 \\
\hline 117592 \\
15219 \\
46972 \\
- \\
- \\
-
\end{tabular}

Table 10. International Tables (Swiss Francs)
1994

1995

\begin{tabular}{|c|c|c|c|c|}
\hline \multirow[t]{5}{*}{241560} & $\begin{array}{r}24304 \\
6184\end{array}$ & 18120 & $\begin{array}{r}19447 \\
5056\end{array}$ & 14391 \\
\hline & 517 & & - & \\
\hline & 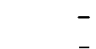 & & - & \\
\hline & 25000 & & - & \\
\hline & 45000 & & 25000 & \\
\hline 179783 & 25000 & 95517 & - & 25000 \\
\hline 61777 & & -77397 & & -10609 \\
\hline 2557 & & -12159 & & -12245 \\
\hline 198389 & & 108833 & & 85979 \\
\hline
\end{tabular}

1993

1994

1995

INCOME

Sales:

Vol A

Teaching Edition of Vol A

Vol B

Vol C

Vols II, III and IV

Less Publisher's commission

EXPENDITURE

Reprinting Vol A

Printing/Typesetting Vol B

Printing/Typesetting Vol C

Editorial expenses

Transfers to other Funds:

Research and Education Fund

Publications and Journals Development Fund

EXCESS OF INCOME OVER EXPENDITURE

FLUCTUATIONS IN RATES OF EXCHANGE

ACCuMUlated BalanCE AT END OF year

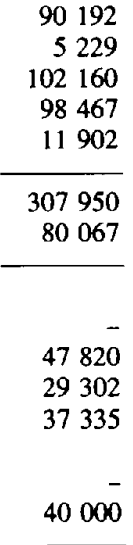

the new Section $D$, which was distributed free of charge in 1993 and at the end of 1995 had attracted 881 subscribers. For further details, see the Triennial Report by the Chairmen of the Commission on Journals.

\section{Structure Reports}

The Structure Reports accounts are shown in Table 9. The final volumes in this series appeared in 1993.

\begin{tabular}{|c|c|c|c|c|}
\hline & $\begin{array}{rl}12 & 918 \\
6 & 103 \\
63 & 512 \\
20 & 141 \\
5 & 399\end{array}$ & & $\begin{array}{r}175068 \\
4711 \\
32248 \\
118185 \\
4362\end{array}$ & \\
\hline 227883 & $\begin{array}{ll}108 & 073 \\
298 & 099\end{array}$ & 79974 & $\begin{array}{r}334574 \\
88 \quad 825\end{array}$ & 245749 \\
\hline & $\begin{array}{r}- \\
- \\
- \\
29188\end{array}$ & & $\begin{array}{r}36619 \\
- \\
38225 \\
14329\end{array}$ & \\
\hline 154457 & $\begin{array}{l}25000 \\
50000\end{array}$ & 104188 & $5000 \overline{-}$ & 139173 \\
\hline 73426 & & -24214 & & 106576 \\
\hline 3107 & & -21794 & & -37606 \\
\hline 241083 & & 195075 & & 264045 \\
\hline
\end{tabular}

\section{International Tables}

The International Tables accounts are shown in Table 10. The costs of printing and reprinting Volumes $\mathrm{A}, \mathrm{B}$ and $\mathrm{C}$ of International Tables for Crystallography are charged to the appropriate years. Sales of all three volumes were higher than expected. This resulted in their becoming out of print for periods during the triennium and this is reflected in the uneven sales figures. For further details, see the Triennial Report by the Chairman of the Commission on International Tables. 
Table 11. Book Fund (Swiss Francs)

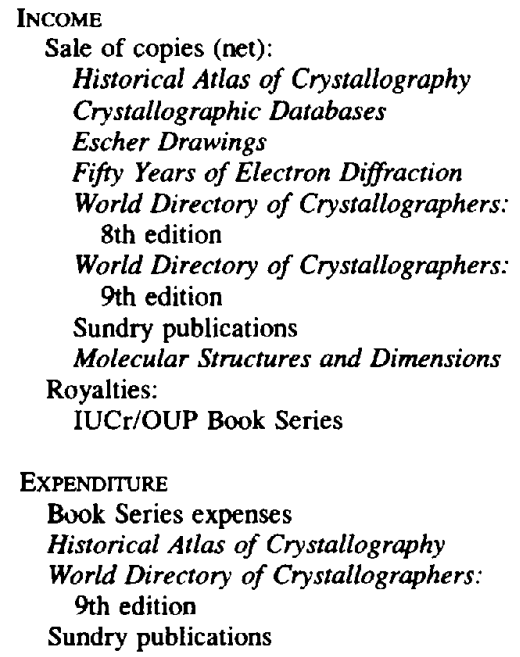

EXCESS OF INCOME OVER EXPENDITURE

FLUCTUATIONS IN RATES OF EXCHANGE

ACCUMULATED BaLANCE AT END OF YEAR
1993

1994

1995

\begin{tabular}{|c|c|c|c|c|c|}
\hline 3013 & & 1153 & & 857 & \\
\hline- & & 25 & & - & \\
\hline - & & 269 & & - & \\
\hline 215 & & 178 & & - & \\
\hline 324 & & 51 & & - & \\
\hline- & & - & & 25548 & \\
\hline 659 & & 225 & & 1178 & \\
\hline - & & 862 & & - & \\
\hline 3015 & 7226 & 4035 & 6738 & 2017 & 29600 \\
\hline 933 & & 204 & & - & \\
\hline 783 & & 300 & & - & \\
\hline 3676 & & 9713 & & 24134 & \\
\hline \multirow[t]{4}{*}{136} & 5528 & - & 10217 & - & 24134 \\
\hline & 1698 & & -3479 & & 5466 \\
\hline & 172 & & -987 & & -1783 \\
\hline & 13305 & & 8839 & & 12522 \\
\hline
\end{tabular}

Table 12. Publications and Journals Development Fund (Swiss Francs)

1993

INCOME

Transfers from other Funds:

General Fund

Acta Crystallographica Fund

Journal of Applied Crystallography Fund

Structure Reports Fund

Intemational Tables Fund

Interest

EXPENDTTURE

Computer expenses:

Purchase of equipment and software

Programming and development

Electronic Publishing

Committee/Section Editors' meeting

Journal of Synchrotron Radiation expenses

Electronic publishing project

EXCESS OF INCOME OVER EXPENDITURE

FLUCTUATIONS IN RATES OF EXCHANGE

ACCUMUlated balance AT END OF YEAR

\section{The Book Fund}

Table 11 gives the accounts of the Book Fund. The decrease in the accumulated balance of this fund during the triennium is small, and the numbers are compatible with those given for the 1990-1992 triennium [Acta Cryst. (1995). A51, 609].
1994

1995

50000

100000

50000

25000

50000

243477

22112

297112

57462

112784

17047

$366530 \quad 4597$

191890

105222

$-82501$

579275

\section{Publications and Journals Development Fund}

Table 12 shows the accounts of the Publications and Journals Development Fund (PJDF). This fund was established in 1984 and has been built up through transfers from other funds, such as $\mathrm{AC}$ and JAC. In order to build up the fund further and in 
Table 13. Research and Education Fund (Swiss Francs)

\author{
INCOME \\ Transfers from other Funds: \\ Acta Crystallographica Fund \\ Journal of Applied Crystallography Fund \\ Structure Reports Fund \\ International Tables Fund \\ Interest \\ EXPENDITURE \\ Young scientists' support \\ Visiting Professorship Programme \\ 1989 ECM Fund creditor
}

EXCESS OF INCOME OVER EXPENDITURE

FLUCTUATIONS IN RATES OF EXCHANGE

ACCUMULATED BALANCE AT END OF YEAR
1993

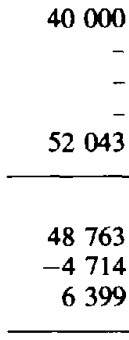

1994

1995

:Table 14. Ewald Fund (Swiss Francs)

1993

\author{
INCOME \\ Transfers from other Funds: \\ General Fund \\ Structure Reports Fund \\ Interest \\ EXPENDITURE \\ Prize \\ Selection Committee and expenses
}

EXCESS OF INCOME OVER EXPENDITURE

Fluctuations in RATES OF EXCHANGE

ACCUMULATEd BALANCE AT END OF YEAR
15000

17910

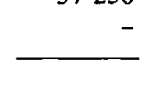

a systematic way, with the goal to make it self-supporting, the EC decided to increase its balance by crediting it with interest currently calculated as $6 \%$ of the balance of the fund, as shown in Table 12. During the triennium, the major expenses are related to the purchase of computer hardware and software, programming and development, the meetings of the Committee on Electronic Publishing, Dissemination and Storage of Information and of the Section Editors, and the launch of JSR.

It is the EC's policy to support and encourage the IUCr's highly qualified staff by supplying them with the best equipment.

\section{Research and Education Fund}

Table 13 shows the accounts of the Research and Education Fund (REF). The fund was also established in 1984 and, like the PJDF, has been built up through transfers from other funds. As for the PJDF, this fund is currently increased by $6 \%$ per year, taken from the interest income, with the goal to make it selfsupporting. CHF 223200 was given as young scientists' support during the triennium.

\section{Ewald Fund}

The accounts of the Ewald Fund are given in Table 14. The interest on the capital is intended to cover the costs of the Prize. It is calculated as $6 \%$ of the balance in the fund, and is taken from the total annual interest income received from the IUCr's investments, in the same way as for the interest credited to the PJDF and the REF. The balance of the interest from the investments is credited to the GF. An additional CHF 90000 has been transferred to the fund during the triennium. This has allowed the IUCr to increase the Prize to USD 30000 in 1996.

\section{Newsletter Fund}

Table 15 shows the accounts of the Newsletter Fund (NF). The fund was established in 1994 following the successful launch of the IUCr Newsletter in 1993 (when the expenses were charged to the GF). The IUCr Newsletter is currently distributed free of charge to 587 libraries and 15000 crystallographers and other interested individuals in 39 countries. The costs to the $\mathrm{IUCr}$ were CHF 47561 in 1993, CHF 90412 in 1994 and CHF 69489 
Table 15. Newsletter Fund (Swiss Francs)

INCOME

Income from advertisements

Reimbursement for CGA-17 second circular

Transfers from other Funds:

General Fund

EXPENDITURE

Editorial

Printing/distribution

Advertising costs

EXCESS OF INCOME OVER EXPENDITURE

FLUCTUATIONS IN RATES OF EXCHANGE

ACCUMULATED BALANCE AT END OF YEAR

in 1995. The handling of the advertising was transferred to the editorial office in Buffalo in 1995. The advertising had previously been handled by the American Institute of Physics with the income being used to offset the printing costs.

\section{Appendix C: Ewald Prize}

The establishment of the Ewald Prize, for outstanding contributions to the science of crystallography, was announced in February 1986 and was given wide publicity. The name of the Prize was chosen with the kind consent of the late Paul Peter Ewald, to recognize Professor Ewald's significant contributions to the foundations of crystallography and to the founding of the International Union of Crystallography, especially his services as the President of the Provisional International Crystallographic Committee from 1946 to 1948, as the first Editor of the IUCr's publication Acta Crystallographica from 1948 to 1959 , and as the President of the IUCr from 1960 to 1963.

Shortly after the death of Professor Ewald, his family informed the President that Professor Ewald had wished to make a bequest to the IUCr. After consulting Mrs Ewald, this generous bequest, together with a donation from the Ewald family and a donation from the IUCr, was used as starting capital for the Ewald Prize. The interest from this capital and further donations from the IUCr are used to finance the Prize.

The Prize consists of a medal, a certificate and an award of USD 30000 . It is presented once every three years during the triennial International Congresses of Crystallography. The first Prize was presented during the Perth Congress, being awarded jointly to Professor J. M. Cowley and Dr A. F. Moodie. The second Prize was presented during the Bordeaux Congress to Professor B. K. Vainshtein. The third Prize was presented during the Beijing Congress to Professor N. Kato.

In March 1996, it was announced that the fourth Ewald Prize had been awarded to Professor M. G. Rossmann for his work on molecular replacement and the use of non-crystallographic symmetry in the determination of macromolecular structure and for his research on the structure of viruses, which is foremost among the triumphs of crystallography.

Professor Michael Rossmann works in the Department of Biological Sciences at Purdue University in West Lafayette, Indiana, USA.
1993

1994

1995

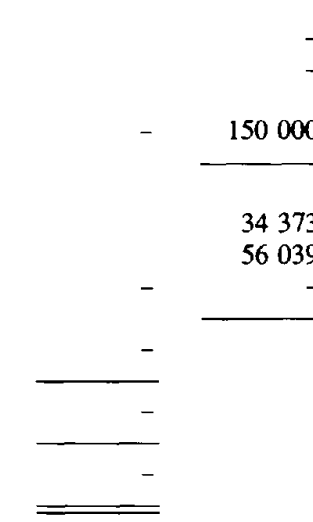

138115

132604

5511

$-7369$

51741

The presentation of the Ewald Prize to Professor Rossmann will be made during the Congress Opening Ceremony.

\section{Appendix D: Reports of Commisssions of the Union}

\section{Commission on Journals}

The journals of the Union, Acta Crystallographica, the Journal of Applied Crystallography, and the new Journal of Synchrotron Radiation, were all published on or close to schedule during the triennium. The number of papers published during the period increased in Acta Cryst. to 3911, and in J. Appl. Cryst. to 459. The number of papers in $J$. Synchrotron Rad. from its inception in late 1994 was 65. Median publication times for Full Articles were up slightly for Sections $A$ and $B$, to 6.1 and 6.7 months, respectively, and Section $D$, inaugurated in 1993, had an average publication time of 5.5 months during the triennium. The median publication times for regular structural papers in Section $C$ decreased to 6.2 months, mainly as a result of the installation of new computer and software facilities, centralized checking procedures, and an expanded editorial staff in Chester, all of which combined to clear a backlog of papers. The number of electronic submissions to Section $C$ using the CIF format increased over the triennium to $85 \%$. The median publication time for Full Articles in J. Appl. Cryst. increased slightly to 6.6 months, and for $J$. Synchrotron Rad. during its first full year of publication, the median publication time was 2.6 months.

New initiatives undertaken during the triennium included the naming of editors for the individual sections of Acta Cryst., including the new Section $D$ which was first published in 1993. Editors appointed were A. Authier for Section A, Fundamentals of Crystallography, F. H. Allen for Section B, Structural Science, S. R. Hall for Section C, Crystal Structure Communications, and J. P. Glusker for Section D, Biological Crystallography. As Chairman of the Commission on Journals, C. E. Bugg remained as Editor-in-Chief of the Acta Cryst. series. A. M. Glazer continued as Editor of J. Appl. Cryst. and Co-Chairman of the Commission.

In response to the synchrotron radiation community's need for a dedicated journal, the Journal of Synchrotron Radiation was instituted with an Inaugural Issue in October 1994. J. R. Helliwell, S. S. Hasnain and H. Kamitsubo were appointed 
Table 16. Sales and stocks of volumes published to date

$\begin{array}{lrrrrrrr}\text { Volume } & \text { II } & \text { III } & \text { IV } & \text { A } & \text { Brief A } & \text { B } & \text { C } \\ \text { Date of publication } & 1959 & 1962 & 1974 & 1983 & 1985 & 1993 & 1992 \\ \text { Dates of reprinting } & 1967 & 1968 & 1989 & 1984 & 1988 & - & 1995 \\ & 1972 & 1983 & - & 1987 & 1989 & - & - \\ & 1985 & 1985 & - & 1989 & 1993 & - & - \\ & 1989 & - & - & 1992 & - & - & - \\ \text { Number of copies sold } & - & - & - & 1995 & - & - & - \\ \text { up to 31 December 1992 } & 9402 & 8682 & 4202 & 4654 & 3546 & - & 450 \\ \text { in 1993 } & 36 & 43 & 29 & 397 & 249 & 507 & 358 \\ \text { in 1994 } & 17 & 18 & 17 & 61 & 332 & 344 & 77 \\ \text { in 1995 } & 19 & 21 & 20 & 870 & 275 & 197 & 513 \\ \quad \text { up to 31 December 1995 } & 9474 & 8764 & 4268 & 5982 & 4402 & 1048 & 1398 \\ \text { Stock at 31 December 1995 } & 49 & 107 & 30 & 77 & 256 & 0 & 560\end{array}$

Editors, and an international Co-editorial board was assembled. The number of papers submitted was below projections, but it is expected that with an expanded editorial board and plans to publish a special issue of conference proceedings in the next triennium, the journal will attract more submissions.

All journals received new cover and contents format designs during the period. Acta Cryst. focused on expanding its Lead Articles to include more subjects of current interest to the crystallographic community and the introduction of Topical Reviews. Three new sections in J. Appl. Cryst. were introduced, one on CIF applications, one on crystallographic teaching and education, and one on cryocrystallography. Revised Notes for Authors for the individual Acta Cryst. sections, J. Appl. Cryst. and $J$. Synchrotron Rad. were published annually. Free offprints were reinstated for Section C papers, putting this section of Acta Cryst. in line with the other journals.

Special issues published during the triennium included the conference proceedings for Direct Methods of Phasing in Macromolecular Crystallography (Section D), Sth International Conference on Crystallization of Biological Macromolecules (Section $D$ ), Structure-Based Drug Design (Section D), and New Trends in Small Moiety Crystallography (Section B).

With the addition of the J. Synchrotron Rad. editorial board, the Commission on Journals reached nearly 90 members at the end of the triennium.

The editorial staff in Chester was expanded during the triennium to handle the increasing submissions of papers created by the new initiatives, and also to manage the increased use of electronic submissions and in-house checking and archiving of structural data. The enthusiasm and dedication of the entire Managing Editor's staff are gratefully appreciated during what was a challenging triennium that resulted in journals of exceptional quality.

12 April 1996

C. E. BugG, Chairman

A. M. Glazer, Co-Chairman

\section{Commission on International Tables}

In July 1993, the Chairman of the Commission on International Tables, A. J. C. Wilson, was succeeded by Th. Hahn. During the Beijing Congress and General Assembly, the new Chairman reported on the present status of and the future plans for the various volumes of International Tables for Crystallography. He used the occasion to discuss this work with a number of interested scientists.
On 1 July 1995, Arthur Wilson died in his 81st year. With him the Commission has lost its Chairman from 1982 to 1993 and Editor of Volume C. We all miss his expertise, his keen interest and his friendly manner very much. In August 1995, the Executive Committee appointed E. Prince, Gaithersburg, Maryland, USA, as the new Editor of Volume C. The Executive Committee has also approved the publication of Volume Al (subsequently relabelled Volume $\mathrm{H}$ ) on Maximal Subgroups of Space and Plane Groups, with $\mathrm{H}$. Wondratschek, Karlsruhe, Germany, as Editor.

Detailed reports on the individual volumes of International Tables are given below. Table 16 contains sales and stock figures for the volumes that are currently active.

\section{Volume A. Space-Group Symmetry; Editor Th. Hahn}

After lengthy preparations, the fourth, revised edition of Volume A was published in March 1995. It contains new diagrams for all plane groups and space groups, as well as new explanatory diagrams in Section 2.6. Furthermore, this edition contains for 17 space groups the new graphical symbols for the 'double' glide plane $e$, introduced in an IUCr Nomenclature Report in 1992. This has led to major changes in Section 1 and to modifications of the Hermann-Mauguin symbols for five space groups (Nos. 39, 41, 64, 67, 68).

A list of corrigenda and addenda to the third, revised edition (1992) appeared in Acta Cryst. (1995), A51, 592-595.

The third, revised and enlarged edition of the Brief Teaching Edition of Volume A appeared in the summer of 1993.

As a new item, it contains the 17 plane groups, so useful for teaching purposes.

Early in 1996, the material for a corrected reprint of Volume A, as well as for the fourth edition of the Brief Teaching Edition of Volume A, was prepared.

\section{Volume B. Reciprocal Space; Editor U. Shmueli}

The first edition of Volume B was published in 1993. Since its preparation suffered serious delays, the planning of the second edition suggested itself almost immediately after the publication of the first edition. Plans for the second edition, which were the main subject of the editorial activities during this triennium, included: (i) minor revisions and corrections, (ii) major revisions of several existing chapters in order to extend their scope and/or update them with recent developments, and (iii) invitations for contributions on several relevant topics not treated in the first edition. 
Most of the minor changes that did not require repagination were taken care of by the corrected reprint of Volume B which was published early in 1996, to ensure further availability of the volume until the second edition was ready.

By the end of 1995, most of the final and advanced drafts of the minor and major revisions of existing chapters had been received by the Editor. These revisions include an extension of Chapter 1.2: The Structure Factor; a modification and extension of Appendix B to Chapter 1.4: Symmetry in Reciprocal Space and a more conveniently readable representation of the structurefactor tables 1.4.3A-G; a major revision and updating of Chapter 2.1: Statistical Properties of the Weighted Reciprocal Lattices; a revised Foreword to Chapter 2.5: Electron Diffraction in Structure Determination; a revision and updating of Section 2.5.2: Space-Group Determination by Convergent-Beam Electron Diffraction; and a revision and extension of Chapter 5.1: Dynamical Theory of X-ray Diffraction.

After extensive consultations, five new contributions on the following topics were invited for the second edition of Volume B:

(1) Space-group representations in reciprocal space;

(2) Direct methods in electron crystallography;

(3) Diffraction by polymers;

(4) Reciprocal-space images of aperiodic crystals;

(5) Dynamical theory of neutron diffraction.

These are scheduled to be treated in Chapter 1.5 (1), Section 2.5.6 (2), and Chapters $4.5(3), 4.6$ (4) and $5.3(5)$, respectively.

By the end of 1995, advanced drafts of two contributions on the above topics had been received. It should also be noted that the contribution to topic (4) was formally invited only in January 1996, although most relevant correspondence belongs to the triennium.

Volume C. Mathematical, Physical and Chemical Tables; Editor E. Prince

E. Prince was appointed Editor of Volume C in August 1995 , replacing the late A. J. C. Wilson, whose death on 1 July 1995 is noted with great sorrow. At the time of his death, Arthur Wilson had finished more than $80 \%$ of the work of preparing an extensively revised and expanded second edition for publication. That work is continuing with the intention to have the second edition ready by the time the stock of the current edition, a corrected reprint of which was published in February 1995, runs out.

At the same time, a project has been initiated that is aimed toward making much of the information in the volume available electronically. There has been a revolution in the technology of publication since the beginning of the preparation of the current edition. One result is that relatively little of the text exists in machine-readable form, but an effort is being made to obtain electronic files of any new material and any older material that may exist.

\section{Volume D. Physical Properties of Crystals; Editor A. Authier}

Volume D will consist of three parts:

Part 1: Tensorial Aspects of Physical Properties: mathematical introduction and reduction of polar and axial tensors according to crystal symmetry, group theory and representations, mechanical properties including non-linear optical properties, transport properties, anisotropic displacement parameters, tensors for quasiperiodic systems;

Part 2: Symmetry Aspects of Excitations: phonons, electrons, Raman scattering;
Part 3: Symmetry Aspects of Structural Phase Transitions, Twinning and Domain Structures.

Relevant tables will be included on an accompanying diskette or CD ROM.

The preparation of Volume $D$ is progressing steadily. The outline of Part 3 was reviewed during a meeting in Aachen (Germany) with the General Editor of International Tables and co-authors of several chapters. The overall plan of the whole volume is now finalized and authors have been found for all chapters. About half of the manuscripts have already been submitted.

Volume E. Subperiodic Symmetry Groups; Editors V. Kopsky and $D$. B. Litvin

The content of Volume $\mathbf{E}$ has been finalized. It consists of two parts:

Part 1: Subperiodic Group Tables: Frieze Groups, Rod Groups and Layer Groups.

Part 2: Scanning of Space Groups, i.e. determining the layergroup symmetries of planes which transect a crystal.

Material originally to be included, concerning subperiodic groups as factor groups of reducible space groups, has been postponed for inclusion in a subsequent edition of this volume. Final drafts are being written to bring about consistency of notation, terminology and style throughout the volume.

Volume A1 (subsequently Volume H). Maximal Subgroups of Space and Plane Groups. Editor H. Wondratschek

In August 1995, the Executive Committee approved the publication of this volume with $\mathrm{H}$. Wondratschek as Editor. The major chapters of this volume are: Introduction to the Tables, User's Guide, Coordinate Transformations, and Subgroup Tables for Plane and Space Groups.

The data for each space-group type are presented in two categories:

I. Maximal translationengleiche subgroups;

II. Maximal klassengleiche subgroups, with the subdivisions: Loss of centring translations; Enlarged unit cell: indices 2, 3, and 4 ; Infinite series of isomorphic subgroups; Minimal supergroups.

In contrast to the subgroup data of Volume $A$, the maximal subgroups of index up to 4 are listed individually, whereas the infinite number of isomorphic subgroups are presented as infinite series. For each subgroup, either its representatives (general position) or at least a set of generators are given. The transformation to the conventional coordinate system of the subgroup is indicated by the matrix for the basis transformation and the column for the origin shift.

In addition, the group-subgroup relations are displayed by two series of diagrams: for each crystal class, one diagram for the klassengleiche subgroups: for the translationengleiche subgroups another set of diagrams which are similar to the subgroup diagrams of crystallographic point groups.

The volume is supplemented by a theoretical section on grouptheoretical aspects and by a practical section on applications of the subgroup data.

The data have been calculated completely and are available in principle. They are presently being transferred to $\mathrm{LT}_{\mathrm{E}} \mathrm{X}$ format, in order to enable the printing to be made directly from these files.

\section{New volumes}

Three new volumes are presently under discussion or in the planning stage: 
(i) Volume A2. N-Dimensional Space Groups. Editor T. Janssen. A proposal for this volume, which would consist of a printed book and a CD ROM, was extensively discussed at the Executive Committee meeting in Lund in August 1995, and a demonstration of the program was given. A final decision on the volume and its financial implications is awaited.

(ii) A new volume on Macromolecular Crystallography with M. G. Rossmann as Editor has been proposed. A memorandum on the scope and the details of this volume is being prepared by M. Rossmann for discussion at the Seattle Congress.

(iii) Another new volume on Crystallographic Information (the official CIF dictionaries and definitions) with S. R. Hall and B. McMahon as Editors has been proposed. Again, a memorandum for discussion at the Seattle Congress is being prepared.

21 March 1996

TH. HaHN, Chairman

\section{Commission on Aperiodic Crystals}

Members have had the opportunity to meet once a year: Beijing (1993), Les Diablerets (1994) and Balatonfüred (1995). In addition, there has been frequent communication among the members by electronic mail, which has established efficient and almost instantaneous working relations. The Commission maintains a World-Wide Web (WWW) server relating the activities in the field of aperiodic crystals (http://emmy.smith.edu/aperiodic). Future meetings, conferences and information on this topic are listed on the server.

\section{Checklist}

The Commission prepared and submitted a checklist for the description of incommensurate modulated crystal (IC) structures. This document specifies the relevant parameters and information that should be included in a database or publication for their complete characterization. It should also assist journal editors and referees in their activities. This document has been approved by the Executive Committee. The Commission on Journals suggested some modifications which were included in the final version, which is expected to appear in Acta Crystallographica [Acta Cryst. (1997), A53, 95-100].

\section{CIF Dictionary for modulated structures}

Following the checklist for the description of incommensurate modulated structures, the CIF Dictionary for modulated structures has been approved by COMCIFS (the IUCr CIF Management Committee). Work has been started for the extension of the CIF Dictionary to include incommensurate structures. The creation of a database containing the information on the IC structures published to date is under discussion. In addition to the structure descriptors fulfilling the checklist, additional items concerning composite crystals have been considered. The Commission is further pursuing its work on this matter.

\section{Aperiodic '94}

Much of the effort of the Commission was dedicated to organizing the conference Aperiodic '94, held 18-22 September 1994 in Les Diablerets (Switzerland). According to its terms of reference, the Commission is to actively promote the organization of this series of conferences on a triennial basis. All the members of the Commission acted as the Programme Committee and thus contributed to the success of the conference by selecting a very high level of invited speakers and by a careful choice of abstracts. The Programme Committee took great care to ensure the interdisciplinary character of the conference by maintaining a balance between quasicrystal, incommensurate and composite crystal, and polytype specialists. A full report of the conference has been published elsewhere (IUCr Newsletter, 1995, Vol. 3, and also our WWW server). The conference organizers took full advantage of the possibilities offered by the WWW, using it to make the abstracts available first to the Programme Committee and then to interested scientists. All the conference information, including the programme, was available on the Internet well in advance of the conference. This was the first meeting sponsored by the IUCr to operate within the framework of the WWW and the experience gathered will be useful to future meeting organizers. The Commission also participated actively in the preparation of the Aperiodic '94 conference proceedings by carefully selecting the contributions. The volume was published by World Scientific (Singapore) in 1995 and was delivered to the participants nine months after the meeting.

\section{Coordination}

The Commission was very active in coordinating meetings in the field of aperiodic crystals and participating actively in Programme Committees: the International School on Quasicrystals (Balatonfüred, Hungary, May 1995); the 5th International Conference on Quasicrystals (Avignon, France, May 1995); ECM-16 (Lund, Sweden, August 1995); the NATO Advanced Study Institute on the Mathematics of Long Range Aperiodic Order (Waterloo, Canada, August 1995); the IUCr Congress (Seattle, USA, August 1996); ECM-17 (Lisbon, Portugal, August 1997).

The Commission supported many organizers in their efforts to obtain financial help from the IUCr.

18 May 1996

G. C. Chapuis, Chairman

\section{Commission on Biological Macromolecules}

A major concern of the Commission during the period has been related to the deposition, validation, retrieval and effective use of macromolecular structural data. The matter was discussed at the closed meeting of the Commission during the Beijing Congress and also through correspondence among the members. The rapid growth of macromolecular crystallography and the insistence, on the basis of the guidelines formulated by $\mathrm{IUCr}$, by most journals on deposition of structural data, have led to a phenomenal increase in deposition at the Brookhaven Protein Data Bank. This calls for new ways of dealing with macromolecular data. The Commission noted with interest the joint North American-European Community initiative in this regard, and the development and usage of different packages, database description tools, macromolecular CIF etc. It further noted that the activities of the Brookhaven Protein Data Bank have received added momentum with the appointment of $\mathrm{J}$. Sussman as its Director and that the PDB has adopted new checking and classification procedures.

The Commission felt that the substantial macromolecular crystallography community that exists in regions outside North America and the European Community countries should also be involved in operations concerned with macromolecular structural data. As an important step in this direction, an International Seminar-cum-School on Macromolecular Crystallographic Data was held in Calcutta. India, 16-20 November 1995. The Seminar-cum-School was organized at the Saha Institute of Nuclear Physics with Professor J. K. Dattagupta as the Convener. The Commission functioned as the international Programme Committee. The meeting was attended by 150 participants from 14 different countries and the lecturers included well known leaders in the area. The scientific programme consisted of 
lectures, demonstrations, discussions and hands-on sessions. The topics covered at the meeting included protein and nucleic acid databases and their management, validation, database description tools, macromolecular CIF, CIF in crystallographic publication, data analysis, crystallization database, molecular modelling and biocomputing, molecular replacement, drug design, protein and nucleic acid structures, and structural comparisons.

Two sessions at the Calcutta meeting were devoted to deposition policies. In fact, the discussions in these sessions followed those among the members of the Commission on this issue. Earlier, the issue was specifically raised with the Commission by the US National Committee of the IUCr. The discussion among the members of the Commission led to the conclusion that the most urgent requirement is the enforcement of the existing $\mathrm{IUCr}$ guidelines on data deposition. The Commission therefore recommended to the Executive Committee that the Cornmittee should take up the matter with major joumals. There were comparatively minor divergences of views on modifications to the existing policy. It was decided that a consensus on the modifications could be arrived at through further discussions. The discussions at the Calcutta meeting also emphasized the urgency of enforcing the IUCr guidelines. The importance of depositing structure factors was also highlighted. Arising out of the discussions at Calcutta, a letter was addressed by a few of the leading participants to major joumals on the need for enforcing the IUCr policy on deposition [e.g. Nature (London), (1996), 379, 202]. This has had the desired effect on some journals such as Nature and Nature Structural Biology as evidenced by their insistence on data deposition before publication with effect from January 1996.

The Commission extended its support to the meeting on Crystal Growth and Crystallography of Biological Macromolecules held 12-17 November 1995 at Hiroshima, Japan, and to the course on Experimental and Computational Approaches to Structure Based Drug Design scheduled to be held 8-19 May 1996, at Erice, Italy.

The Commission has been involved in formulating the programme of the Seattle Congress and the associated meetings.

\section{April 1996}

M. VIJAYAN, Chairman

\section{Commission on Charge, Spin and Momentum Densities}

The Commission promotes the study of electron density distributions in both real and momentum space by bringing together physicists, chemists and crystallographers in conferences, workshops and schools, and by initiating and executing projects.

The highly successful 1995 Sagamore meeting in Brest, France, organized by $G$. Loupias on behalf of the Commission, showed that the field of interest is still an excellent focal point for scientists of different disciplines. The increasing accessibility of synchrotron sources has given the field a second youth by fulfilling old dreams and by enabling new experiments with unexpected accuracy. At the same time, the increase of computing facilities has continued without any sign of slowing down, with the corollary that good progress was made with the interpretation of the experimental results.

Projects

(1) Fermiology via High Resolution Synchrotron-Based Compton Scattering (A. Bansil). The project was initiated during the 1991 Sagamore conference in Konstanz, Germany. It envisages three steps, of which the first consists of standardizing procedures for evaluating high-resolution Compton data from synchrotron- based instruments with $\mathrm{Si}$ as test case. In the second step, the ability of Compton scattering to contribute to the fermiology of metallic systems is evaluated, while in the third step the participating groups are expected to concentrate on the momentum distribution at the Fermi energy of the high- $T_{c}$ superconductor $\mathrm{YBa}_{2} \mathrm{Cu}_{3} \mathrm{O}_{7}$. In the second meeting of the group, Tokyo, Japan, 1995 (see below), the reports concentrated on the first two steps. The experimental results obtained by different groups showed substantial differences, whereas, on the theoretical side, quite different methodologies - FLAPW and KKR - yield highly similar results.

(2) Quantum Mechanical Description of Electronic Structure from Experimental Charge and Momentum Densities (W. Weyrich and V. Smith Jr). After an incubation period, the project was established during the 1991 Sagamore conference in Konstanz. The aim of the project is to investigate to what extent the combination of accurate experimental density data from both position and momentum space can enable a direct access to wave functions and density matrices. The possibility of obtaining information on the non-diagonal elements of the density matrix from coherent Compton scattering adds to the value of the field. Ten groups are active in the field. Their activities comprise four areas: theory, analysis, reconstruction and direct measurement. The major achievements have been the identification of the elements of matrices which are fixad by observables, the extension of the analysis to the Wigner and Husimi functions and to the pure momentum-density matrix and the exploration of the limits of reconstruction. Most of this work was reported at the Brest 1995 Workshop, preceding the conference (see below).

The following projects are in a final state of preparation and will start soon.

(3) Multipole Refinement. In the course of recent decades, several programs were written to carry out multipole refinements of the electron-density distribution. Comparison of the results shows differences in outcome, while at the same time a number of limitations became apparent. This led to a number of activities: (a) The development of a new program, $X D$, by an international team under the leadership of T. Koritszanski. The task has been accomplished successfully and versions of the new program have been sent to several groups for critical tests. (b) The initiation of a new project for critical assessment of the multipole refinement method (Claude Lecomte).

(4) Maximum Entropy Method (MEM) (Matt Sakata). Since the Konstanz Sagamore meeting in 1991, the MEM has received the full attention of the community served by the Commission. Some highly interesting results have been reported at several conferences since. No subject led to more heated discussions than this and recently it was shown that different programs lead to different results. Several questions stand insufficiently answered such as: what is the basis of the method, which algorithms should be used, how different are the results? The project is in the final state of preparation.

\section{Meetings, Workshops and Schools}

Since bringing scientists of 'different persuasion' together is one of the main objectives of the Commission, meetings play a major role in its activities. Several were organized either under the close guidance of the Commission, such as the triennial Sagamore conferences, or in some form of cooperation such as the Gordon conference, or in an intermediate form of interaction.

(1) The First International Workshop on High-Resolution Compton Scattering as a Probe of Fermiology. The meeting was organized in Krakow, Poland, 3-5 July 1994, by L. Dobrzynski, and chaired by W. Schülke and A. Bansil. It 
brought together theoreticians and experimentalists familiar with Compton scattering and/or synchrotron techniques. Joint approaches within the context of the project were discussed.

(2) Workshop on Density Matrices. The meeting was organized in Brest, France, 5-6 August 1994, by W. Weyrich and V. Smith Jr. It dealt with theory of density matrices, relation to specific experiments, measurement and reconstruction, and density matrices as an interpretative tool. There were 39 participants, half of which were from the field. During the conference, density matrices grew from a well defined but vaguely experienced concept to a lively tool.

(3) Sagamore XI Conference. The conference was organized in Brest, France, 7-12 August 1994, by G. Loupias. With a record attendance of 180 , it demonstrated the vitality of both the science and the scientists. Progress was noted in all parts of the field: the theoreticians discussed beyond local density methods, experimentalists, coming from neutron sources and from synchrotron facilities, brought new results on magnetization densities, and computational scientists hotly discussed maximum-entropy methods.

(4) Intemational School on Charge Density Analysis. The school was organized in La Plata, Argentina, 18-25 May 1995, by $G$. Punte. The main topics of the school were: the physical principles of accurate structure analysis, $\mathrm{X}$-ray and synchrotron data-collection techniques (including advanced methods), crystallization techniques, electron-density modelling with diffraction data, error analysis of experimental results, theoretical methods in charge-density studies, chemical interpretation of the electron density in terms of orbital concepts and topological analysis, calculation properties from the multipole model, comparison of an experimental electron density with an $a b$ initio one, application to structural activity problems. The school was attended by (mainly young) participants from Argentina, USA, UK, France, Germany, Mexico, Chile, Cuba and Uruguay. Much attention was paid to the new program package $X D$ (Koritsansky's Project of our Commission), where much progress was noted since the Brest meeting.

(5) The Gordon Conference on Electron Distributions and Chemical Bonding. The meeting was organized in Plymouth, New Hampshire, USA, 2-7 July 1995. About 75 crystallographers and theoretical chemists discussed the experimental determination, the quantum-chemical calculation, the interpretation and the use of electron-density distributions. The use of the maximum-entropy method and the contribution of electron diffraction raised much interest and heated discussions. By electing two members of the Commission as organizers of the next conference, the participants made sure that the conference fits in well with the activities of the Commission.

(6) Second Intermational Workshop on Compton Scattering and Fermiology. The meeting was organized by N. Shiotani in Tokyo, Japan, 28-31 August 1995. 64 scientists from 12 countries attended the three-day meeting with 44 invited talks. Synchrotron radiation has made it possible to use ultra high momentum resolution (0.02 a.u.) and photon energies up to the electron rest energy can be employed. One of the objects of the Fermiology Project is to standardize procedures with $\mathrm{Si}$ as test case. The results of the various groups show significant differences, probably owing to background contribution and multiple scattering. On the theoretical side, quite different methodologies - FLAPW and KKR - yield highly similar results. Compton studies on different systems were extensively discussed. Other techniques such as positron annihilation, angle-resolved photoemission and electron Compton scattering contributed to yield a robust picture of the underlying electronic structure.

\section{Commission meetings}

The Commission met in Beijing during the Congress in its new composition to discuss the next Sagamore conference. Other meetings were held at the Sagamore meeting in Brest (twice), where it was decided to hold the next Sagamore meeting in Canada because several meetings had been held in Europe in succession. The invitation to go to Poland was gratefully acknowledged and kept in mind. The fields of multipole refinements and maximum entropy, magnetization densities, and encounter of theory and experiment in charge-density studies were identified for microsymposia at the Seattle meeting (all honoured). At the Gordon conference, a proposal was made for new candidates and a Chairman. At all meetings, the projects were discussed.

10 May 1996

D. FEIL, Chairman

\section{Commission on Crystal Growth and Characterization of Materials}

The Commission continued its tradition of organizing international schools on crystal growth and characterization with the aim to train young scientists, mainly from economically disadvantaged countries. The following two schools were held:

(1) The International School on Growth and Characterization of Crystals, which was held 4-14 September 1994 in Krynica, Poland, for young scientists from East European countries. The organization of the school was in the hands of Professor S. Hodorowitz (Cracow) and Professor K. Sangwal (Lublin). Several present and previous members of the Commission were engaged in the International Programme Committee and acted as lecturers. The number of participants was 29, most from East European countries. The school was sponsored and financially supported by the IUCr and by Polish Institutions. Ten participants received IUCr Young Scientist Awards.

(2) The International School on Advanced Electronic Materials was held 6-15 February 1995 in the Crystal Growth Centre of Anna University, Madras, India. The Commission was strongly engaged in the International Programme Committee with six present and two past Commission members. Three members acted as lecturers. The local organization was carried out by Professor C. Subramanian and his staff. The total number of participants (without lecturers) was 102, about 90 from India and nine from neighbouring Asian countries. The school was sponsored by the IUCr, mainly for the support of 16 young scientists, by the International Centre for Theoretical Physics (ICTP), Trieste (Italy), and by Indian Institutions. A serious problem arising during the organization of the international school in Madras should be noted: despite the sponsorships mentioned above, it was not possible to grant travel support to the lecturers. Therefore, with the invitation the lecturers were requested to try raising travel funds from their home institutions or own sources. This action was successful: despite some resignations, 16 speakers from European countries and Japan and 7 Indian speakers were recruited, and a programme of 46 lectures, covering the fundamentals and all essential techniques of bulk and epitaxic crystal growth, including characterization, was established.

The Commission helped to organize the 2nd European Symposium on X-ray Topography and High-Resolution Diffraction, which was held 5-8 September 1994 in Gosen (near Berlin, Germany). About 220 scientists attended the symposium, 138 from West European countries, 62 from East European countries and 16 from countries outside Europe (mainly USA and Japan). 
192 contributions ( 43 oral, including reviews and invited reports, and 149 posters) were presented. This relatively high number of participants and scientific contributions clearly demonstrates the great and worldwide interest in symposia on these topics. The symposium was sponsored and financially supported by the $\mathrm{IUCr}$ and other national and international Institutions. 11 participants received IUCr Young Scientist Awards.

The Commission recommended $\mathrm{IUCr}$ sponsorship of the following International Conferences: Sixth International Conference on Crystallization of Biological Macromolecules (ICCBM-6), 12-17 November 1995, Hiroshima, Japan; Fourth International Symposium on Ferroic Domains and Mesoscopic Structures (ISFD-4), 25-30 March 1996, Vienna, Austria.

In addition, the Commission helped with the scientific programme of the forthcoming Seattle Congress by suggesting topics, microsymposia Chairs/Co-Chairs and speakers in the fields of crystal growth and defect characterization. Four microsymposia on crystal growth were established, three (Fundamentals; Methods and Materials; and Controlling and Prediction of Crystal Morphology) being subject to the care and responsibility of the Commission Chairman.

During the Eleventh International Congress on Crystal Growth (ICCG-11), 18-23 June 1995, The Hague, The Netherlands, the Commission Chairman attended the council meeting of the International Organization of Crystal Growth (IOCG). Among the various topics on the agenda (see report on the IOCG), following an initiative of the Commission, stronger interaction and cooperation of the IUCr and the IOCG in fields of common interest were discussed. It was agreed to consider holding a joint symposium on the characterization of crystal perfection.

17 May 1996

H. KLAPPER, Chairman

\section{Commission on Crystallographic Apparatus}

During the triennium, the Commission has promoted two major projects: Precision in Lattice Parameters Measurements and Absolute Structure Determination of Light Atom Compounds. This report first describes these projects and then provides a summary of the activities of the high-pressure crystallography group. The project or group leaders are indicated.

(1) Precision in Lattice Parameters Measurements (G. DeTitta and L. Finger)

This is a long-standing, some would say long-suffering, project initiated by the IUCr to do two things. One is to estimate the magnitude of the variance in lattice parameters as reported by structural crystallographers; i.e. those scientists who are primarily reporting structure determinations and for whom the lattice parameters are a necessary ingredient for the calculation of bond distances etc. The group to be surveyed is in particular not those scientists who make their living by the accurate measurement of lattice parameters as an end in itself, such as those in the doped semiconductor business. The other, a purpose added by the Chairman, is to uncover the causes of these variations so that structural crystallographers might become more aware of them and might report more accurate lattice parameters.

In the early stages of the project, we solicited opinions and information from structural crystallographers as to how they determined lattice parameters and as to their opinions on what constituted sufficient data to analyse the raw data coming from their diffraction equipment. The survey also identified a number of scientists willing to participate in a round robin of measurements on crystals to give an experimental estimate to the true variances of reported lattice parameters.
We chose an unknown crystal with a number of considerations in mind. The crystals should be stable in the X-ray beam, have fairly well developed morphology and have lattice parameters that range from small to large. The appearance in the literature of a report on large zeolite crystals made the choice rather simple. The kind gift of these crystals by Professor Juan Garces, University of Toronto, Canada, made it possible to select a suitable number of samples for the round robin. In addition to the unknown, a crystal with well known lattice parameters was chosen to furnish particular information about the state of the diffraction equipment used in the round robin. The ruby spheres given as gifts to those who attended the IUCr meeting in Ottawa were still commercially available at a reasonable price and a quantity of them was purchased from Arcanum in Wisconsin. The zeolite crystals were deliberately chosen because their alignment at the centres of the diffractometers would be non-trivial. No effort was made to make the crystal mount deliberately difficult to centre but no effort was made to ensure that the crystal edges were parallel, or faces perpendicular, to the mount direction. On the other hand, the ruby spheres are small $(0.015 \mathrm{~mm}$ diameter $)$ and are thus very readily placed at the diffractometer centres.

The bulk of the mounting, screening and analysis of the two kinds of crystal was carried out in the last two years. This is described in the 1995 annual report. As mentioned, the kits are still out in the field, and it is expected to have the results from 30 or more participants in hand by mid-July. It is planned for the organizers to digest the information submitted by the participants and write an interim report on the results. As to the future, we plan to pursue the participants who have yet to make measurements on the kits we sent them. When we have concluded that waiting further will be unrewarding, we will write a report, in the form of an article in Acta Crystallographica, describing the results in full. This work has received financial support from various groups and individuals. The IUCr provided the original funding and there was additional support from the American Crystallographic Association, NIST, and finally from the organizer.

(2) Absolute Structure Determination of Light Atom Compounds (E. Weckert and L. Malakhova)

Purposes. The main purpose of this project is the comparison of different methods for the determination of the absolute structure of light-atom compounds. These are compounds that will be comprised solely from elements from $\mathrm{H}$ to $\mathrm{O}$. Depending on the space group of the crystal, the term absolute structure has different meanings. For a chiral molecule in a chiral space group, it is the determination of the absolute configuration. It is the absolute conformation for an achiral molecule in a chiral space group. In a polar space group, the structure will be fixed with respect to the polar direction. And in space groups that have rotoinversion axis $\overline{4}$ and $\overline{6}$ the structure will be fixed with respect to an absolute coordinate system. The significance of the knowledge of the absolute structure, e.g. in pharmacy or for understanding physical properties, is selfevident. The traditional way to fix the absolute.structure is the use of anomalous-dispersion effects. The anomalous-dispersion effects of the $\mathrm{O}$ and $\mathrm{N}$ atoms in very careful experiments using copper radiation are normally sufficient to solve the absolute structure if the ratio of the $\mathrm{C}$ to $\mathrm{O}$ atoms is nearly one. A comparison of the results obtained in different laboratories on several compounds which vary from a $\mathrm{C}: \mathrm{O}$ content of $1: 1$ to O-free compounds with a $\mathrm{C}: \mathrm{N}$ ratio of $14: 1$ is planned. It is expected that these comparisons will reveal the limits of what can be achieved with present-day equipment and software. Another 
important question to solve is down to what $\mathrm{O}$ or $\mathrm{N}$ content a reliable determination of the absolute structure is possible. It is further planned to compare not only the results of these investigations but also the effort that was necessary, including the equipment and data-processing software that was used. As a result, we expect guidelines of general interest for the regime in which the determination of the absolute structure will be reliable. This should enable other researchers to optimize their effort for an absolute structure determination. As many researchers rely on standard data-processing software, a comparison of different systems might be very important for providing general guidelines. In many laboratories, 2D detectors are meanwhile used also for small-molecule structures. The question we wish to answer is whether the quality of these data compared with four-circle diffractometer data is sufficient to solve the absolute structure. There is another method for the determination of the absolute structure, which is the direct measurement of triplet phases by three-beam interference experiments. The advantage of this method is that it works even in the absence of anomalousdispersion effects. The disadvantage is the need for crystals of low mosaicity. It is planned to compare the results, reliability and the effort of this method with those that use the breakdown of Friedel's law.

Progress. 1994: The project started. The discussion was entirely dedicated to the selection of suitable test samples. 1995: Purchase of test compounds and distribution among the participants. Start of both kinds of experiment (anomalous dispersion and three-beam diffraction). 1996: Experiments are still going on. First results have been obtained. No comparisons between the results of different laboratories have been made so far.

Results. Only partial results have been obtained so far. The first batch of test crystals, which contains mainly crystals with relatively high oxygen content, has been distributed among the participants. These experiments are not yet finished. The determinations of the absolute structure by three-beam diffraction are nearly finished and have been successful so far. The second batch of crystals, which is more difficult, has not yet been distributed among all the participants. A final comparison of all experimental results can only be carried out if a major part of the data is available.

Future prospects. The project is lasting longer than originally planned. A rough estimate for having a major part of the intensity data sets available would be spring to summer of 1997 . For the evaluation of the data and the discussion of the results, we should plan at least six months. As this procedure does not depend on the availability of diffractometers and beam time, it should be much faster than the data-collection part. This means that this project should come to a final conclusion by the end of 1997 . Despite the delay, there seems to be no reason for this project not to come to a successful end.

\section{(3) High-Pressure Group (R. J. Nelmes)}

The principal activities of the High-Pressure Group (HPG) in 1993-1996 have been the promotion, support and organization of specialist meetings of various kinds. New experimental techniques on synchrotron and neutron sources, plus the advent of third-generation synchrotrons, are stimulating such an extraordinarily rapid growth in the range and quality of high-pressure crystallography that quite frequent meetings are needed to keep the community in touch with the latest developments. The HPG has been involved, at varying levels, in the following meetings since the last Congress.

(i) A one-day Workshop on Synchrotron Radiation at High Pressure, Stony Brook, USA, organized as a satellite to the
Synchrotron Radiation Instrumentation '94 conference, in July 1994.

(ii) A Microsymposium on High-Pressure Crystallography at the European Crystallography Meeting (ECM-15) in Dresden, September 1994. The organizing chairman was R. J. Nelmes, Chairman of the HPG, with H. Schulz, past Chairman of the HPG, acting as Co-Chairman.

(iii) A one-day Workshop on Diffraction at High Pressure, in Dresden, Germany, immediately following ECM-15. The organizer was D. Hausermann, a member of the HPG.

(iv) An International Seminar on Neutron Scattering at High Pressure, held in Dubna, Russia, October 1994. The Proceedings have been published in High Pressure Research, Volume 14.

(v) The major event was a three-day international Workshop held in Tsukuba, Japan, March 1995. This was the fourth in a series of HPG Workshops, following previous ones in Munich (1989), Daresbury (1991) and Washington (1992). The organizing Chairman was $\mathrm{O}$. Shimomura, a member of the HPG. About 80 participants from UK, Germany, France, Russia, China, USA and Japan attended. The programme began with a technical session on new optics, detectors and high-pressure techniques for diffraction experiments. Then followed sessions on data collection using diamond-anvil cells and large-volume cells, and data analysis by the Rietveld and maximum-entropy methods. The Proceedings will appear shortly in High Pressure Research.

(vi) During the past year, members of the HPG have also been heavily involved in preparations for the 1996 Congress in Seattle, where there is to be a substantial high-pressure programme comprising two keynote lectures and six microsymposia over the first three days of the Congress. All current members of the HPG are chairing or co-chairing sessions and several are giving talks. There are to be 39 invited speakers from USA, Japan, France, Germany, UK, Russia, Switzerland, Canada, The Netherlands and Spain, 8 other contributed talks, and 35 poster presentations. It is expected to prove to be a major meeting, celebrating the vitality and exciting future prospects of the field.

It has been a long-term objective of the HPG to raise the profile of high-pressure crystallography within the $\mathrm{IUCr}$ - particularly following the demise of the previous Commission on High Temperature and Pressure and we are grateful to the Congress Organizers for their willingness to accommodate our plans for Seattle so generously. All the Chairs and Co-Chairs of the highpressure sessions have worked hard to create a programme that justifies this support.

25 June 1996

H. Hashizume, Chairman

\section{Commission on Crystallographic Computing}

In the present triennium, the Commission has been engaged in the following activities:

(1) Organization of an Open Commission Meeting at the Beijing Congress with seven communications on different modern aspects of crystallographic computing.

(2) Since August 1993, refereeing the section Computer Program Abstracts in J. Appl. Cryst. has been carried out by D. Watkin and $\mathbf{M}$. Ramanadham.

(3) The seed spread by H. D. Flack (past Chairman and Consultant to the Commission) of a Crystallography WWW page has grown into a very useful tree with many branches, accessed by thousands of people. Recently, P. Bourne has set up a Commission on Crystallographic Computing home page and a software repository. 
(4) The plans for the organization of a small regional school, more oriented towards computational aspects, after the poor response to D. Watkin's explorations, were deferred.

(5) The Asian Crystallographic Computing School was held in Bangkok, Thailand, 25-28 November 1995. The school was organized jointly with the Commission on Crystallographic Teaching as a satellite of AsCA '95. The school programme included lectures in the mornings, and a short lecture and practical sessions in the afternoons. The morning lectures covered all basic aspects of crystallographic computing, with also some introductions to more advanced topics. In the afternoon, after a short introduction to some computational aspects, the practical sessions were mainly hands-on usage of a rather wide variety of crystallographic software running on PCs. Handouts with lecture notes were distributed to the participants. The lecturers who contributed to the school were: P. Coppens, G. R. Desiraju, Fan Hai-fu, C. M. Gramaccioli, S. R. Hall, C. Kennard, P. Phavanantha, M. Ramanadham, W. T. Robinson, J. Simpson, B. Skelton, H. Toraya, D. Viterbo and T. Yamane. The local organizational aspects were coordinated by $\mathrm{P}$. Phavanantha, A. Ungkitchanukit and C. Poorakkiat. The number of participants was 42 from seven different Asian countries. The setting up of the school encountered many difficulties and problems and its realization took a lot of effort and determination from the Chairmen and some members of the two IUCr Commissions, the AsCA President W. T. Robinson, with the invaluable help of J. Simpson, and of the local organizers. Before embarking on another initiative of this type, in a large and inhomogeneous region, it is advisable to make sure that there is a strong and general will to realize it and that the more developed countries are willing to support the meeting financially and scientifically. The only alternative would be to have a guarantee of almost total support from the IUCr.

(6) The Macromolecular Crystallography Computing School, a satellite meeting of the Seattle Congress, will take place 17-23 August 1996, at the Western Washington University, with P. Bourne and $\mathrm{K}$. Watenpaugh acting as local organizers.

(7) The Commission is also contributing to the organization of the Seattle Congress. P. Bourne and G. Kruger, as members of the International Programme Committee, have contributed to the setting up of the microsymposia on computing. In particular, the organization and programme for the microsymposium Computing Il on General Advances \& Applications as an Open Commission Meeting is being undertaken. H. D. Flack is organizing both the microsymposium Computing I - The Internet and two half-day workshops on Surfing the Crystallographic Net.

6 May 1996

D. L. M. VITERBo, Chairman

\section{Commission on Crystallographic Data}

No report was received.

\section{Commission on Crystallographic Nomenclature}

The work of the Commission during the triennium was conducted entirely by electronic and snail mail. All members are ex officio appointments, as Editors of the Union's journals or volumes of International Tables for Crystallography or as Chairpersons either of the IUCr/OUP Book Series Committee or the Commission on Crystallographic Teaching. The Commission's principal activities have been carried out partly through its internal efforts and partly through the contributions of its subcommittees and working groups.
The Commission records with deep sadness the loss of its longest serving and highly effective member Professor A. J. C. Wilson, who died 1 July 1995 [see obituary in Acta Cryst. (1996), A52, 7-10].

A Working Group on the Expression of Uncertainty in Measurement, consisting of D. Schwarzenbach (Chair), S. C. Abrahams, H. D. Flack, E. Prince and A. J. C. Wilson, was appointed during the triennium. It completed its charge of examining the possible impact of the International Standardization Organization's Guide to the Expression of Uncertainty in Measurement on crystallographic statistical nomenclature with a report entitled Statistical Descriptors in Crystallography. II, which was published in Acta Cryst. (1995), A51, 565-569. Among its major recommendations are replacement of the term estimated standard deviation by either standard uncertainty or combined standard uncertainty in statements of the statistical uncertainties of data and results. The report presents the concepts of standard uncertainty as developed by the International Organization for Standardization, and of Type A and Type B evaluations of standard uncertainties. The result of a measurement is only an estimate of the value of the measurand and is to be considered complete only when accompanied by a quantitative statement of the uncertainty of that estimate.

Several membership changes have occurred in the Subcommittee on the Nomenclature of $N$-Dimensional Crystallography. Its new Chair is Professor T. Janssen, with J. L. Birman, Th. Hahn, V. Koptsik, M. Senechal, D. Weigel, H. Wondratschek, A. Yamamoto and S. C. Abrahams, ex officio, as members and N. D. Mermin of Cornell University and G. Chapuis of the Université de Lausanne as advisors. The Sub-committee is proceeding very systematically in its consideration of the concepts, definitions and terminology of crystallography in $N$ dimensions, achieving consensus as it progresses. Definitions of higher-dimensional point groups, crystal classes, holohedry and space groups, for example, have been considered, as have rules for ordering fourdimensional families and symbols for point groups and their transformations. The task is large and progress is expected to be slow but deliberate.

A Sub-committee on Atomic Displacement Parameter Nomenclature, consisting of K. N. Trueblood (Chair) and H.-B. Bürgi, H. Burzlaff, J. D. Dunitz, C. Gramaccioli, H. H. Schulz, U. Shmueli as members and S. C. Abrahams, ex officio, was appointed during the triennium. Its report entitled Atomic Displacement Parameter Nomenclature was completed in record time, was accepted by the Commission, and is now in press [Acta Cryst. (1996), A52, 770-781]. The report considers the confusing and inconsistent terms and symbols in current use for parameters denoting dynamic or static displacements of atoms in crystals. It focuses on individual atomic anisotropic displacement parameters representing atomic motion and possible static displacive disorder, provides clear definitions for these quantities, discusses graphical representations of the Gaussian mean-square displacement matrix and the expressions used if the Gaussian approximation is inadequate, and makes recommendations for symbols and nomenclature.

A Working Group on Phase Transition Nomenclature was also appointed during the triennium. Professor $P$. Tolédano was elected Chair, with A. M. Glazer, E. Parthé, R. L. Snyder and Th. Hahn as members and S. C. Abrahams ex officio. Professor P. Tolédano subsequently resigned and was succeeded by Professor J.-C. Tolédano. R. L. Snyder has also resigned very recently and a ballot on his successor is in progress. The working group is charged with studying the multiple nomenclature in 
current use for naming the sequence of phases that a material may form as a function of temperature or pressure and with making whatever recommendations may be appropriate. In view of the interdisciplinary interests in phase transitions, the members were elected both for their expertise in the field and their varied scientific backgrounds. In addition, at the Commission's invitation, Professor R. S. Berry was appointed by IUPAP and Professor R. Metselaar by IUPAC as liaisons to the working group.

8 May 1996

S. C. ABRahams, Chairman

\section{Commission on Crystallographic Teaching}

The activity of the Commission has covered a number of different subjects.

\section{Visiting Professorship Programme}

Dr D. K. Smith gave a 15 hour course on Geometrical Crystallography at Ain Shams University, Cairo, Egypt, 27 January-7 February 1993. This course was given immediately after the Fourth International Workshop of Crystallography: Computational Methods in X-ray Powder Diffraction Analysis, which was held in Aswan, Egypt, 16-26 January 1993. In his role as a Visiting Professor, Dr Smith also visited students and crystallographers at Assult University (Aswan Branch), the Egyptian Geological Survey in Cairo, Cairo University, Military Technical College, Suez Canal University, Heiwan University, and the Egyptian Antiquities Museum. In each case, he discussed techniques in powder diffraction.

A one-week course by Professor E. Parthé of the University of Geneva, Switzerland, an IUCr Visiting Professorship, was held at the Instituto de Física, Benemérita Universidad Autonòma de Puebla, Mexico, in the fall of 1994. Professor Parthé was also a Visiting Professor (of Inorganic Crystal Chemistry) at the Universidad de los Andes in Mérida, Venezuela, and such an activity has been deeply appreciated by both these universities.

In December 1993, Professor W. T. Robinson and Professor S. R. Hall were IUCr Visiting Professors in various Asian universities (Kuala Lumpur, Mysore, Tiruchiapalli, Bombay etc.). Professor N. Kasai, a member of this Commission, was granted a Visiting Professorship of three weeks in March-April 1994 in Hanoi, Vietnam, and in August 1994 he also visited Chiang Mai University in Thailand.

Two Visiting Professorships were granted to Professor Th. Hahn and Professor $H$. Wondratschek for a school on crystal chemistry held in Sofia, Bulgaria, 3-10 June 1994.

Dr P. Mallinson from the University of Glasgow, UK, was Visiting Professor in the Laboratory of Crystallography at La Plata University, Argentina, in May 1995, in connection with the IUCr School on Charge Density.

Professor Th. Hahn and Professor $\mathrm{H}$. Wondratschek were Visiting Professors in St Petersburg, Russia, 22-29 August 1995, in connection with a school on space-group symmetry. Among the major organizers of this school was Professor L. A. Aslanov from this Commission.

\section{International Schools}

An Asian-Region Seminar on Crystallography in Molecular Biology took place in Madras, India, 9-14 December 1993. Professor S. Parthasarathy was the Convener and some members of this Commission were on the Organizing Committee, with Dr J. P. Glusker as the Chairperson. All members of the Commission who were present (J. P. Glusker, C. M. Gramaccioli, P. Phavanantha, W. T. Robinson and H. Schenk) took an active part in teaching. This meeting was sponsored by the IUCr, which also provided funds for young scientists to attend. The meeting was well attended, with several speakers from various countries dealing with interesting topics (among whom were $\mathrm{Dr} \mathrm{T}$. Ashida from Nagoya, Japan, Dr B. C. Wang from Pittsburgh, USA, Dr M. Sundaralingam from Columbus, USA, and Dr D. Davies from Bethesda, USA). The contributions made by industrial companies and by the IUCr were much appreciated. During the time of this school, an informal meeting of the Commission members present took place: on that occasion, it was pointed out that the best teaching activity should include either Visiting Professorships and schools or seminars, since these activities do not exclude each other and perform different functions.

Sponsorship and active participation in organizing two schools taking place in Bangkok. Thailand, for the next Asian Crystallographic Association (AsCA) meeting were considered. In America, Dr I. D. Brown started the organizational work for a school on the structural chemistry of solid-state material to be held in Canada in the summer of 1995, and support for the school on charge density taking place in La Plata, Argentina, was given by granting a Visiting Professorship (see above). In April 1994, Dr K. El-Sayed organized a workshop on the Fourier series, Fourier transforms and their application in physics and crystallography; sponsorship of this Commission was requested and two Visiting Professorships were granted for the purpose.

A Fifth Intensive Course in X-ray Structural Analysis for young scientists took place at Aston, UK, 2-8 April 1995 and Dr D. Watkin was one of the organizers. Another school of crystallography (Rietveld: RSS95-RS) took place in Moscow, Russia, 20-22 July 1995. Among the organizers of this school was Professor L. A. Aslanov. A three-day course on Symmetry as a Basis for Structure Analysis was held during the first week of October at the University of Natal, South Africa, coordinated by Professor M. Laing.

In November 1995, two IUCr-supported schools of crystallography took place at Chulalongkorn University, Bangkok, Thailand, in connection with the AsCA meeting. In organizing these schools, this Commission and the Commission on Crystallographic Computing were considerably involved. The first, the Asian School on Crystallography of Precious Materials, took place 20-21 November, just before the AsCA meeting; the second, the Asian School on Crystallographic Computing, took place immediately after the meeting (27-30 November). Just before the opening of these schools (16-20 November), another school of crystallography (on Macromolecular Crystallographic Data) took place in Calcutta, India, and this Commission was active in supporting this project within the IUCr and in ensuring connection and coordination with the other schools taking place in Asia.

\section{Pamphlet Project}

The Pamphlet project has been reinstated and an arrangement has been made for Polycrystal Book Service to print and distribute the pamphlets. The pamphlet activity is being coordinated mainly by Dr J. P. Glusker. A set of notes for authors for pamphlets has been prepared and the IUCr technical editing staff will assist with technical editing when requested. The previous set of 19 pamphlets is still available from Polycrystal Book Service (PO Box 3439, Dayton, OH 45401, USA). Future pamphlets include:

20. Crystals: a Handbook for School Teachers. E. A. Wood. (Permission has been obtained from the copyright owner for a reissue of this book as a pamphlet.)

21. Radiation Measurement and Protection in X-ray Laboratories. H. von Philipsborn. (Under review.) 
22. Crystal Packing. A. Gavezzotti. (Under review.)

23. Gamma-ray Diffraction Study of Single Crystals. A. Kurbakov. (In preparation.)

24. Crystal Summetry. (New entirely rewritten edition, in preparation.) G. D. Nigam, H. Wondratschek.

Several letters of invitation have been sent out, and several crystallographers have promised to write new pamphlets.

\section{Other activities}

At the Beijing Congress, a microsymposium (OCM-19.1) was held on Crystallographic Teaching: Practical Hints and New Concepts. As usual, the room was filled for the entire symposium and the quality of presentations was high. An informal meeting of this Commission took place at the beginning of the Congress.

At the European Crystallographic Meeting (ECM-16, Lund, Sweden, 6-11 August 1995), a Workshop on Crystallographic Teaching was held. Besides the host, Dr $\AA$. Oskarsson, who provided excellent help and contributions, several members or consultants of the Commission were present (L. A. Aslanov, K. El Sayed, J. P. Glusker, C. M. Gramaccioli). Here the possibilities for the future were discussed, especially involving initiatives for developing countries. A seminar concerning crystallographic teaching for the Seattle Congress is being organized by this Commission (mainly by Professor Oskarsson and Professor Aslanov).

\section{May 1996}

C. M. Gramaccioli, Chairman

\section{Commission on Electron Diffraction}

At the Beijing Congress, the members of the Commission spent some time discussing the appropriateness of the continued inclusion of the gas electron diffraction community in its membership. Subsequent discussions have persuaded the Commission that this community's best interests would be served by transfer to the Commission on Small Molecules and steps have now been taken with a view to making this change.

The period under review has seen the rapid expansion of interest in a wide range of applications of quantitative electron diffraction. This has been stimulated by the arrival of various models of commercially available transmission electron microscopes with facilities for energy-filtering electron diffraction patterns. The elastic-only diffraction patterns are capable of being analysed to give accurate data about bonding charge distributions, atom locations and strains. In recognition of these developments, the Commission organized, with IUCr financial support, two workshops on Electron Crystallography - Theory and Practice. One of these was held in the East, at Beijing, in association with the Beijing Congress, the second in the West, at Bristol and Bath, UK, in association with the 13th International Congress on Electron Microscopy in Paris, France. Both workshops were judged as considerable successes, each with an attendance of about 50 people from 20 different countries.

This period has also been one of the flowering of surface electron diffraction techniques and theory. It was therefore decided to organize a round robin of those who had written computer programs for calculating surface electron diffraction data and to run a workshop on the subject. This workshop, held in Arizona, USA, in January 1996, was also sponsored by the $\mathrm{IUCr}$ and attracted 75 attendees with 16 invited lecturers from five different countries.

At the Beijing Congress the Commission was responsible for a microsymposium on Direct Phasing from Electron Diffraction Data. Building on the success of that meeting, the Commission has been responsible for the organization of five microsymposia at the Seattle Congress.

23 January 1996

J. W. STEEDS, Chairman

\section{Commission on Neutron Scattering}

A significant event for the former Commission on Neutron Diffraction was its change of name to the above at the Beijing General Assembly. This change of name had been thoroughly canvassed by members of the Commission throughout the neutron scattering community and represents more accurately the comprehensive constituency of the Commission. Neutron diffraction from both single crystals and powders still constitutes the core of the Commission's structural interest but recent General Assemblies, satellite meetings and microsymposia have reflected the growing interest in less well ordered materials (such as biological systems), mesocrystalline materials, crystalline disorder and dynamical phenomena. The emphasis in the recent letter of Professor P. Coppens [IUCr Newsletter (1994), Vol. 2, No. 1] is welcomed by the Commission.

The major event of 1993 was the Beijing meeting and its satellites. J. W. White was a member of the Congress Programme Committee and a number of members of the Commission contributed not only to the programme development of the Cangress and microsymposia, but helped to make the satellite meeting at Beidaihe the resounding success that all who participated there felt it to be. At it and in the open meeting the forward going plans for the Commission were discussed with plans being outlined for an Asia-Pacific meeting in 1995 to complement the ICNS meeting being organized for Kyoto, Japan, October 1994.

The major event of 1994 was the award of the Nobel Prize for Physics to Professors B. N. Brockhouse, FRS, and C. Shull for their pioneering work on neutron diffraction and neutron inelastic scattering. At the informal meeting of the Commission at Sendai (Japan) messages of congratulation were sent. The occasion was especially joyful as the news came during the course of the meeting. With the change of name of the Commission agreed at the Beijing General Assembly, the Commission now embraces both of the subject areas recognized in the awards.

The Commission, while still holding neutron diffraction from both single crystals and powders at the core of its work, has initiated and become involved with projects likely to be of longterm value to both structural and dynamical studies. A series of consultations by e-mail and by the Chairman in Europe and USA (June 1994) and in Japan, Europe and USA (November 1994) indicated that the Commission might be able to facilitate two projects: International standards for neutron inelastic scattering cross sections (NISC); Internationally agreed exchange format for neutron and synchrotron data. These projects are at a very early stage but cooperation has been agreed for the first, which will involve the exchange of a standard sample of $\mathrm{PrAl}_{3}$ between, initially, eight major neutron scattering centres.

The Commission has offered to facilitate the work of the second programme which was started by members of the European Network for Neutron Instrumentation (ENNI) and reported at the ISIS (Rutherford Appleton Laboratory, UK) International Science Advisory Committee in December 1994. A workshop on neutron scattering software (SoftNEss) was organized by Dr R. Osborne (Argonne National Laboratory) in October 1994 with the data exchange format as the main topic. A proposal for a world-wide neutron scattering data format was agreed and will be prepared by $\mathrm{P}$. Klosowski, J. Tischler and M. Konnecke for 1995. Dr Osborne has agreed to keep the Commission informed. 
The Commission held an informal meeting at the ICNS meeting in Sendai, Japan, in November 1994. Present at Sendai were: Y. Endoh, J. Kulda, B. Lebech, S. A. Mason, C. T. Ye, J. W. White. Absent: E. Prince, B. M. Powell, J. B. Forsyth, A. Albinati. In addition, Professor K. McEwan (UK) was invited as a key person for item 4 of the agenda, which covered (1) satellite meeting for Seattle Congress, (2) main programme for Seattle Congress, possible plenary lecturers, (3) regional international meeting and workshop (Asia-Pacific) 1997, (4) absolute inelastic cross section project, (5) any other business.

In 1995, the Commission continued its work over the broad field of neutron scattering. Preparations for the Seattle Congress and, in particular, for the two microsymposia and the satellite meeting to be held at the National Institute of Science and Technology (NIST), Washington, DC, USA, 5-7 August, have been major activities. The latter has been organized by the Chairman, Professor J. W. White, and Dr E. Prince (NIST), the Commission being kept abreast of developments of the programme.

The year also saw the proposed formation of a Commission on Small-Angle Scattering and the Commission on Neutron Scattering is supportive of this. We see that from time to time specialist groups may wish to organize this way (as the Commission on Powder Diffraction has shown) but we will continue to sustain a broad interest in the whole field of neutron scattering. The current programme for the neutron scattering satellite meeting in Washington illustrates this, since the emphasis has been placed upon the science while showing the way in which new methods can be brought to bear on particular problems. In the case of the Washington meeting, giant magnetoresistance phenomena as looked at by diffraction, small-angle scattering and inelastic scattering will be one of the themes.

The Commission continues its work on the two projects started in 1994.

Dr Osborne and his colleagues have now not only proved the value of the $\operatorname{PrAl}_{3}$ compound as a standard material, but also demonstrated the quality of the actual sample that was used in the original experiments. As reported in 1994, agreement of a number of major neutron scattering centres has been obtained to measure this at their instruments. We are looking forward to an interesting programme in the next few years on this substance.

Two meetings of the working groups for an internationally agreed format on neutron and synchrotron data work have taken place. This format is expected to benefit from the support that the Commission on Neutron Scattering and the $\mathrm{IUCr}$ (ultimately) can give to the project. Spallation neutron sources produce large data sets which should have an internationally agreed format structure. An attempt is being made to achieve uniformity with data format from synchrotron sources. In many cases, the data are only partially used (e.g. looking along particular symmetry directions in single-crystal experiments) and may be reanalysed for further physical information as new aspects of problems present themselves.

The Chairman (J. W. White) attended two meetings of considerable importance for the future development of neutron scattering. The first was the European Neutron Scattering Association (ENSA)/European Science Foundation (ESF) workshop Scientific Prospects for Neutron Scattering with Present and Future Neutron Sources. This was held at Autrans, France, 11-14 January 1996. A series of working parties examined the prospects for new science and technology using enhanced existing facilities and with the new neutron sources now proposed in Japan, Europe and America. The second meeting was held at the KEK, Tsukuba, Japan, 25-27 March 1996. All major neutron scattering centres in the world were represented and papers were presented on advanced neutron instrumentation and recent advances in the whole field of neutron scattering from fundamental physics to engineering testing.

The publication of Neutron News continues to be an important contribution to the development of neutron scattering science worldwide. I would like to thank the Editor, Dr G. Lander, for his cooperation with the Commission. I should also like to thank all members of the Commission itself for their help during the last three years and wish those members who are retiring well for the future

15 May 1996

J. W. WhiTe, Chairman

\section{Commission on Powder Diffraction}

During its third triennium, the Commission on Powder Diffraction has continued to be very active on a wide variety of fronts. Its major achievements have included the organization of three international round robin projects (one now complete), continuation of a series of workshops/schools on the Rietveld method, a journal publication, organization of several international meetings, continued support for a directory of powder diffraction programs, and expansion of its biannual Newsletter to include a mailing list of 850 powder diffractionists, translation of the Newsletter into the Chinese language, and its incorporation onto the World-Wide Web.

\section{Meetings/Workshops/Schools}

The CPD organized a satellite meeting entitled Advances in Powder Diffraction, SMP-93, in Hangzhou, China, $31 \mathrm{Au}-$ gust-3 September 1993, immediately after the Beijing Congress. The main aim was to present recent developments in powder diffraction theory and practice and to emphasize the power of modern diffraction methods in materials science. A total of 140 delegates from 18 countries attended. The undoubted success of the meeting was due to the excellent efforts of Professor Ling Rong-Guo, Chairman of the Organizing Committee, and to CPD member J. I. Langford, Chairman of the Scientific Programme Committee, with much appreciated assistance from Professor Shen Shan-Hong, President of Hangzhou University, and Professor Lin Shao-Fan.

An International Workshop on Advanced Powder Diffraction Techniques in Mineral and Materials Processing was held in Pretoria, South Africa, in October 1994, and was co-organized by the Crystallographic Society and Mineralogical Association of South Africa. CPD member L. B. McCusker was an invited speaker and served as Chairman of the Scientific Programme Committee, member J. I. Langford was also an invited speaker, while CPD Chairman R. J. Hill contributed to the Programme Committee. The meeting was an outstanding success, with participants from many countries in southern Africa gaining valuable experience from a series of carefully crafted lectures, tutorials and hands-on workshop sessions on all aspects of powder diffraction analysis, including sessions presented by the ICDD.

An International Conference on Powder Diffraction and Crystal Chemistry was held in St Petersburg, Russia, in July 1994 co-organized by the Russian Association for Powder Crystallography, the Department of Crystallography of St Petersburg University, and the CPD. Lectures and posters were presented to 165 participants from 20 countries, including a workshop run by the ICDD, and a 211-page book of abstracts was produced. St Petersburg's strong past and current links with crystallography, dating from Federov's discovery of the 230 space groups in 1890 , 
along with its geographic beauty, provided a very appropriate and delightful backdrop for a most successful conference.

After undertaking largely independent activities over the past six years, the CPD and the European powder diffraction community (in the form of the EPDIC series of meetings) started what is hoped to be an increasing level of cooperation. This interaction began with the invitation to the CPD Chairman, $\mathrm{R}$. J. Hill, along with other members of the CPD, J. Fiala and D. Louër, to serve on the Programme Committee of the EPDIC IV meeting in Chester, UK, in July 1995. The collaboration will continue with similar CPD involvement in the organization of EPDIC V in Italy in 1997 and with assurances by the CPD and the ECC to coordinate their meetings in Europe so as to prevent overlap.

The CPD lent its support to the very successful International Meeting on Structure Solution from Powder Diffraction Data, held in Oxford, UK, in July 1995 and organized by W. I. F. David and colleagues from the Rutherford Laboratory, UK. CPD members D. E. Cox, L. B. McCusker, D. Louër and R. J. Hill presented invited lectures and workshops, and the $\mathrm{IUCr}$ provided a generous grant to the Organizing Committee. The conference was a very timely meeting with a productive mixture of lectures and workshops that captured much of the excitement of this rapidly evolving area of powder diffraction. A book is expected to evolve which will be a member of the IUCr Monograph Series.

The CPD was also involved in the International Conference on $\mathrm{X}$-ray Powder Diffraction Analysis of Size/Strain, Macrostress and Texture held in Liptovsky Mikulas, Slovakia, in August 1995 under the local guidance of Dr P. Sutta. CPD members J. Fiala, J. I. Langford and D. Louër and Chairman R. J. Hill served on the Programme Committee, with J. Fiala as Chairman, and the $\mathrm{IUCr}$ again provided generous support in the form of a grant. The extended proceedings of this conference will be published shortly, with advice provided by the CPD.

CPD consultant and immediate past Chairman, R. A. Young, continued the series of CPD-organized three-day Rietveld Summer Schools with co-lecturers R. B. Von Dreele and A. K. Cheetham. The latest in this series was held in July 1995 at the Moscow State University, Russia, with Professor L. A. Aslanov as head of the local organizing group. The meeting was very well attended by 86 students and local scientists and, as usual, led to a significant enhancement of the participant's awareness of the capabilities of Rietveld analysis, particularly by young scientists. The CPD is once again grateful to the IUCr for providing financial support to assist with the travel expenses of the main lecturers and for registration and living-costs grants for students.

The CPD maintained a high profile in preparations for the Seattle Congress through the involvement of its Chairman, R. J. Hill, and member D. E. Cox on the Programme Committee and with associated responsibility for the coordination of lecturers and other contributions to most of the powder diffraction related microsymposia. The CPD's nominee, D. Louër, was invited by the IUCr to present a Plenary Lecture entitled Modern Powder Diffraction in Materials Science at the Congress, and the CPD-initiated microsymposium entitled Materials VIII - Powder Diffraction was also accepted, with R. J. Hill and J. B. Cohen (USA) as Co-Chairs.

In a novel initiative, the CPD combined forces with the 45th Annual Denver X-ray Conference (DXC) to organize jointly the Powder Diffraction Satellite Meeting in Denver, USA, 3-8 August 1996, associated with the Seattle Congress. Two members of the CPD, D. E. Cox and D. K. Smith, served on the Organizing Committee, and several CPD members and consultants were involved as invited speakers or workshop and special session organizers, including D. Louër (France), D. E. Cox (USA), R. J. Cernik (UK), H. Toraya (Japan), R. A. Young (USA) and R. J. Hill (Australia). In response to a joint request from the DXC and the $\mathrm{CPD}$, the IUCr provided support for this ground-breaking meeting.

\section{Projects}

The CPD, through the Task Group Chairmanship of J. I. Langford, contributed to the development and acceptance of a powder diffraction dictionary for use in the CIF/STAR format for archival and transferral of crystallographic data. This CPD project was undertaken in collaboration with the ICDD through the leadership of now CPD consultant J. I. Langford and, representing the ICDD, B. Toby. The CPD was also involved in extended negotiations with the ICDD prior to acceptance of the CIF format for ICDD databases.

The CPD remained active in the execution of its existing projects and in the initiation of new ones. The results of Part II of the Rietveld Refinement Round Robin Project were published by Hill \& Cranswick in J. Appl. Cryst. (1994), 27, 802-844. This concluding part of the project provided outcomes of the analysis of Rietveld refinements of the monoclinic zirconia crystal structure undertaken by 28 respondents using $27 \mathrm{X}$-ray and 14 neutron powder diffraction data sets collected on a 'standard' sample with a wide spectrum of instruments located in 12 countries around the world. The results were used to provide an assessment of the performance (resolution) of various diffraction configurations and the relative merits of the data collection and structure refinement protocols used by respondents. These findings were used to define limiting factors for parameter accuracy and precision and to produce a series of 'best practice' recommendations for the collection and analysis of powder data using the Rietveld method.

Continued organizational and financial support was provided by the CPD for the maintenance and updating of the World Directory of Powder Diffraction Programs, co-organized by S. Gorter (The Netherlands) and CPD member D. K. Smith. This compilation has now appeared in two updated versions and includes summary descriptions and contact information for several hundred programs. It has become a major resource that is available to the worldwide powder diffraction community. Two grants from the CPD have been used to enable the database to be even further expanded in scope and size, and to provide hardware for it to be distributed by anonymous FTP.

In conjunction with the Slovakia meeting, CPD member $J$. Fiala and R. L. Snyder (ICDD) co-chair a task group working on a Round Robin on Crystallite Size and Microstrain Determination. The preliminary results of studies on a widely circulated 'standard' sample of a ceramic material containing inclusions of crystallites of known size were reported during the Slovakia meeting.

Two new projects were initiated in 1995. One involves the production of summary guidelines and protocols for the collection and analysis of powder data for Rietveld analysis and, related to this, the identification of a new Rietveld method 'standard' material with higher complexity than the monoclinic zirconia sample used as a benchmark for the recently completed CPD Rietveld Refinement Round Robin Project. This work is being coordinated by CPD members L. B. McCusker and D. E. Cox. The second new project is being coordinated by D. K. Smith and R. J. Hill, and involves a new round robin survey of the accuracy, precision, capabilities and limitations of quantitative phase analysis by diffraction methods. The selection of appropriate 
multiphase samples and discussion of the protocols for the survey are well advanced, with the recommendations planned for open discussion during a workshop at the Denver Powder Diffraction Satellite Meeting in August 1996. The centre for distribution of survey materials and data analysis will be maintained by $R$. J. Hill and I. C. Madsen at Port Melbourne, Australia.

\section{Newsletter}

The CPD continued to produce two Newsletters per year during the triennium, with editorship rotated among the various members of the CPD. More than 850 copies are distributed to the current CPD mailing list, with a further 600 made available for pickup at various conferences and as part of other mailings. Feature articles have included the explanation, establishment and use of crystallographic newsgroups on the worldwide Internet (by L. Cranswick of CSIRO in Melbourne, Australia), use of synchrotron diffraction information from single powder grains for structure solution prior to Rietveld refinement using bulk powjer diffraction data (by R. J. Cernik of Daresbury Laboratory, UK), description and use of CIF for powder diffraction (by B. Toby, Terrytown, USA), introduction to the SPring-8 project (by $\mathrm{H}$. Toraya, Nagoya, Japan), the new high-resolution neutron powder diffractometer at the high-flux isotope reactor, Oak Ridge, USA (by B. Chakoumakos, Oak Ridge National Laboratory, USA), award of the Aminoff Prize to Hugo Rietveld (by R. Tellgren, Uppsala, Sweden), the contributions of Gunnar Hägg to powder diffraction (by S. Rundquist, Uppsala, Sweden), neutron powder diffraction at Kjeller (by Hauback, Fjellvåg and Steinsvell, Norway), a tribute to Arthur C. Wilson (by J. I. Langford, Birmingham, UK), and current powder diffraction activities at the Photon Factory (by H. Toraya, Nagoya, Japan).

CPD Member Professor Lin Shao-Fan of Nankai University, China, arranged for Newsletter No. 10 to be translated into Chinese and for it to be distributed, along with a translation of the journal Powder Diffraction, to 300 powder diffractionists in China. This process will be continued for the foreseeable future and will significantly expand the number of people exposed to the CPD by more than 500 persons.

An innovative feature of the CPD Newsletter's availability now and in the future is its recent installation on the WorldWide Web with access via a pointer from the $\mathrm{IUCr}$ Home Page. CPD member R. J. Cernik (Daresbury Laboratory, UK) has installed a copy of Newsletter No. 15 along with contact details and a brief introduction to the CPD and has agreed to continue this service for subsequent issues. It is expected that this innovation will ultimately provide even more widespread access and contributions to the activities of the CPD during the next triennium. The CPD is grateful to the Daresbury Laboratory for its agreement to support the distribution of the Newsletter in both hard and soft form in this manner.

\section{$I C D D$}

The CPD continued its strong interaction with the International Centre for Diffraction Data through the representation of several of its members on ICDD Subcommittees and the election of others to ICDD membership. In particular, CPD Secretary, D. Louër (France), is Chairman of the ICDD Data Collection and Analysis Sub-committee and Consultant to the Board of Directors, while CPD members J. Fiala (Czech Republic) and $\mathrm{H}$. Toraya (Japan) were elected members of the ICDD during 1993. The CPD Chairman, R. J. Hill (Australia), is ex officio IUCr representative to the ICDD, and Dr L. K. Frevel (USA), Distinguished Fellow of the ICDD, is their representative to the CPD.

I February 1996

R. J. HILL, Chairman

\section{Commission on Small Molecules}

Details of Commission activities are given in the annual reports. Here the background and an overview are given in more general terms. It is no secret that the centre of gravity of crystallographic structure determination has shifted from small molecules to macromolecules of biological interest. And yet small-molecule crystallography still has an essential role to play in the continued development of our subject. Crystals with cell dimensions in the $\AA$ range are much easier to handle than those in the hundreds of $\AA$ range; the structures can be analysed in much greater depth, in much more detail and with much greater precision. There is greater hope of relating physical properties and structure and the information gathered may even, one day, enable us to predict crystal structures. Each of us will be able to add more specific contentions to this list. Thus, the Commission has endeavoured to encourage activities at the cutting edge of current capabilities, to broaden contacts with other methodologies, and to bring these developments through refereed publications to the notice of a much wider audience than can hope to attend particular meetings. This has been done on a broad (but not broad enough) geographical basis, with meetings in China, North America, eastern and western Europe and South Africa. Extension to other Asian countries and South America still remains to be accomplished. The envisaged change in name to Commission on Structural Chemistry will hopefully not be only semantic; organic crystal chemistry has been encouraged and inorganic neglected and this imbalance needs to be corrected.

25 April 1996

F. H. HerbStein, Chairman

J. FLIPPEN-ANDERSON, Secretary

\section{Commission on Synchrotron Radiation}

Synchrotron radiation in the field of crystallography has during the triennium been in a very expansive phase. New third generation sources with strong crystallographic programmes have been commissioned in Grenoble, Argonne, Trieste, Berkeley and Lund and the Japanese SPring- 8 project is in an advanced construction phase. The triennium has also seen the emergence of the Joumal of Synchrotron Radiation published under the auspices of the IUCr to provide a forum for progress in the field. General information on synchrotron resources and application procedures are now readily available over the Internet for many of the facilities. The Commission's work during this period has been concentrated on spreading the information on the new experimental opportunities available by actively organizing microsymposia and giving general review talks. Some of the major efforts are listed below.

The Commission was responsible for the organization of a microsymposium on Synchrotron and Neutron Diffraction Results and Perspectives in the Geosciences at the 16th General Meeting of the International Mineralogical Association in Pisa, Italy, September 1994. The symposium was organized by W. A. Bassett and $\AA$. Kvick and featured review talks mainly in the area of high-pressure applications and available experimental synchrotron facilities.

Synchrotron radiation featured prominently at the 16th European Crystallographic Meeting in Lund, Sweden, 5-11 August 1995. Three different half-day symposia: Synchrotron Radiation Applications I and II and Synchrotron Radiation Instrumentation, were organized by the Chairman and applications both in smallmolecule and macromolecular crystallography were covered. The instrumentation part included talks on microcrystal diffraction, detectors and novel optics development. 
The Commission is involved in the Programme Committee of the Third International School and Symposium on Synchrotron Radiation in Natural Sciences, 31 May-8 June 1996, Jaszowiec, Poland. This school covers a very wide area of synchrotronradiation techniques and applications in the natural sciences.

The Commission is heavily involved in the Seattle Congress and has been active in the Programme Committee. Three microsymposia: Synchrotron Radiation I, II and III have been scheduled. In addition to the main Congress, a Synchrotron Radiation Satellite Meeting at the Advanced Photon Source in Argonne is being organized under the auspices of the Commission (4-7 August 1996). The main feature of the satellite meeting is to give a broad overview of the state-of-the art developments in the synchrotron-radiation field and in particular to give a review of the impact of the new third generation sources.

The next triennium also promises to be very dynamic with rapid advances in areas such as detectors and time-resolved studies predicted.

14 May 1996

A. H. KVICK, Chairman

\section{Appendix E: Committee on Electronic Publishing, Dissemination and Storage of Information}

Members: F. H. Allen, A. Authier, I. D. Brown, C. E. Bugg, P. W. Codding, E. Dodson, Y. Epelboin, H. D. Flack, A. M. Glazer, J. P. Glusker, S. R. Hall, S. S. Hasnain, J. R. Helliwell, H. Kamitsubo, E. N. Maslen (Chairman), B. McMahon, P. R. Strickland, M. Teeter.

The Committee has advised the IUCr Executive Committee on electronic submission of information, on data delivery and on other networked services. It generally agreed on principles, but conducted a lively Internet debate on how the objectives could best be achieved. The Committee met in Chester (1994) and in Montreal (1995). The Executive Committee approved the appointment of a consultant to advise on electronic publishing, and the report is being studied closely. A summary of the Committee's deliberations follows.

\section{Electronic submission of information}

Submission is linked so closely to utilization and storage that it proved desirable to consider all aspects together. The extension of CIF from small molecules to powders to proteins made it appropriate to allocate each task to specialist groups that work and report separately. The crystallographic community has been well served by their response to these demanding tasks.

During the triennium, Acta Crystallographica Section C standardized on electronic submission for manuscript submission. To reduce publication times and achieve economies, manuscripts should be submitted in word processor format to other IUCr journals and transmitted to and from referees electronically. It is impractical to implement total electronic submission to all journals simultaneously. Changes are to be made on a timescale that optimizes the benefits.

Electronic submission is favoured by the emergence of SGML as a de facto publishing industry standard. This does not define publishing procedures fully, because SGML permits adaptation by users. While the broad thrust of future developments is clear, aspects such as the range of manuscripts for which CIF to SGML translation will be preferred have yet to be determined.

\section{Delivery}

The IUCr's pilot electronic delivery of the World Directory of Crystallographers provided a network-accessible service, along with valuable experience. Originally, the Directory was to be based on STAR tools, no alternatives being available at that time. Considerable effort was expended in developing those tools before the World-Wide Web (WWW) protocol emerged. Since WWW links were installed, the electronic Directory has been used mainly in that mode. Most users prefer standard protocols even when technical performance favours alternatives.

Further developments in electronic delivery are planned. Scientific importance would assign top priority to Acta Crystallographica Section $D$, but there are technical and financial counterarguments. Protein crystallography depends on high-quality diagrams, for which the low information density of raster graphics is inefficient. For many applications, raster graphics' generality is offset by difficulty in synthesizing information - at which current computing technology competes unfavourably with more versatile human observers. High loads imposed by inefficient graphics protocols are tolerable on lightly used networks served by powerful hardware, but performance deteriorates rapidly as network loadings increase.

Most information seeking on networks is interactive. An acceptable interactive service within a single land mass spanned by a strong network is readily provided, but one cannot guarantee satisfactory response that depends on inter-continental communication. Ideally, the IUCr should provide a comparable service to all of its members, but the service at many locations is limited by communications. Lack of information security on networks is a further but less acute problem. One must ensure that $\mathrm{IUCr}$ publications accessible on-line are not copied and re-sold.

Services that the IUCr could provide electronically include some ancillaries to journals. Currently (i) titles, (ii) titles and abstracts, and (iii) full articles on request (in appropriate formats) could be provided with at worst modest delays that would be tolerable for a free or low-cost service. There is no danger in making option (i) available as publicly accessible information. Options (ii) and (iii) could complement normal journal subscriptions. Option (iii) could be provided on a charge per page basis. It is appropriate to provide these for Acta Crystallographica Section $C$ initially, extending this to other journals if the Acta Crystallographica Section C trial proves successful. The WWW could provide cost-effective communication between IUCr members and its publishing activities. Publishing the IUCr Newsletter on the WWW could expedite delivery and cut production costs. That would be relatively straightforward as neither full cost recovery nor high-quality graphical information is needed. Timing of full implementation requires care, because of the need to avoid adverse impact on scholarly publications by the Chester office.

\section{Other networked services}

B. McMahon's World-Wide-Web-based information server, an information interface on the e-mail network for the crystallographic community, is suitable both for structured documents and for informal publications. It has a Gopher option, allows transmission of CIFs and provides access to the World Directory of Crystallographers. It has the potential to provide information on journal papers.

It costs approximately GBP 50 per compound to check structural information prior to publication in Union journals. The amount of incorrect structural information presented by those without crystallographic training is significant. Problems are compounded by the number of crystallographic studies now submitted by research workers with limited training.

The high cost of checking makes it difficult for crystallographic databases to provide an affordable service. The CIF 
submissions to Acta Crystallographica Section $C$ indicate that automatically generating crystallographic information via CIFs using the major crystallographic computing packages will reduce errors dramatically. Such CIFs are also well suited to standardized checking.

The IUCr is the largest single publisher of structural data, but the total published by others is far greater. Other journals' norms are well below IUCr standards, and it is difficult for those journals to achieve higher reliability in their crystallographic publications. Automatic checking of CIFs accessible through the WWW information server is an important service that does not impact strongly on the IUCr's finances. It has potential to reduce the cost of the crystallographic databases, benefitting all crystallographers. From a narrow perspective, it might seem opportune to make this self-supporting, but that is complicated by the limited success rate for automatic checking. A small but significant fraction of the errors in structural data that are not identified readily by automatic procedures inhibits such charging. It is appropriately provided free, because so many crystallographers benefit. Eventually, all structure solving packages should check structures automatically, so that fewer errors survive.

Electronic publishing of reference data, affecting mainly the International Tables for Crystallography, requires careful consideration. The Tables are widely used but the need for detailed and up-to-date information is not large enough to make crystallographic reference data attractive for electronic publishing. However, viewing electronic delivery in isolation from the printed publications over-simplifies the situation. An up-to-date archive that is accessible electronically could simplify the preparation of new editions of International Tables. A steady increase in the use of electronically accessible tables could be expected.

CD ROM back-up of Union journals was addressed by the consultant. A possible scenario is for abstracts to be delivered electronically to subscribers, who can optionally extract the desired full papers and/or deposited material from a central archive. Back-up copies of journal articles would be supplied on a CD ROM annually. This assumes that the subscriber is equipped with the software needed to perform text typesetting, and has access to a $C D$ reader.

26 February 1996

E. N. MASLEN, Chairman

\section{Report by Managing Editor}

$S G M L$ implementation in IUCr journals

The Editorial Office is currently undertaking a project to implement standard generalized mark-up language (SGML) for the production of $\mathrm{IUCr}$ journals.

An SGML document-type definition (DTD) for journal articles is being developed in conjunction with an outside consultant. The DTD will conform to publishing industry standards and to ISO 12083, the standard for the publication of scientific papers.

Templates allowing authors to submit papers using standard word-processing packages (e.g. $\mathrm{LT}_{\mathrm{E}} \mathrm{X}$ ) are to be written, as are programs to translate from these formats to SGML. A number of SGML editing and translation tools are currently being assessed for the in-house editing of papers.

The implementation of SGML will be linked to the introduction of a new production database and database management system. It is envisaged that this will improve office efficiency, facilitate communications with editors, authors and referees, and lead to shorter publication times.

The SGML files will not only allow increased automation in the preparation of the conventional printed issues of the journals, but will also allow the production of electronic versions of the journals.

The existing CIF environment for structural papers is being maintained, and we are investigating the best way to integrate both production strands.
21 May 1996
P. R. STRICKLAND, Managing Editor

\section{Appendix F: Reports of Representatives on Regional and Scientific Associates}

\section{American Crystallographic Association ( $A C A$ )}

During the triennium, the ACA increased its membership and held three annual meetings which continued to attract large numbers of attendees. During the 1993 meeting, held in Albuquerque, New Mexico, the Patterson Award was presented to Professor G. Sheldrick of Göttingen, Germany. The meeting was preceded by a workshop on Biomolecular Interactions: a Practical Workshop on Computational Approaches. The 1994 meeting was held in Atlanta, Georgia. The Bertram E. Warren Award was presented to Dr M. J. Bedzyk and the Martin J. Buerger Award to Professor P. Coppens. A three-day Symposium on New Trends in Small-Moiety Crystallography provided an interesting and well attended opening session for the meeting. The 1995 meeting was held in Montreal, Quebec, Canada. The Abstracts were posted on the World-Wide Web and this proved to be a useful way to highlight the science presented at the meeting. The Fankuchen Award was presented to Dr K. N. Trueblood and Dr J. P. Glusker.

During the triennium, the ACA continued to offer a Summer School for Crystallography in Pittsburgh, which provides practical education in crystal structure determination. The ACA was also particularly successful in raising funds to support crystallographers in the countries of the Former Soviet Union. The ACA remains an active member of the American Institute of Physics (AIP) and provides representatives to several AIP committees. The ACA accepted an application from Mexico to join the regional association.

$$
8 \text { April } 1996
$$

P. W. CoDDING, Representative

\section{Asian Crystallographic Association (AsCA)}

The 1993 council meeting was held during the Beijing Congress and for 1993-1996 Professor W. T. Robinson was elected as President, Professor Yu Wang as Vice-President and Professor Z. Zhang as Secretary and Treasurer.

The second conference of the Asian Crystallographic Association (AsCA '95) was initially planned to be held in Kuala Lumpur, Malaysia. However, in 1994 circumstances forced the Organizing Committee to change the location to Bangkok, Thailand. AsCA ' 95 was held on the campus of Chulalongkorn University, 22-24 November 1995. About 240 people attended the highly successful meeting, including about 100 from Japan. Each day's sessions began with two plenary lectures (with speakers from Japan, Australia, China, India and Taiwan and a special lecture by the IUCr President, P. Coppens) followed by six microsymposia and accompanying poster sessions.

AsCA '95 has contributed much to AsCA itself which now seems to be firmly established. In association with AsCA '95, two schools were held: the Asian School on Crystallography of Precious Materials just before the meeting (20-21 November) 
and the Asian School on Crystallographic Computing just after (27-30 November).

29 May 1996

J. HARADA, Representative

\section{European Crystallographic Committee (ECC)}

No formal meeting was held in 1993.

The main event in 1994 was the 15th European Crystallographic Meeting (ECM-15) in Dresden, Germany. As usual, ECM-15 was supplemented by interesting satellite and related meetings: the Second European Symposium on X-ray Topography and High-Resolution Diffraction in Berlin, Germany, the 16th General Meeting of the International Mineralogical Association in Pisa, Italy, the Aperiodic '94 International Conference on Aperiodic Crystals in Lausanne, Switzerland, the XVI Conference on Applied Crystallography in Cieszyn, Poland, a meeting on Practical Aspects of Crystal Structure Analysis in Dresden, Germany, a Workshop on High-Pressure Crystallography in Dresden, Germany, and the especially productive traditional pre-ECM symposium on Organic Crystal Chemistry OCC94 in Poznan, Poland.

Five new member countries were elected: Russia, the Czech and Slovak Republics (joint membership), Serbia, Estonia and Moldova. The traditional discussion on the formation of a European Crystallographic Association and collaboration with other parties concerned with crystallography in Europe took place.

The above report has been prepared from the annual reports for 1993 and 1994. Sadly, the IUCr representative, Yuri Struchkov, died in 1995.

24 May 1996

M. H. DACOMBE, Executive Secretary

\section{International Centre for Diffraction Data (ICDD)}

\section{Background}

The International Centre for Diffraction Data (ICDD) is a non-profit scientific organization that collects, edits, publishes, and distributes powder diffraction data for the identification of crystalline materials. The current ICDD Board Chairman is Professor R. L. Snyder who succeeded Dr G. C. Johnson in early 1996.

\section{Mission Statement}

The International Centre for Diffraction Data will continue as the world centre for quality diffraction data to meet the needs of the technical community. The ICDD promotes the applications of materials characterization methods in science and technology by providing a forum for the exchange of ideas and information.

\section{The ICDD organization}

The ICDD membership is comprised of scientists from various affiliations - educational, governmental, industrial. Approximately 100 scientists elected from around the world constitute the active membership from which the organization draws its Board of Directors, Subcommittees and Task Groups. The members, who are volunteers, are all actively engaged in developments in the field of X-ray powder diffraction and related disciplines. A paid scientific and administrative staff of about 30 fulltime employees is responsible for the production of the various databases offered by the ICDD.

\section{Technical Committee}

The Technical Committee (TC) is chaired by Professor T. C. Huang and consists of the Chairs of 15 active Subcommit- tees: Ceramics, Crystal Data, Data Collection and Analysis, Diffraction Problems, Education, Electron Diffraction, Metals and Alloys, Minerals, New Product Research \& Development, Organic and Forensic, Pattern Calculations, PDF Database, PDF Editorial Staff, Search/Match Methods and Target Systems for Technical Committee Activity. These Subcommittees meet twice a year to receive and discuss reports from their Task Groups, and to pass on recommendations through the $\mathrm{TC}$ to the ICDD board of directors and Committees for action.

\section{ICDD assisted research}

The ICDD sponsors a worldwide Grants-in-Aid Program to provide high quality data and to develop search techniques for the identification of materials by powder diffraction methods. These grants continued at an annual rate of USD 300000 . Three Crystallographic Scholarships (USD 2000 each) were awarded in 1994 and 1995, and four in 1996, to students in USA, Canada, UK and Australia. Grants were also made to the Denver $\mathrm{X}$-ray Conference, the European Powder Diffraction Conferences EPDIC III and EPDIC IV, and additional Grants-in-Aid to scientists in the FSU, including one-year free subscriptions to Powder Diffraction and discounts on Powder Diffraction File products.

\section{ICDD educational commitments}

The ICDD sponsors a worldwide programme of workshops, seminars and schools, often in association with major powder diffraction meetings. The ICDD Clinic on X-ray Powder Diffraction is comprised of two one-week courses in the fundamentals of qualitative and quantitative X-ray diffraction. The ICDD also sponsors a Clinic on X-ray Fluorescence Spectrometry in the fundamentals of qualitative and quantitative $X$-ray fluorescence. Both the XRF Clinic and the XRD Clinic are conducted annually during the summer months.

Involvement with the IUCr Commission on Powder Diffraction CPD Secretary, Dr D. Louër (France), is Chairman of the ICDD Data Collection and Analysis Subcommittee and Consultant to the Board of Directors. CPD members Dr J. Fiala (Yugoslavia) and Dr H. Toraya (Japan) were elected members of the ICDD during 1993 and CPD member Professor D. K. Smith, recently retired from Penn State University, was elected as a Distinguished Fellow in 1995. The CPD Chairman, Dr R. J. Hill (Australia), is ex officio IUCr representative to the ICDD, and Dr L. K. Frevel (USA), Distinguished Fellow of the ICDD, is their representative to the CPD. The current ICDD ViceChairman (elected in 1996) is Professor R. A. Young, former CPD Chairman and current CPD consultant.

Dr J. Fiala jointly chairs, with Professor R. Snyder of the ICDD, a Task Group on Crystallite Size and Microstrain, which was the main focus of the CPD-sponsored meeting in Slovakia in August 1995, and which may evolve into a round robin study. The ICDD contributed USD 5000 to the IUCr Satellite Meeting on Powder Diffraction in Hangzhou in August 1993, and USD 3000 to assist the attendance of young Chinese scientists. Further support is anticipated for the 1996 satellite meeting on powder diffraction in Denver.

\section{ICDD Activities during the triennium}

One of the highlights of the triennium was the dedication of the new ICDD Headquarters in Newtown Square, Pennsylvania, in October 1993. The building represents a USD $4.2 \mathrm{M}$ investment for the ICDD and offers excellent facilities for conferences, with modern and well equipped lecture rooms. On this occasion, special recognition was given to the Distinguished Fellows of the ICDD, J. W. Caum, W. L. Fink, L. K. Frevel, J. D. Hanawalt, 
H. F. McMurdie, M. E. Mrose, B. Post, S. Weissmann and A. J. C. Wilson. Awards were also made to Ben Post and Sig Weissmann for 40 years of editing of the Powder Diffraction File'.

Also during 1993, Dr R. Jenkins of the ICDD was presented with the Barrett Award for his outstanding work on diffraction techniques and instrumentation and for his untiring global activities in educating a generation of powder diffractionists. Member $\mathrm{H}$. Hitchcock was given an award by the Director of the Kennedy Space Centre (NASA) as a Manned Flight Awareness Honoree for her contribution to the manned space programme. Dr L. D. Calvert and Professor Y. Takeuchi were elected to join the other members who have been recognized as Distinguished Fellows by the Board of Directors for their sustained outstanding contributions to the ICDD. Dr Calvert is the first such member to be honoured posthumously.

A report by $\mathrm{T}$. Blanton (Eastman Kodak) on silver behenate as a possible candidate for a low-angle standard sample [ $d$ spacing $(001)=58.38 \AA]$ was published in J. Appl. Cryst. (1993), 26, 180-184. Search manuals and software for the analysis of organic functional group functionality were made available on CD ROM for operation under Windows.

On 20 December 1995, the then Chairman G. C. Johnson Jr announced to staff and ICDD members that D. Richardson had submitted his resignation as the General Manager of ICDD as of 1 January 1996 and that the Executive Committee had begun the process of locating a new General Manager.

Recent Specific Highlights of Technical Activities

ICDD Products. PDF Set 45, Alphabetical Index \& Search Manual: 2000 new pattems; Electron Diffraction Database released in 1995: total entries $82 \mathrm{~K}$ (new 10K); Crystal Data Identification File 1994 Release (Update G): total entries 200K (new $15 \mathrm{~K}$ ).

Round Robin Studies. Crystallite Size/Strain (co-sponsored by ICDD and CPD); Evaluation of Practices in Ab Initio Pattern Indexing (Chair: CPD Secretary, D. Louër); Profile Fitting; Preferred Orientation; X-ray Reflectivity.

Conference Workshops. Denver X-ray Conference (Colorado Springs, USA), EPDIC IV (Chester, UK), BCA Annual Spring Meeting (Cardiff, UK).

The ICDD clearly continues to be a very dynamic and growing organization, with a strong cooperative relationship with the CPD.

14 May 1996

R. J. HILL, Representative

\section{International Organization of Crystal Growth (IOCG)}

During the triennium 1993-1996, the activities of the IOCG were governed by the preparation and performance of the Ninth International Summer School on Crystal Growth (ISSG-IX), Papendaal/Arnhem, The Netherlands, 11-16 June 1995, and the Eleventh International Conference on Crystal Growth (ICCGXI), The Hague, The Netherlands, 18-23 June 1995. Both events were organized by the Dutch Association for Crystal Growth (KKN) with Chairpersons J. O. van der Eerden (for ISSCGIX) and C. F. Woensdregt (for ICCG-XI), both University of Utrecht, The Netherlands.

During ICCG-XI, meetings of the IOCG Executive Committee, of the IOCG Council and of the General Assembly were held under the Chair of its resigning President B. Cockayne. The following resolutions, among others, have been approved: The Brazilian Society for Crystal Growth, the Czech and Slovak Association for Crystal Growth and the Romanian Materials
Science \& Crystal Growth Society are formally accepted into the IOCG. The offer of the Japanese Association for Crystal Growth to hold ISSCG-XI and ICCG-XIII in Japan is accepted. The possibility of the IOCG becoming an International Scientific Associate affiliated to ICSU, with a possible change of name to International Union for Crystal Growth will be explored by the new President and the Executive Committee. An honorary post entitled Honorary Principal Founder of IOCG is created on the Executive Committee for the period 1995-1998 for the retiring Secretary and Principal Founder of the IOCG, M. Schieber, Jerusalem, Israel, in recognition of his distinguished service to this organization. The following Officers and Executive Committee members are elected for the period 1995-1998: President: T. Nishinaga (Japan); Vice-Presidents: K. W. Benz (Germany), R. F. Sekerka (USA); Secretary: G. B. Stringfellow (USA); Treasurer: C. F. Woensdregt (The Netherlands); Past President: B. Cockayne (UK); Honorary Principal Founder of the IOCG: M. Schieber (Israel). Executive Committee: P. Bennema (The Netherlands). A. A. Chernov (Russia), J. J. Favier (France), A. Horowitz (Israel), Jiang Min-Hua (China), H. Komatsu (Japan), H. J. Scheel (Switzerland), J. N. Sherwood (UK). Ex officio members: C. F. Woensdregt (The Netherlands), Chairman of ICCG-XI; M. Schieber (Israel), President of ICCG-XII; P. M. Dryburgh (UK), IOCG representative to the IUCr; H. Klapper (Germany), IUCr representative to the IOCG; and others.

In addition, 35 Councillors representing national associations, five Councillors representing nations who do not have a national association, and four ex officio Councillors representing International Unions have been approved. The ex officio Councillor representing the $\Pi \mathrm{UCr}$ is $\mathrm{M}$. $\mathrm{H}$. Dacombe, the Executive Secretary of the IUCr.

The following IOCG Prizes, sponsored by the Dutch Association for Crystal Growth and by the ICCG-XI Organizing Committee, were awarded: The Frank Prize to P. Bennema (The Netherlands) and the Laudise Prize to R. F. Feigelson (USA). The first IOCG Distinguished Service Award, sponsored by the Japanese, Italian and British Associations for Crystal Growth, was presented to $\mathrm{M}$. Schieber (Israel).

17 May 1996

H. KLAPPER, Representative

\section{Appendix G: Reports of Representatives on bodies not belonging to the Union}

IUPAC Interdivisional Committee on Nomenclature and Symbols (IDCNS)

IDCNS reviews all recommendations originating within IUPAC Commissions and Divisions that concern matters of nomenclature and symbols. Following revision and acceptance, these recommendations are published in Pure and Applied Chemistry and then become binding on all IUPAC-related publications. The IUCr representative and his alternate evaluate each document and provide critical comment as appropriate from the crystallographic point of view.

IDCNS met during the triennium in Lisbon, Portugal, in August 1993, in Reading, UK, in August 1994, and in Guildford, UK, in August 1995. The dates of two IDCNS meetings in this triennium so closely overlapped those of major crystallographic meetings that neither the representative nor his alternate were able to take part. The representative participated very actively at the Reading meeting, at which a major matter of concern to the IUCr was the 1994 proposal by the Comité Consultative d'Unités (CCU) of the Bureau International des Poids et Mesures (BIPM) to deprecate further use of the angström. Our strong objections at 
Reading to this proposal, together with those expressed later by many of our Editors and others associated with IUCr publications and presented in absentia in Guildford as well as those of other IDCNS members proved persuasive. The IDCNS Chair, who is also IUPAC representative to $\mathrm{CCU}$, was able in turn to reach an agreement at the April 1996 meeting of $\mathrm{CCU}$ in which the new edition of the SI Brochure (the official French and English text of the BIPM document on the International System of Units) will be substantially revised in a major change of style. There will be no further deprecatory remarks on the ångström; instead, it will be regarded as a unit currently accepted for use with the SI. However, its relationship to the SI should be expressed henceforth in every document in which it is used in a footnote such as $1 \AA=10^{-1} \mathrm{~m}$. The $\AA$ remains far from being part of the SI, and while the words "currently accepted" imply no time limit, they are intended to suggest that the CCU envisages a future time at which this unit will drop out of use since the angström is not a self-defining unit as is the nanometre or the picometre.

8 May 1996

S. C. Abrahams, Representative

Th. HAHN, Alternate

Intermational Council for Scientific and Technical Information (ICSTI)

In the triennium, ICSTI has made strenuous efforts to review its activities to make them more relevant to current needs, to increase its membership and to improve its financial viability. The recruitment of additional members met with limited success. The geographical spread of members has increased, and its 1996 General Assembly is to be held in South Africa. The main effort to improve its financial viability has been to improve its record of viable publications. It has recently published a multi-lingual thesaurus for the geological sciences, which is a significant work, but it is likely to prove hard to repeat.

There have been more notable successes in the technical programme section at its General Assemblies, where the 1994 reports on electronic distribution of journal information within academic institutions by libraries and the 1995 report on a networking project provided valuable information about possible difficulties in mounting financially viable enterprises. A 1995 report on possible changes to the legal status of electronic information was also useful.

Perhaps the most encouraging sign from the IUCr's point of view is that ICSTI seems to have outgrown excessive preoccupation with the legal aspects of the ownership of information in databases, and in the second half of the triennium has taken a more balanced view of scientific information as a whole.

I believe that the community would be better served if CODATA and ICSTI were to amalgamate. If one were conspicuously stronger than the other it would be appropriate for the IUCr to abandon the weaker organization. For the time being, however, their strengths do not overlap, and the main factor the bodies have in common is some weaknesses, such as limited financial strength. I suggest a formal approach by the IUCr to the Executives of both organizations, asking that they consider again the potential benefits of amalgamation.

20 February 1996

E. N. MASLEN, Representative

\section{International Council of Scientific Unions (ICSU)}

The International Council of Scientific Unions (ICSU) has been established to facilitate the coordination between the activities of the Scientific Union Members and the National Scientific Members. It acts as the non-governmental adviser to the UN,
UNESCO and similar organizations on all major scientific issues of international dimensions such as global environmental change, population issues, the prevention of natural disasters, nuclear waste disposal, water quality, biodiversity etc. It plays a major role in the development of interdisciplinary research programmes (for instance, plans are made for initiatives in the domain of World Energy Supplies and the Management of the Earth System) and its action has been decisive in enforcing free circulation of scientists.

ICSU consists of 23 Scientific Union Members (the Scientific Unions), 74 National Scientific Members, observers and associates (scientific, national and regional). It has established 18 Interdisciplinary Bodies and is also involved in a number of joint initiatives with other organizations.

It is run by an Executive Board which follows its activities on a day to day basis and meets several times a year, a General Committee where every Scientific Union Member has a representative and where there is an equal number of National Scientific Members' representatives, elected by the General Assembly, and a General Assembly which meets every three years. It is assisted in its work by a number of Standing Committees and ad hoc Committees. The 24th General Assembly met in Santiago de Chile, 4-8 October 1993 and the 25th General Assembly will meet in Washington, USA, 24-26 September 1996. The General Committee meets just prior and just after every General Assembly and, until now, met every year in between: in Rabat, Morocco, 13-15 October 1994, and in Chang Mai, Thailand, 7-9 October 1995. It is recommended that it will convene only once between General Assemblies in the future.

During its meetings, the General Committee surveys in turn the various interdisciplinary bodies associated with ICSU and the international programmes where ICSU is involved and discusses scientific issues of major interest. It also holds scientific sessions open to the scientists of the country where it meets. These have included Biodiversity, El Niño phenomena and megatelescopes in the Southern Sky in Santiago de Chile, Confronting Complexity and Science in Morocco in Rabat, Informatics and Basic Sciences, 21st Century Issues in Biosciences and Science in Asia in Chang Mai.

Review of the activities of the most important Standing Committees of ICSU

Committee on Science and Technology in Developing Countries \& International Biosciences Network (COSTED-IBN)

See separate report.

Committee on Science in Central, Eastern Europe and the Former Soviet Union (COMSCEE)

The role of this Committee is to promote the role of science in rebuilding Central and Eastern Europe and to help scientists and scientific research in these countries. It has been considered that the action of this Committee is a long range one and it was decided to transform it from an ad hoc Committee to a special Committee. The representative of the IUCr has been elected a member of that committee. A meeting was organized in Leeds Castle (UK) in June 1994 on the role of science in rebuilding the countries of the Former Soviet Union. It was attended by 28 persons from 14 different countries and led to very fruitful discussions. A meeting of heads of independent national research funding organizations from the FSU, CEE and selected OECD countries to share experiences on the way science is funded was held in 1995. Several other projects are still in development, but the situation in Central and Eastern Europe and in the Former Soviet Union is now stabilizing and the mandate 
and programme of COMSCEE will be revised during the 1996 General Assembly. Furthermore, several countries of the Former Soviet Union are not a part of Europe which raises a problem which should be resolved with COSTED-IBN and the countries concerned

Standing Committee on the Free Circulation of Scientists (SCFCS)

This Committee has been very successful. Recently, it ensured that bona fide scientists from all parts of the former Republic of Yugoslavia were able to publish personal scientific papers in internationally distributed scientific journals. The General Assembly, considering that this action should be amplified in order to help to avoid possible violations of free collaboration among scientists and free exchange of scientific information, decided to widen the mandate of the Committee and to change its name to Standing Committee on Free Conduct of Science, with the same acronym. The General Assembly also encourages its members to consider the impact of increasing charges for scientific meetings and of page charges applied by some journals on science and developing countries and to bear in mind the position of scientists in developing countries when setting these fees or prices. The General Committee in 1995 revised its statement on Freedom in the Conduct of Science and produced, after advice of legal experts, a document on the impact of UN Sanctions on Freedom in the Conduct of Science. Members of the ICSU family are encouraged to use these documents whenever necessary.

Committee on Capacity Building in Science (CCBS) See separate report.

\section{ICSU Press}

This Committee gives advice to the Unions in all matters related to publishing. ICSU has established an International Network for the Availability of Scientific Publications (INASP). ICSU Press organized during the General Assembly in Santiago de Chile an exhibition of scientific books and publications where the IUCr was very well represented. An ongoing series of demonstrations of software took place in this framework and the IUCr Executive Secretary made daily demonstrations of the possibilities of CIF and of the advances of the IUCr in the matters of checking and electronic publishing. A new activity of ICSU Press is related to the emphasis now given to electronic publishing. It organized in February 1996, jointly with UNESCO, a Conference on Electronic Publishing in Science. 150 experts in electronic publishing, scientists, publishers, librarians and lawyers attended the conference, which was held at UNESCO headquarters in Paris. The main topics included electronic data storage and archiving, legal issues in electronic publishing, protection and control of data, scientists' view of electronic publishing and issues raised and economics and organization of primary electronic publishing. The conference overwhelmingly recommended that strict peer review should be applied to all scientific material submitted for publication in electronic journals. ICSU and UNESCO are invited to organize a forum involving scientific societies in order to formulate codes of ethics and of conduct for electronic publication on such matters as peer review, citation, integrity, priority of publication and authentication of material and archiving. An international committee should also be established by ICSU in coordination with ICSU members and associates and involving representatives of the library and scientific publishing communities to conduct a technical study of the costs and benefits of electronic publication.

17 May 1996

A. AUTHIER, Representative
ICSU Committee on Data for Science and Technology (CODATA)

No report was received from the IUCr Representative.

ICSU Committee on Science and Technology in Developing Countries (COSTED)

It was decided at the 24th General Assembly of ICSU in 1993 to merge the ICSU Committee on Science and Technology in Developing Countries (COSTED) and the International Biosciences Network (IBN), which is a joint ICSU-UNESCO undertaking established to assist developing countries build up their capacities in the biosciences.

The first joint meeting was held in Ghana in April 1994 where it was decided that COSTED-IBN, which will be cosponsored by UNESCO, would, in the future, work along the lines of the IBN, by allowing the regional networks to set their own priorities and their own modalities for actions. These regional offices will be located in Accra and Dakar for Africa, Amman for the Arab Region, Madras for Asia, and Santiago de Chile for Latin America. A regional Secretariat was also opened in South Africa in 1995. The Central Secretariat is located in Madras (India) where a new building is being funded by the government of India. The new officers as of 1 January 1996 are: R. Nichols (USA), Chairman, A.-M. Cetto (Mexico), Vice-Chair, G. T. Thyagarajan (India), Scientific Secretary. Modest support may be made available by COSTED-IBN for one or two participants from developing countries at meetings such as those organized by the IUCr, depending on the priorities of the regional offices, which should be directly contacted by the organizers of these meetings. A certain lack of communication has been noted in the past in COSTED. The President of the new organization has promised an improvement in this direction. Guidelines for applicants of grants will be prepared. The Visiting Professorships Scheme (similar to the IUCr Visiting Professorship Programme) is working well, and could be used by the $\mathrm{IUCr}$ as a complement to its own programme. The question of including the countries of Central and Eastern Europe in the activities of COSTED-IBN was raised and it was agreed that this should be pursued as a matter of urgency.

17 May 1996 A. AUTHIER, Representative

\section{ICSU Committee on Space Research (COSPAR)}

The essential activities of COSPAR 1993-1996 were connected with the 30th COSPAR Scientific Assembly and Associated Events, which were held 11-21 July 1994 in the Congress Centre of Hamburg, Germany, under the chair of its resigning President, Professor W. I. Axford. During the Council Meeting held on 11 July 1994, the new President, VicePresidents, COSPAR Bureau members and Finance Committee Chair and members for the period 1994-1998 were elected. The new COSPAR President is Professor G. Haerendel, Max-PlackInstitut für Extraterrestrische Physik in Garching and Technical University of Braunschweig, Germany. The new Vice-Presidents are Professor L. J. Lanzerotti, AT\&T Bell Laboratories, Murray Hill, NJ, USA, and Professor A. Nishida, University of Tokyo, Japan. The 31st COSPAR Assembly will be held 14-21 July 1996 at the University of Birmingham, UK, and the 32nd Assembly in 1998 in Tokyo, Japan.

17 May 1996

H. KLAPPER, Representative

ICSU Committee on Capacity Building in Science (CCBS)

On 4 July 1993, this Committee met in Paris at the ICSU Headquarters. On this occasion, the main item of business was 
the fact that there will be a reorganization of this Committee in some yet-to-be-determined manner.

On 21 June 1995, this Committee met in Paris at the ICSU Headquarters. On this occasion, an outstanding problem discussed was the needs of scientists in developing countries, and the Visiting Professorship Programme and schools organized by the IUCr were deeply appreciated.

An excellent feature of these meetings consisted in active interactions with Chairmen of Teaching Commissions of other scientific societies.

7 May 1996 C. M. GRAMACCIOLI, Representative

\section{Appendix H: Sponsorship of meetings:} Sub-committee on the Union Calendar

The Sub-committee on the Union Calendar is a sub-committee of the Executive Committee and therefore, according to Statute 8.1, has no obligation to report to the General Assembly. However, a summary of its activities is given in this Appendix for the information of delegates.

During the period since the last General Assembly, the Subcommittee has considered many requests for sponsorship and financial support by the IUCr and has made recommendations accordingly to the Executive Committee. The Executive Committee's policy, of giving financial support specially devoted to help young scientists, was successfully applied. An important aspect that must be guaranteed by the organizers of all meetings sponsored by the IUCr is the free circulation of bona fide scientists.

The following meetings on topics of crystallographic significance have received IUCr sponsorship, financial support for young scientists and, often, additional finance for general organizational expenses. The IUCr also provided substantial financial support to the Beijing Congress and the Seattle Congress. The financial support given to assist young scientists totalled CHF 48763 in 1993, CHF 83728 in 1994 and CHF 90709 in 1995. This support has helped several hundred young scientists attend a scientific meeting during the triennium.

Summer School on Electron Crystallography - Theory and Techniques, Beijing, China, 16-20 August 1993 (satellite meeting of Beijing Congress)

Neutron Scattering, Beidaihe, China, 17-19 August 1993 (satellite meeting of Beijing Congress)

Symposium on Molecular Structure, Fuzhou, China, 31 August-3 September 1993 (satellite meeting of Beijing Congress)

Application of Synchrotron Radiation in Crystallography, Beijing, China, 31 August-3 September 1993 (satellite meeting of Beijing Congress)

Powder Diffraction, Hangzhou, China, 31 August-3 September 1993 (satellite meeting of Beijing Congress)

Crystallography in Molecular Biology, Madras, India, 9-14 December 1993

Gordon Research Conference on Structural Phase Transitions in Non-Metallic Solids, Volterra, Italy, 8-13 May 1994

Symposium on Computational Methods in Chemical Design, Molecular Modeling - Theory and Experiment, Kloster Irsee near Kaufbeuren, Germany, 16-20 May 1994

21 st Crystallographic Course on Crystallography of Molecular Biology, Erice, Italy, 27 May-5 June 1994

1994 American Crystallographic Association Annual Meeting, Atlanta, USA, 26 June-1 July 1994

Symposium on New Trends in Small Moiety Crystallography, Atlanta, USA, 26 June-1 July 1994
Summer School on Electron Crystallography - Theory and Practice, Bristol and Bath, UK, 11-15 July 1994

Third ACA Summer Course on Crystallography, Pittsburgh, USA, 1-12 August 1994

Sagamore XI Conference, Brest, France, 7-12 August 1994

Pre-ECM-15 Symposium on Organic Crystal Chemistry, Poznan-Rydzyna, Poland, 23-27 August 1994

Fifteenth European Crystallographic Meeting (ECM-15), Dresden, Germany, 28 August-2 September 1994

International Summer School on Growth and Characterization of Materials, Cracow, Poland, 4-14 September 1994

Second European Symposium on X-ray Topography and High

Resolution Diffraction, Berlin, Germany, 5-7 September 1994

International Conference on Aperiodic Crystals, Lausanne/

Les Diablerets, Switzerland, 18-22 September 1994

Meeting on Neutrons in Biology, Santa Fe/Los Alamos, USA,

24-28 October 1994

Southern Africa Powder Diffraction Workshop, Pretoria, South Africa, 24-27 October 1994

XIII Iberoamerican Congress of Crystallography and III Iberoamerican School of Crystallography, Montevideo, Uruguay,

4-9 December and 12-16 December 1994

International School on Advanced Electronic Materials. Madras, India, 6-15 February 1995

BCA Fifth Intensive Course in X-ray Structure Analysis, Aston, England, 1-9 April 1995

International School on Quasicrystals, Balatonfüred, Hungary, 13-20 May 1995

Charge Density School, La Plata, Argentina, 18-26 May 1995

Erice School on Crystallography of Supramolecular Compounds, Erice, Italy, 2-12 June 1995

Gordon Research Conference on Electron Distribution and

Chemical Bonding, Plymouth, USA, 2-7 July 1995

Fourth European Powder Diffraction Conference (EPDIC IV), Chester, England, 10-15 July 1995

Workshop on Structure Determination from Powder Diffraction Data, Oxford, England, 16-20 July 1995

Workshop on the Description, Understanding and Prediction of the Structure of Inorganic Solids, Montreal, Canada, 19-22 July 1995

Rietveld Summer School '95-RS, Moscow, Russia, 20-22 July 1995

Sixteenth European Crystallographic Meeting (ECM-16), Lund, Sweden, 6-11 August 1995

International Conference on Interference Phenomena in X-ray Scattering, Moscow, Russia, 14-19 August 1995

Conference on Fundamental Principles of Molecular Modelling, Skukuza, South Africa, 20-24 August 1995

International Conference on X-ray Powder Diffraction Analysis of Real Structure of Matter: Size-Strain '95, Liptovsky Mikulós, Slovakia, 21-25 August 1995

Summer School on Neutron Scattering, Oxford, UK, 12-21 September 1995

Sixth International Conference on Crystallization of Biological Macromolecules, Hiroshima, Japan, 12-17 November 1995

International Seminar-cum-School on Macromolecular Crystallographic Data, Calcutta, India, 16-20 November 1995

Asian Crystallographic School of Gems and Precious Materials, Bangkok, Thailand, 20-21 November 1995

2nd Conference of the Asian Crystallographic Association (AsCA '95), Bangkok, Thailand, 22-24 November 1995 1995 Asian Crystallographic Computing School, Bangkok, Thailand, 27-30 November 1995

Winter Workshop on Electron Diffraction and Imaging at Surfaces, Scottsdale, USA, 3-6 January 1996 
International Symposium on Ferroic Domains and Mesoscopic Structures, Vienna, Austria, 25-30 March 1996

School on X-ray and Neutron Dynamical Diffraction - Theory and Applications, Erice, Italy, 9-21 April 1996

3rd European Symposium on X-ray Topography and High

Resolution Diffraction, Palermo, Italy, 22-24 April 1996

School on Experimental and Computational Approaches in Structure Based Drug Design, Erice, Italy, 8-19 May 1996

The organizers of all IUCr-sponsored meetings are requested to recommend the journals of the IUCr as a suitable channel of publication for the original papers presented at the meeting.

Organizers of meetings wishing to seek IUCr sponsorship should submit applications at least nine months in advance of the date of the meeting, writing to the Chairman of the Sub-committee. The present Chairman is P. W. Codding. A new Chairman will be appointed in Seattle. Applications for sponsorship of satellite meetings must be submitted through the Chairman of the Organizing Committee of the main meeting.

\section{Appendix I: IUCr/Oxford University Press Book Series}

The launching of this Series was reported to the General Assembly at Perth (1987). The agreement between the IUCr and the OUP was finalized soon afterwards. The Series has consisted of three sub-series:

IUCr Crystallographic Symposia (IUCr CS)

IUCr Monographs on Crystallography (IUCr MC)

IUCr Texts on Crystallography (IUCr TC)

The above arrangement continued over the initial seven years of the Series but was revised by the Executive Committee in 1994, when it was decided that, with the exception of the series on Crystallographic Computing, the Symposia Series (IUCr CS) could be dropped because it had become possible for that type of publication to be handled by Special Issues of the $\Pi \mathrm{UCr}$ journals. Thus, the Book Series consists now of Monographs and Texts only, except for the books on Crystallographic Computing (such as that edited by Flack et al. listed below).

The Book Series Committee membership currently is: J. H. Robertson (UK; Chairman), A. M. Glazer (UK), J. P. Glusker (USA), K. Kuchitsu (Japan) and V. I. Simonov (Russia), with H. J. Stanbury as the ex officio representative of the OUP and the President and the General Secretary of the IUCr as ex officio members. This Committee considers proposals for new publications and makes recommendations to the $\mathrm{IUCr}$ Executive Committee and to the Delegates of the Press (the body responsible for approving all publications handled by the OUP).

Books published since the Beijing General Assembly

IUCr CS-6. Flack, H. D., Párkányi, L. \& Simon, K. (Eds.) 1993. Crystallographic Computing 6. A Window on Modern Crystallography.

IUCr CS-7. Jones, D. W. \& Katrusiak, A. (Eds.) 1994 Organic Crystal Chemistry: Correlations, Transformations and Interactions. (Proceedings of the Poznan Symposium of July 1992.)

IUCr MC-6. Shmueli, U. \& Weiss, G. H. 1995. Introduction to Crystallographic Statistics.

Books expected to be published soon

A Monograph: Glaeser, R. et al. Electron Crystallography of Biological Macromolecules.

A Monograph: Authier, A. Dynamical Theory of X-ray Diffraction.

A Monograph: Coppens, P. Accurate Crystallography and the Study of Charge Density Distributions.

A Text: Hammond, C. The Basics of Crystallography and Diffraction: An Introduction.
A Monograph: David, W. I. F. (Ed.) Structure Determination from Powder Data.

A Text: Paufler, P. Physical Crystallography.

A Text: Howard, J. A. K., Aslanov, L. A. \& Fetisov, Sc. G. V. Instrumental Methods of X-ray Crystallography.

A Monograph: Snyder, R. L., Fiala, J. \& Bunge, H. Microstructure Analysis from Diffraction.

A Text: Giacovazzo, C. Direct Methods in Crystallography. Fundamentals, Applications and Perspectives.

Other topics under consideration

Protein Crystallography

Molecular Interaction and Recognition

Life's Molecular Machinery

Crystal Twinning

Crystal Structure Analysis: a Working Approach

\section{A comment}

A total of about 16 books have been published, so far, in these first nine years of the Book Series. The introduction of Texts (in 1988 ) as a standard component of the Series has been a definite success. While sales of Monographs and Proceedings are usually in the region of $300-400$, the sales of Texts - although there are only two at present (by Guinier and by Giacovazzo) - have averaged $3000-4000$. Currently there are four new Texts in the pipeline, as mentioned above.

\section{Future membership of the Book Series Committee}

The current membership is willing to continue for a further three-year period, except for the Chairman, who will be retiring at the Seattle General Assembly.

8 May 1996

J. H. ROBERTSON, Chairman

Appendix J: Budget estimates for period to Eighteenth General Assembly: determination of unit contribution

(a) Budget estimates

The estimated budget for the General Fund (GF) is set out below, for the period until the next General Assembly. Since the budget estimates had to be prepared at a time when the decisions on many activities were still to be made, these estimates should be considered with due reserve. With this proviso, and in accordance with Statute 9.3, the Executive Committee presents to the General Assembly the following estimates for the three-year period 1 January 1996-31 December 1998.

General Fund

INCOME

Subscriptions from Adhering Bodies

CHF CHF

Yield from investments and banking accounts

Subventions from UNESCO through ICSU

870000

EXPENDITURE

Administration

Subscriptions to ICSU and bodies of ICSU

60000

1383000

Administrative meetings

Scientific meetings

Transfers to other accounts

541500

258000

279000

300000

l 402800 
(b) Unit Contribution

According to Statute $5 \cdot 10(k)$, the General Assembly has to determine the Unit Contribution to be paid by the Adhering
Bodies for the period to the next General Assembly. The Executive Committee recommends to the General Assembly that the Unit Contribution should remain at its present level of CHF 1000 for the years $1997-1999$. 


\section{Statutes and By-Laws of the International Union of Crystallography}

as Adopted by the Fourth General Assembly in 1957 and Amended by the Fifth General Assembly in 1960, the Sixth General Assembly in 1963, the Seventh General Assembly in 1966, the Eighth General Assembly in 1969, the Ninth General Assembly in 1972, the Tenth General Assembly in 1975, the Eleventh General Assembly in 1978, and the Seventeenth General Assembly in 1996

\section{Statutes}

\section{Objects of the Union}

1.1. The objects of the Union are

(a) to promote international cooperation in crystallography;

(b) to contribute to the advancement of crystallography in all its aspects, including related topics concerning the non-crystalline states;

(c) to facilitate international standardization of methods, of units, of nomenclature and of symbols used in crystallography;

(d) to form a focus for the relations of crystallography to other sciences.

1.2. For these purposes the Union shall have the power

(a) to adhere to the International Council of Scientific Unions:

(b) to organize international meetings and conferences on subjects falling within the purview of the Union;

(c) to promote international publication of crystallographic research and of crystallographic works;

(d) to set up Commissions or other bodies for special objects;

(e) to initiate, promote and coordinate crystallographic research requiring international cooperation;

(f) to organize Special Projects which shall be financed independently of the regular operations of the Union;

(g) to participate in Joint Commissions with other Unions or other scientific bodies in matters of interest to the Union;

(h) to perform all such other legal acts as are essential for or conducive to the objects of the Union including the constitution or organization of separate or independent bodies having an appropriate legal status;

(i) to receive into association existing regional organizations of crystallographers having substantially the same aims and objects as the Union; these organizations shall be known as Regional Associates of the Union;

(j) to receive into association existing international scientific organizations whose interests overlap with the aims and activities of the Union; these organizations shall be known as Scientific Associates of the Union.

\section{Organization and Legal Domicile}

2.1. Under the name of International Union of Crystallography an Association has been organized and incorporated; it is governed by Articles 60 and following of the Swiss Civil Code and by the present Statutes of Incorporation.

2.2. The duration of the Union is not limited.

2.3. The legal domicile of the Union is in Geneva, Switzerland.

\section{Membership}

3.1. The members of the Union are its Adhering Bodies.

3.2. There shall be only one member for each country. Only under extraordinary circumstances the General Assembly may admit a suitably designated additional Adhering Body from a country, provided a corresponding Adhering Body of that country has already been admitted as a National Member of the International Council of Scientific Unions (ICSU). In this case, each Adhering Body will have separate delegates and will be treated separately in questions of voting and finances.

3.3. The Adhering Body can be a National Academy, National Research Council or similar body, or a scientific society or group of such societies. Each Adhering Body shall form a National Committee for Crystallography to represent it in the Union.

3.4. Any number of Countries may agree to form a group in order to name or establish a single Adhering Body. This Body shall form a joint National or Regional Committee for Crystallography. Wherever the terms Country and National Committee for Crystallography are used in these Statutes or in the By-Laws, they shall be taken to include such groups of Countries and joint National or Regional Committees for Crystallography.

3.5. Membership in the Union shall be fully effective when the nature of the Adhering Body and the membership of the National Committee have been reported to and accepted by the General Assembly. Any replacement of an Adhering Body is subject to the approval of the Executive Committee and acceptance by the General Assembly. Any major change in the nature of an Adhering Body shall be considered valid only after it has been reported to and accepted by the General Assembly.

3.6. Adherence to the Union shall be in one of five Categories I-V with corresponding voting powers and contributions as set out in Statutes 5.5 and 9.4. A Body applying for adherence to the Union shall specify in which Category it wishes to adhere; this choice of Category, or any desired change in the Category, is subject to the approval of the Executive Committee and confirmation by the General Assembly.

3.7. Any extension of a joint adherence formed in accordance with Statute 3.4 is subject to the approval of the Executive Committee and acceptance by the General Assembly.

3.8. Participation in Special Projects [Statute 1.2(f)] shall not be obligatory. The extent of financial participation shall be a matter for special negotiation for each such project, except that the relationship between contribution and voting power within the project shall be that of the Category scheme defined in Statutes 5.5 and 9.4 to determine this relationship in the General Assembly. 
3.9. Each National Committee has the right to submit to the Union through the General Secretary questions within the competence of the Union.

3.10. Any Adhering Body may withdraw from the Union if it has given notice of withdrawal at least six months before the end of the current financial year; it is required to fulfil its obligations relating to the time period when it was a member of the Union. Its membership and any further obligations shall then be suspended by the Executive Committee at the expiry of the notice of withdrawal. The withdrawal shall take effect when it has been reported to the General Assembly.

3.11. An Adhering Body which withdraws from the Union in accordance with Statute 3.10, or any Adhering Body whose membership is cancelled in accordance with Statutes 5.12 or $9 \cdot 6$, loses all rights in connexion with the Union.

3.12. If the Countries of a group formed in accordance with Statute 3.4 agree that the group should be dissolved, or if a Country wishes to withdraw from such a group, with or without the agreement of the other Country or Countries of the group, the adherence of the original group shall be suspended by the Executive Committee at the expiry of an appropriate notice, provided that the original group has fulfilled its obligations. The termination of the original adherence shall take effect when the matter has been reported to the General Assembly. Pending this report, the Countries of the group, or any of them, may submit proposals for the continuation of their representation in the Union. In each of such proposals the nature of the Adhering Body, the membership of the National Committee and the desired Category of adherence shall be specified. These proposals are subject to the approval of the Executive Committee, which shall then make ad interim arrangements concerning these adherences. These arrangements are subject to acceptance by the General Assembly.

\section{Administration}

$4 \cdot 1$. The work of the Union shall be conducted by

(a) the General Assembly;

(b) the Officers of the Union, constituting the Executive Committee;

(c) the Commissions as defined in Statute 8.1.

The composition and function of these bodies are defined in the following paragraphs, whose application is governed by the By-Laws.

\section{General Assembly}

5.1. The work of the Union shall be directed by the General Assembly which is composed of delegates appointed by the Adhering Bodies.

5.2. The Executive Committee is responsible to the General Assembly and shall participate in its deliberations. Members of the Executive Committee have no voting power in the General Assembly, except for the casting vote of the Chairman [Statute $5 \cdot 8]$.

5.3. The General Assembly shall, as a rule, hold an ordinary meeting once every three years. The date and the place of the meeting, unless determined by the previous General Assembly, shall be determined by the Executive Committee. The General Secretary shall communicate the date and the place of the meeting to the National Committees and to the Commissions at least twelve months in advance.

5.4. In special cases, the President of the Union, with the consent of the Executive Committee, may call an extraordinary meeting of the General Assembly. He shall do so at the request of one-fifth of the Adhering Bodies. The routine business of a General Assembly prescribed in Statute 5.10 shall normally be omitted, unless specifically included in the agenda; but an extraordinary General Assembly shall have the same powers, and be subject to the same rules, as an ordinary General Assembly, except where otherwise is stated in the Statutes and By-Laws. The General Secretary shall communicate the date and the place of the extraordinary General Assembly to the National Committees and to the Commissions at least eight months in advance if amendment of the Statutes is contemplated, or at least four months otherwise.

As an alternative, in special cases not requiring an amendment to or a change of the Statutes, the President of the Union with the consent of the Executive Committee may ask for a postal ballot of the Adhering Bodies. He shall also do so at the request of one-fifth of the Adhering Bodies. The voting power of an Adhering Body in a postal ballot is the same as that at General Assemblies. The General Secretary will communicate the matter for determination to the National Committees and to the Commissions four months before the deadline for the votes to be received by the General Secretary. In order to facilitate a full discussion between the participants in the postal ballot, the comments and questions of the Adhering Bodies, the responses of the President as well as any amendment to the initial proposal will be circulated among the Adhering Bodies using fast means of communications at the latest one month before the deadline.

5.5. The voting power of an Adhering Body at General Assemblies and in postal ballots shall be in accordance with its Category of adherence, as follows

$\begin{array}{llcccc}\text { Category } & \text { I } & \text { II } & \text { III } & \text { IV } & \text { V } \\ \text { Number of votes } & 1 & 2 & 3 & 4 & 5 .\end{array}$

5.6. Each Adhering Body, through its National Committee, shall make known to the General Secretary before the opening of each General Assembly the names of its delegates (and of their alternates, if any), and also the name of the chairman of the national or regional delegation. No Officer of the Union may be a member of any delegation, nor shall any person serve as a member of more than one delegation.

5.7. Normally each of the delegates present at a General Assembly shall have one vote only, but when for special reasons an Adhering Body cannot be fully represented at a General Assembly it may distribute its votes among a number of delegates smaller than the number of votes which that Adhering Body has in accordance with the Category in which it adheres; such a decision has to be made known to the General Secretary before the opening of the General Assembly concerned. Any Adhering Body not represented at a General Assembly may forward its views to the General Secretary by letter, and such views shall be made known to the General Assembly if received before voting takes place.

5.8. Except where otherwise provided in the Statutes and By-Laws, decisions of the General Assembly are taken by a majority of the votes cast. In the event of an equal division of votes the Chairman shall take the final decision.

5.9. No question which has not been placed on the agenda of business to be transacted at the General Assembly shall be discussed or put to the vote unless a proposal to that effect be approved by at least two-thirds of the votes there represented.

5.10. The General Assembly shall

(a) take appropriate action on any matters concerning membership in the Union [Statutes 3.5, 3.6, 3.7, 3.10, 3.12 and $5 \cdot 12]$; 
(b) elect the President, the Vice-President, the General Secretary, the Treasurer and the other Officers of the Union [Statutes 6.1 and 6.3];

(c) consider, and make decisions regarding, the confirmation of the appointments of Editors of publications of the Union [Statute 7.1];

(d) determine the number of elected members of each Commission set up by the General Assembly [Statutes 5.11(c) and 8.2 ];

(e) elect the Chairmen and members of the Commissions [Statute 8.2];

(f) elect representatives of the Union on Joint Commissions with other Unions, and on other scientific bodies [Statutes $1.2(g)$ and 8.5$]$

(g) receive the reports on the activities of the Union and of its Commissions [Statutes 6.8 and 8.4 ];

(h) receive the audited accounts for the years elapsed since the previous General Assembly [Statute 9.1];

(i) on receipt of satisfactory reports or accounts, release the Treasurer, or any other Officer, or the Chairman or any member of any Commission or other body, from financial or other liability to the Union;

(j) determine the budget for general expenditure for the period to the next General Assembly, on the basis of the estimate prepared by the Executive Committee [Statutes 9.2 and 9.3 ;

(k) determine the unit contribution for the period to the next General Assembly [Statute 9.5];

(l) determine the general policy and the timetable for the period to the next General Assembly;

(m) give preliminary consideration to the activities of the Union for the three-year period following the next General Assembly.

5.11. The General Assembly shall have the power

(a) to amend these Statutes in accordance with Statute 13.1;

(b) to formulate and amend By-Laws on any matters not covered by these Statutes;

(c) to set up any Commission or other body it may deem necessary for the administrative and scientific work of the Union, and to determine the terms of reference of such a body [Statute $1 \cdot 2(d)$ ];

(d) to dissolve any Commission or other body set up in accordance with Statute $5 \cdot 11(c)$ when its existence is deemed no longer necessary;

(e) to determine the nature of Special Projects which shall be financed independently of the regular operations of the Union [Statute 1.2(f)];

(f) to accept Regional Associates, to determine the nature of the association in each case, and to determine any mutual financial commitments;

(g) to accept Scientific Associates, to determine the nature of the association in each case, and to determine any mutual financial commitments;

(h) to decide on all other questions falling within the competence of the Union.

5.12. The General Assembly may cancel the membership of any Adhering Body of the Union for any serious cause; such a decision may only be taken after the member in question has been previously given an opportunity to furnish an explanation to the Executive Committee for forwarding to the General Assembly. At least three-fourths of the total number of the votes of all Adhering Bodies are required for cancellation.

\section{Executive Committee}

6.1. The Officers of the Union constituting the Executive Committee are

(a) the President;

(b) the Vice-President;

(c) the General Secretary;

(d) the Treasurer:

(e) the immediate Past President;

(f) six ordinary members.

6.2. The election of Officers of the Union shall be arranged in such a way that there will not be more than two Officers from any one Country. A person is regarded as belonging to the Country in which he is normally resident and where he conducts the main part of his work. In cases of doubt the General Assembly shall decide to which Country a person is considered to belong.

If during the period between General Assemblies the number of Officers from a Country is increased above two because of any change of Country of residence, the Officer or Officers who changed his or their Country of residence may continue his or their service until the close of the next General Assembly. If at that time the number of Officers from the Country concerned would remain above two, one or more of the Officers who changed his or their Country of residence shall be considered to have resigned.

6.3. The offices of General Secretary and Treasurer may be combined and shall then be considered as a single office. Otherwise no person shall hold more than one office simultaneously. The voting power of the Officer holding the combined office of General Secretary and Treasurer shall not be more than that of either the General Secretary or the Treasurer.

6.4. The President holds office as President until the close of the ordinary General Assembly following his election, and continues as a member of the Executive Committee until the close of the ordinary General Assembly next but one following that of his election. He is not then eligible for immediate reelection to the office of President, nor to any other office in the Executive Committee.

The Vice-President holds office until the close of the ordinary General Assembly following his election. He is not eligible for immediate re-election to the same office.

The General Secretary and the Treasurer hold office until the close of the ordinary General Assembly following that of their election. They are eligible for immediate re-election to the same office, but shall not serve in that office for more than three full consecutive terms.

Three ordinary members are elected at each ordinary General Assembly and hold office until the close of the ordinary General Assembly next but one following that of their election. They are not eligible for immediate re-election to the same office.

In the event of a vacancy, through resignation, death or other cause, any Officer elected by the General Assembly to fill the unexpired term of office shall serve only to the end of the normal term of the Officer he replaces; at the end of this service he may be nominated for re-election for a full term to the same office.

6.5. The Executive Committee shall carry out the decisions of the General Assembly and give effect to the general policy of the Union as determined by the General Assembly.

6.6. During the periods between General Assemblies the Executive Committee shall have full power to carry on the business of the Union in all matters not specifically assigned 
by the Statutes, the By-Laws or the General Assembly to individuals or to Commissions or other bodies. If necessary, it may make ad interim arrangements in all matters assigned by the Statutes and By-Laws to the General Assembly.

6.7. In the event of an individual, a Commission or another body of the Union failing to act in any matter assigned to him or it by the Statutes, By-Laws or the General Assembly, the Executive Committee may, after reasonable notice to the individual or body in question, take action on behalf of the Union.

6.8. The Executive Committee shall report on its activities to the General Assembly. The action taken by the Executive Committee in accordance with Statutes $3 \cdot 5,3 \cdot 6,3 \cdot 7,3 \cdot 103 \cdot 12$, $6.6,6 \cdot 7,7 \cdot 1,7.2,8 \cdot 2,9.6$ and 9.9 shall be included in this report. The report to the General Assembly shall be dispatched by the General Secretary to the National Committees and to the Commissions at least ten weeks before the meeting.

\section{Publications of the Union}

7.1. The Editors of the publications of the Union are appointed by the Executive Committee for initial terms extending through not more than six years beyond the ordinary General Assembly following the appointment. Each initial appointment is subject to confirmation by that General Assembly. Reappointments may be made by the Executive Committee for terms of not more than three years, and are subject to confirmation by the ordinary General Assembly following the reappointment.

7.2. Co-editors and Assistant Editors are appointed by the Editors for terms of not more than three years, but they may be reappointed immediately for terms of the same length. The appointments and reappointments are subject to the approval of the Executive Committee.

7.3. Editors and Co-editors are members of the Commissions set up for their respective publications.

\section{Commissions and Joint Commissions}

8.1 . The term 'Commission' shall be understood to include all Commissions, Committees, and other bodies of the Union with the exception of National Committees for Crystallography, and the Executive Committee and its subcommittees.

8.2. The Chairmen and members of the Commissions are elected at each General Assembly. Subject to the approval of the Executive Committee, Commissions may co-opt further members during the periods between General Assemblies, and may fill vacancies arising from resignation, death or other cause. Members (but not Chairmen) may be nationals of or residents in a Country not adhering to the Union.

8.3. The Commissions shall be responsible to the General Assembly. They shall generally have full freedom in arranging their internal structure and work. They may formulate their own Rules of Procedure within the framework of the Statutes and By-Laws of the Union, and within their terms of reference.

8.4. The Chairmen shall report on the activities of the Commissions to the General Assembly. These reports shall reach the General Secretary at least fourteen weeks before the General Assembly and shall be dispatched by him to the National Committees and the Commissions at least ten weeks before the meeting.

8.5. The representatives of the Union on Joint Commissions and on other scientific bodies [Statute $1.2(\mathrm{~g})$ ] are elected at each General Assembly. For each such body one representative shall be designated as the chief representative of the Union. His obligations to report are the same as those of the Chairmen of the Commissions.

\section{Finance}

9.1. The Executive Committee shall be responsible to the General Assembly for all the financial affairs of the Union.

9.2. The Chairman of each Commission (or other member approved by the Executive Committee) shall be responsible to the Executive Committee for any expenditure of funds by his Commission. Five months before each General Assembly he shall submit to the Executive Committee an estimate of the budget of his Commission for the period between that General Assembly and the one following it. He shall submit annually to the Executive Committee a revised budget for the ensuing year and a statement of accounts for the preceding year. His accounts shall be available for audit by the Executive Committee or its appointees.

9.3. The Executive Committee shall prepare an estimate of the budget for the period between the next General Assembly and that following it. This estimate shall be dispatched by the General Secretary to the National Committees and to the Commissions at least ten weeks before the meeting.

9.4. Each Adhering Body shall pay an annual subscription in accordance with its Category of adherence, as follows:

$\begin{array}{lccccc}\text { Category } & \text { I } & \text { II } & \text { III } & \text { IV } & \text { V } \\ \text { Number of unit contributions } & 1 & 3 & 6 & 10 & 15 .\end{array}$

The annual subscriptions are payable during the calendar year to which they apply.

9.5. The unit contribution, stated in terms of a currency to be designated by the Executive Committee, shall be determined by the General Assembly for the period to the next General Assembly.

9.6. Any Adhering Body which is in arrears with its subscription for two years shall be wamed and shall be deprived of its voting power. The membership of any Adhering Body which is in arrears for four years shall be automatically suspended and may be cancelled by the General Assembly under Statute 5.12. An Adhering Body whose membership has been suspended shall receive no privileges of the Union and incur no further responsibility for dues; it may be reinstated by action of the Executive Committee.

9.7. The financing and management of publications of the Union shall be kept distinct from general expenditure. Editors and Co-editors shall be responsible to the Executive Committee for any receipts or expenditure of funds by them with respect to their publications.

9.8. The financing and management of Special Projects of the Union shall be kept distinct from the regular operations of the Union.

9.9. No funds may be solicited or accepted on behalf of the Union or any of its Commissions from any international, governmental or other agency or person without the prior approval of the Executive Committee. Any National Committee for Crystallography may however solicit funds within its own Country for the support of its own activities or in its capacity as host for a General Assembly, Congress or other meeting sponsored by the Union. Any funds, in the form of donations, legacies, or grants, accepted by the Executive Committee shall be used so far as is possible in accordance with the wishes of the donors. 


\section{Liability}

10.1. The Union is liable only to the extent of its assets, and the Adhering Bodies are not individually liable for its corporate debts and liabilities.

10.2. The liabilities of the Adhering Bodies are limited to the payment of their annual subscriptions and to such contributions to the Special Projects of the Union as they may have pledged.

10.3. No Officer of the Union shall be individually liable for the corporate debts and liabilities of the Union. The Union shall indemnify any Officer or former Officer in respect of any claims laid against him in respect to his authorized actions on behalf of the Union. At its discretion the Executive Committee may extend this indemnity to other persons in respect of their authorized actions on behalf of the Union.

10.4. The Union shall not accept any liability for any personal loss, damage or accident sustained by an individual, not being an employee of the Union, engaged in any activity, including travel, on behalf of the Union.

\section{Auditor and Representation of the Union}

11.1. The Auditor of the Union shall be a person or corporation authorized to act as a public accountant. The Auditor shall be appointed by the Executive Committee on the recommendation of the Treasurer and maintained thereafter subject to the approval of the General Assembly.

$11 \cdot 2$. With the exception of cheques, all contracts and formal agreements involving the Union shall be signed by two Officers of the Union. The Executive Committee may restrict the power to sign a particular document or type of document to specific persons among the Officers; and it shall determine rules for the signing of cheques.

11.3. The President shall be the official representative of the Union on all other civil and legal occasions and in dealing with other organizations. He may in this respect delegate his powers to another Officer of the Union, or, with approval of the Executive Committee, to any other person.

\section{Dissolution of the Union}

$12 \cdot 1$. The Union shall not be dissolved except on a motion presented at a General Assembly. If a motion to dissolve is to be presented, the notice for that General Assembly as given under Statute 5.3 or 5.4 shall include a statement of the motion to dissolve and shall refer specifically to this Statute.
Such a motion shall be presented to the General Assembly without amendment and at least three-fourths of the votes there represented shall be required for dissolution.

In the event that less than three-fourths of the total number of the votes of all Adhering Bodies are represented at the General Assembly, a postal ballot may be arranged, and in such a postal ballot at least three-fourths of the total number of the votes of all Adhering Bodies shall be required for dissolution.

12.2. In the event of dissolution of the Union in accordance with Statute $12 \cdot 1$, the General Assembly shall appoint a special Committee, reporting to the International Council of Scientific Unions, for the liquidation of the assets of the Union. The net assets shall be given to one or more, preferably international, organizations or institutions which shall spend the assets for purposes so far as is possible in accordance with the objects of the Union.

\section{Statutes}

13.1. Amendments to the Statutes require action at a General Assembly. An amendment is adopted at such an Assembly only if (i) at least two-thirds of the votes represented at the General Assembly are affirmative and (ii) if these affirmative votes amount to more than half the total number of the votes of all Adhering Bodies. In the event that the vote on a proposed amendment satisfies condition (i) but not condition (ii), the Executive Committee may refer the proposed amendment to a postal ballot of the Adhering Bodies. If the proposed amendment then obtains affirmative votes amounting to more than half the total number of the votes of all Adhering Bodies, the amendment is adopted.

Proposals for amendments may be made by the Executive Committee or by any National Committee. Such proposals made by National Committees shall reach the General Secretary at least six months in advance of the General Assembly. The General Secretary shall dispatch these proposals, and those made by the Executive Committee, to the National Committees and to the Commissions at least four months before the meeting.

13.2. The present English text shall be considered the authoritative text in the interpretation of these Statutes. Where disputes arise concerning this interpretation, the matter shall be decided by the General Assembly, or, during the periods between General Assemblies, by a ruling of the President of the Union.

\section{By-Laws}

\section{General Assembly}

1.1. The agenda of business to be transacted at a General Assembly shall be determined by the Executive Committee and shall be dispatched by the General Secretary to the National Committees and to the Commissions at least ten weeks before the meeting.

1.2. Any National Committee and any Commission of the Union may propose business to be transacted at a General Assembly. Such proposals shall reach the General Secretary at least four months before the meeting, and shall be included in the agenda of the General Assembly.

1.3. The General Assembly may provisionally determine the date and the place of the next but one ordinary meeting of the General Assembly.
1.4. Chairmen of the National Committees and of the Commissions, and representatives of Regional Associates and Scientific Associates may attend the General Assembly and take part in the discussions but shall have no voting power. The President may invite representatives of scientific bodies, or individuals, to attend the General Assembly; such invited guests may take part in the discussions but shall have no voting power. Other interested persons may also attend the General Assembly but they shall not take part in the discussions, unless specifically invited or permitted to do so by the Chairman, and they shall have no voting power.

At the discretion of the Chairman any or all of the persons attending the General Assembly under this By-Law may be required to withdraw. 
1.5. If a delegate to a General Assembly is absent from a session of the Assembly, his place may be taken by any of the alternates nominated to the Assembly under Statute 5.6 provided that the Secretary of the Assembly is notified before the beginning of the session of the name of the delegate and of the name of the alternate, either by the delegate or by the chairman of his delegation. In general no such substitution may take place during a session of the Assembly, but the Chairman of the Assembly may permit substitution to be made under special circumstances.

1.6. The names of the representatives of a Body whose application for adherence to the Union has been received and declared in good order by the Executive Committee under ByLaw 2.9(a) shall be made known to the General Secretary as prescribed in Statute 5.6. These representatives shall be seated with the delegates of the Adhering Bodies during the preliminary ceremonies and the initial business of the General Assembly. At the discretion of the Chairman or by a vote of the Assembly, the representatives may be required to withdraw during the discussion of and voting on matters concerning adherence to the Union. The delegates of a new member may take their seats among the other delegates as soon as the General Assembly has accepted their Adhering Body as a member of the Union.

1.7. Unless decided otherwise by the General Assembly, matters concerning adherence to the Union shall take precedence over all other business at the first business session of the General Assembly, and shall normally precede the reading of the minutes and the discussions of matters arising therefrom.

1.8. Delegates of an Adhering Body may not vote on any matter concerning its membership in the Union.

1.9. In the event of the General Assembly considering a change in a group of Countries according to Statute $3 \cdot 12$, the delegates from the Countries belonging or previously belonging to the group may not vote on any matters concerning the representation in the Union of any of these Countries. After acceptance of the ad interim arrangements made by the Executive Committee under Statute 3·12, these delegates have full voting power.

1.10. The delegates of new members may not vote on any matters concerning adherence to the Union, nor on any matters concerning the adoption of the minutes of the previous General Assembly, during the General Assembly at which they themselves are admitted.

1.11. The General Secretary shall post on the official bulletin board of the General Assembly the names of the Chairmen and members (and alternates, if any) of the delegations and the numbers of votes represented by them.

$1 \cdot 12$. During the General Assembly any delegate (or alternate) and any Officer of the Union is considered to have been notified of any action of the General Assembly, or of the Executive Committee, or of any Commission, if one of the two following procedures is adopted

(a) a notice is placed in the mail box or other location at which the delegate (or alternate) or the Officer is accustomed to receive his mail during the course of the General Assembly, or

(b) a notice is handed to the designated Chairman of each delegation with the specific request that he communicate its contents to his delegation, and to the General Secretary with the specific request that he communicate its contents to the Executive Committee,

provided that in either case a similar notice is posted on the official bulletin board.
1.13. Minutes of the meetings of the General Assembly shall be made. Copies of the draft minutes shall be communicated by the General Secretary to the National Committees, to the Officers of the Union and to the Chairmen of its Commissions. After approval at a subsequent General Assembly, two copies of the definitive minutes shall be signed by the Chairman and the Secretary of the session at which they are approved, and shall be kept by the President and the General Secretary.

\section{Executive Committee}

2.1. The Executive Committee shall meet at each General Assembly. There shall be at least two additional meetings during the period between General Assemblies, unless the Executive Committee by a postal vote decides otherwise.

2.2. The Executive Committee shall make nominations to the General Assembly for the Officers of the Union, for the Chairmen and members of the Commissions, and for representatives on Joint Commissions and on other scientific bodies. Normally these nominations shall be made after a preceding postal communication with the National Committees. In each case in which an Officer of the Union is nominated for another office, either by the Executive Committee or by delegates to the General Assembly [By-Law 8.2], the Executive Committee shall also include a nomination for the office which would be vacated if the election to the other office occurs. If the election to the other office does not occur and if the Officers term has not expired, the nomination to the office which would have been vacated shall not be considered.

$2 \cdot 3$. In the event of the resignation, death or disability of the President, the Vice-President shall assume the office of President until the close of the next ordinary General Assembly.

In the event of the resignation, death or disability of the Vice-President, the Executive Committee may appoint one of its members to serve as Vice-President until the close of the next ordinary General Assembly.

In the event of such circumstances that the General Secretary or the Treasurer cannot carry out his duties, the other shall assume those duties until the Executive Committee has considered the situation. In that event the Executive Committee may, but need not, appoint a new General Secretary or Treasurer to serve until the close of the next ordinary General Assembly.

In the event of the resignation, death or disability of an ordinary member of the Executive Committee, the Executive Committee may co-opt a new member to serve until the close of the next ordinary General Assembly.

The accession of an Officer of the Union to a new office under the conditions of this By-Law shall be accompanied by his resignation from the office to which he was previously elected, but service under this By-Law shall not affect his eligibility for immediate re-election to the new office.

2.4. Any Officer unable to attend a meeting of the Executive Committee may designate a deputy to attend that meeting. Such a deputy shall be named in writing to the President or the General Secretary. He shall have no voting power and shall not be counted as part of a quorum.

2.5. The President, on his own initiative or at the request of the Executive Committee, may invite any individual to be present at a meeting of the Executive Committee; such an invited guest may take part in the discussions but shall have no voting power.

2.6. At a meeting of the Executive Committee two-thirds (fractional parts neglected) of the Officers specified by Statutes $6 \cdot 1$ and $6 \cdot 3$, excluding any who have resigned or died, shall 
constitute a quonum; and decisions shall be taken by a simple majority of the Officers present and voting. The Chairman of the meeting shall not vote in open ballots; but in the event of an equal division of votes the Chairman may take the final decision. In secret ballots required by the Statutes or By-Laws or ordered by the Chairman he may vote at his discretion. If he does not vote and there is an equal division of votes he may take the final decision. If he has voted in a secret ballot he may not take the final decision, and must leave it to further discussion and ballot.

2.7. During the period between meetings of the Executive Committee, voting may take place by post. Adoption of a proposal shall require affirmative votes from two-thirds (fractional parts neglected) of the Officers specified by Statutes $6 \cdot 1$ and 6.3 , excluding any who have resigned or died. No decision on any proposal other than calling or cancelling a meeting of the Executive Committee shall be made by postal vote in the event that at least two Officers express the wish that the matter concerned should first be given more or further consideration, either by correspondence or at a meeting of the Executive Committee.

2.8. Minutes of the meetings of the Executive Committee shall be made. Two copies of the minutes shall be signed by the Chairman and the Secretary of the meeting at which they are approved, and shall be kept by the President and the General Secretary. A summary of the draft minutes of meetings of the Executive Committee shall be despatched by the General Secretary to the National Committees within ten weeks of the conclusion of each meeting.

2.9. In addition to the obligations described in the Statutes and elsewhere in these By-Laws, the Executive Committee shall

(a) receive and report on applications for adherence to the Union if the nature of the applying Body and the membership of the National Committee have been duly reported to and considered to be in good order by the Executive Committee; pending the next General Assembly the Executive Committee may in the case of such applications provide such services of the Union as it deems proper;

(b) consider and report on any other questions concerning adherence to the Union;

(c) present an annual report, including an audited statement of receipts and expenditure, to the National Committees;

(d) report to the Commercial Registry of Geneva any changes in the registered information concerning the Union;

(e) have the power to appoint representatives on scientific bodies not belonging to the Union.

\section{President}

3.1. The President of the Union is Chairman of the General Assembly and of the Executive Committee. In the absence of the President from a session or meeting, the Vice-President, or if he is not present another Officer of the Union designated by the Executive Committee, shall act as Chairman.

3.2. The President of the Union is an ex officio member, with voting power, of all Commissions of the Union.

\section{General Secretary}

4-1. The General Secretary of the Union is Secretary of the General Assembly and of the Executive Committee. In his absence from a session or meeting, another Officer of the Union designated by the Executive Committee shall act as Secretary.
4.2. The General Secretary of the Union is an ex officio member, with voting power, of all Commissions of the Union.

4.3. The General Secretary is responsible for conducting the ordinary business of the Union, with the exception of the financial administration, and for keeping its records.

\section{Treasurer}

5.1. The Treasurer of the Union is responsible for the financial administration of the Union and for keeping its accounts.

5.2. The Treasurer is an ex officio member of all Commissions of the Union, with voting power only for those questions which may involve the Union in financial commitments.

\section{Sub-committees of the Executive Committee}

6.1. The Finance Committee is appointed by the Executive Committee to advise on finances, establishment and salaries. The Convener of the Finance Committee should normally be a resident of the same country as the Union Secretariat. If the Convener is not an elected member of the Executive Committee he will attend ex officio the meetings of the Executive Committee without voting rights.

6.2. The Sub-committee on the Union Calendar is appointed by the Executive Committee to advise on the sponsorship of the Union for meetings, symposia and schools. The Chairman of the Calendar Sub-committee should be a member of the Executive Committee.

6.3. The Executive Committee may establish, modify or abolish any other Sub-committees.

\section{Commissions of the Union}

$7 \cdot 1$. The Chairmen of the Commissions and the chief representatives on Joint Commissions or other bodies shall forward records of all meetings of the Commissions to the President and the General Secretary. They shall report annually on the activities of these bodies to the Executive Committee.

7.2. If funds are provided for the use of a Commission, it may make its own financial arrangements, with the prior approval of the Executive Committee and subject to the provisions of the Statutes and By-Laws. In cases where the Executive Committee has given prior approval, payments toward travelling expenses of Chairmen and members of Commissions may be made from the general funds of the Union.

7.3. No person who has served for three consecutive full terms of office on a Commission is eligible for nomination for a fourth consecutive term of service on the same Commission except as Chairman. In no case is any person eligible for more than four consecutive full terms of service on the same Commission. These limitations do not apply to Editors [Statute 7.1], Co-editors [Statute 7.2] and ex officio members. Any Commission, in its Rules of Procedure, may reduce the length of service specified here.

7.4. In the event of the resignation, death or disability of the Chairman of any Commission, the Executive Committee shall appoint a member of that Commission to serve as Chairman until the close of the General Assembly following this appointment.

\section{Nominations and Elections}

8.1. All delegates (and alternates) shall be notified of the nominations presented by the Executive Committee under ByLaw 2.2 for the Officers of the Union as early as possible and 
at least ninety-six hours before the scheduled commencement of the session of the General Assembly at which the vote is to be taken.

8.2. After the delegates have been notified of the nominations by the Executive Committee as prescribed in By-Law $8 \cdot 1$, other nominations for Officers of the Union may be made by any six or more delegates. Such nominations shall be made in writing to the General Secretary not less than thirty-six hours before the voting session and shall be accompanied by a written statement that the consent of the nominees has been obtained. These nominations shall be posted by the General Secretary on the official bulletin board not less than twenty-four hours before that session.

8.3. Recommendations from each Commission for the Chairman and members of the Commission shall be made in writing to the General Secretary not less than seventy-two hours before the voting session of the General Assembly. These recommendations shall be approved by a majority of the members of the Commission and shall be accompanied by a written statement that the consent of the persons recommended has been obtained. All delegates (and alternates) shall be notified of the nominations presented by the Executive Committee under By-Law 2.2 for the Chairman and members of each Commission at least forty-eight hours before the voting session.

8.4. After the delegates have been notified of the nominations by the Executive Committee as prescribed in By-Law 8.3, other nominations for the Chairman and members of each Commission may be made by any six or more delegates. Such nominations shall be made in writing to the General Secretary not less than twenty-four hours before the voting session and shall be accompanied by a written statement that the consent of the nominees has been obtained. These nominations shall be posted by the General Secretary on the official bulletin board not less than twelve hours before that session.

8.5. In voting for the President, Vice-President, General Secretary and Treasurer of the Union, each of these offices shall be taken separately and voting shall be by secret ballot. A simple majority of the votes represented by the delegates present at the voting session shall be required for election. If there is only one candidate for one of these offices, his nomination shall be presented to the General Assembly and the candidate concerned shall be considered as elected. If there are two candidates or more, and an election is not achieved after two ballots, the candidate receiving the smallest number of votes in the second ballot shall be removed from the list. If an election is not achieved after a third ballot, this procedure shall be repeated until an election is achieved. Any ballot form showing more than one mark shall be invalid. Any contingency arising during the balloting shall be resolved by a ruling of the Chairman of the General Assembly.

8.6. The election of the ordinary members of the Executive Committee shall be by secret ballot, the ballot form showing the nominations presented by the Executive Committee and the nominations made by delegates. A simple majority of the votes represented by delegates present at the voting session shall be required for election. If there are not more candidates than vacancies, the nominations shall be presented to the General Assembly and the candidates shall be considered as elected. If there are more candidates than vacancies and all vacancies are not filled by election at the first ballot, a second ballot shall be arranged containing the names of the candidates not elected. If there are vacancies after the second ballot, the balloting procedure shall be repeated until all vacancies are filled; for each of these subsequent ballots the name of the candidate receiving the smallest number of votes on the preceding ballot shall be removed from the list. Any ballot form showing more marks than the appropriate number of vacancies shall be invalid. Any contingency arising during the balloting shall be resolved by a ruling of the Chairman of the General Assembly.

8.7. In the event that an election must be held to fill the unexpired term of an office vacated by an ordinary member [Statute 6.4], the nominations for this office shall be distinct from the nominations for ordinary members for full terms. A person may be nominated for both categories, but can be elected to only one office [Statute 6.3]. If ballots are required in the elections for both categories, the ballots for the full-term offices shall take place first. A person who has been elected to two consecutive non-full terms is not eligible, on completion of his second term, for immediate re-election as an ordinary member of the Executive Committee.

8.8. In voting for the Chairmen and members of the Commissions each Commission shall be considered separately. For the election of the Chairmen the procedure described in ByLaw 8.5 shall be followed. For the election of the members of the Commissions the procedure described in By-Law 8.6 shall be followed except that no more than two ballots shall be held. Any vacancies still remaining may be filled as provided in Statute $8 \cdot 2$.

8.9. The procedure for the nomination and election of representatives of the Union on Joint Commissions and on other scientific bodies is so far as is possible the same as that for the nomination and election of the Chairmen and members of the Commissions.

\section{By-Laws}

9.1. These By-Laws may be amended or suspended at any General Assembly and at least two-thirds of the votes there represented are required for an amendment or suspension. A motion to amend or suspend, if not already included in the agenda of business of the General Assembly, may be placed there by the procedure of Statute 5.9. No notice is required for a proposal to suspend the time limits prescribed by By-Laws 8.2 and 8.4. Notification of any other motion to amend or suspend the By-Laws must be given by its originators to all delegates (and alternates) and to all Officers of the Union in accordance with the procedure prescribed in By-Law 1.12, at least fortyeight hours before the session of the General Assembly at which the motion is to be considered.

$9 \cdot 2$. Words importing the male sex in the Statutes and By-Laws shall include the female sex.

9.3. The present English text shall be considered the authoritative text in the interpretation of these By-Laws. Where disputes arise concerning this interpretation, the matter shall be decided by the General Assembly, or during the periods between General Assemblies, by a ruling of the President of the Union. 


\section{APPENDIX}

Timetable in Preparation for General Assembly

12 months Notice of date and place of ordinary General Assembly to National Committees and Commissions

8 months Notice of date and place of extraordinary General Assembly to National Committees and Commissions, if amendment of Statutes is contemplated

6 months Proposals for amendments to Statutes to General Secretary

5 months Estimated budgets from Commissions to Executive Committee

4 months Proposals for agenda of General Assembly to General Secretary

4 months Notice of date and place of extraordinary General Assembly to National Committees and Commissions, if amendment of Statutes is not contemplated

4 months

14 weeks

10 weeks

10 weeks

10 weeks

10 weeks

Proposals for amendments to Statutes to National Committees and Commissions Reports of Commissions to General Secretary

Report of Executive Committee to National Committees and Commissions

Reports of Commissions to National Committees and Commissions

Budget to National Committees and Commissions

Agenda to National Committees and Commissions

\section{Timetable during General Assembly}

'Before' Notice by National Committees to General Secretary of names of delegates, alternates and chairmen of delegations, and of distribution of votes if not one per delegate 


\section{ANNEX III}

\section{Committees, Commissions and representatives on Regional and Scientific Associates and bodies not belonging to the Union}

\section{Memberships of bodies belonging to the Union}

\section{EXECUTIVE COMMITTEE}

President

E. N. Baker*

Department of Biochemistry,

Massey University,

Palmerston North,

New Zealand

Vice-President

Dr R. Chidambaram* (India)

General Secretary and Treasurer

S. Larsen*

Centre for Crystallographic Studies,

Department of Chemistry,

University of Copenhagen,

Universitetsparken 5,

DK-2100 Copenhagen,

Denmark

Immediate Past President

P. Coppens* (USA)

Ordinary members

L. A. Aslanov (Russia) $\dagger$

J. C. A. Boeyens (South Africa)*

H. Fuess (Germany) $\dagger$

M. Hart (USA)*

H. Schenk (The Netherlands)*

M. Tanaka (Japan) $\dagger$

Executive Secretary

M. H. Dacombe

International Union of Crystallog-

raphy,

2 Abbey Square,

Chester CH1 2HU,

England

\section{COMMISSION ON JOURNALS}

Chairman and Editor-in-Chief of Acta Crystallographica and an Editor of

Joumal of Synchrotron Radiation

J. R. Helliwell

Department of Chemistry,

University of Manchester,

Oxford Road,

Manchester M13 9PL,

England

$($ Acta $A+B+C+D ; J S R ; J A C)$

\footnotetext{
* Until the close of the Eighteenth General Assembly (1999).

$\dagger$ Until the close of the Nineteenth General Assembly (2002).
}

Co-Chairman and Editor of Journal of Applied Crystallography:

A. M. Glazer

Clarendon Laboratory,

University of Oxford,

Parks Road, Oxford OX1 3PU,

England $(J A C ; J S R)$

Editors of Journal of Synchrotron

Radiation

S. S. Hasnain

Molecular Biophysics Group,

Daresbury Laboratory,

Daresbury, Warrington,

Cheshire WA4 4AD,

England (JSR; JAC)

H. Kamitsubo

SPring-8, Jaeri-riken,

Kamigori-cho,

Hyogo-ken 678-12,

Japan (JSR)

Section Editors of Acta

Crystallographica

A. Authier

Laboratoire de Minéralogie et

Cristallographie,

Université Pierre et Marie Curie,

4 place Jussieu,

F-75252 Paris Cedex 05,

France (Acta A)

F. H. Allen

Cambridge Crystallographic Data Centre,

12 Union Road,

Cambridge CB2 1EZ,

England (Acta B)

S. R. Hall

Crystallography Centre,

University of Western Australia,

Nedlands 6009, WA,

Australia (Acta C)

J. P. Glusker

Institute for Cancer Research,

Fox Chase Cancer Center,

7701 Burholme Avenue,

Philadelphia, PA 19111,

USA (Acta D)

Co-editors of Acta, JAC and JSR

M. J. Adams (UK; Acta $A+B+D$ )

E. T. Adman (USA; Acta $A+D$ )

J. Albertsson (Sweden; Acta $A+B+C$; $J A C$ )

Y. Amemiya (Japan; JSR)

M. Ando (Japan; JSR)
T. Ashida (Japan; Acta $B+C+D$ )

L. A. Aslanov (Russia; Acta $A+B+C+D)$

D. H. Bilderback (USA; $J S R$ )

A. J. Blake (UK; $A c t a B+C$ )

L. Brammer (USA; $A$ cta $B+C$ )

C. P. Brock (USA; $A c t a A+B+C$ )

G. E. Brown (USA; JSR)

I. D. Brown (Canada; Acta $A+B+C$ )

E. E. Castellano (Brazil; Acta $A+B$ )

W. Clegg (UK; Acta $B+C$ )

M. Colapietro (Italy; JSR)

B. M. Craven (USA; $A c t a A+B+C$ )

G. R. Desiraju (India; $A$ cta $B+C$ )

A. Durif (France; Acta $B+C$ )

P. Elleaume (France; $J S R$ )

G. Ferguson (Canada; Acta $B+C$ )

R. Fourme (France; JSR)

F. R. Fronczek (USA; $(A c t a B+C)$

C. Giacovazzo (Italy; Acta A)

J. Harada (Japan; Acta $A ; J A C$ )

M. M. Harding (UK; Acta $B+C$ )

M. Hart (USA; Acta A; JSR)

H. Hashizume (Japan; Acta A; JAC)

F. H. Herbstein (Israel; Acta $A+B$ )

C. J. Howard (Australia; $J A C$ )

T. C. Huang (USA; JAC)

T. Janssen (The Netherlands; Acta $A$ )

P. G. Jones (Germany; Acta $B+C$ )

T. A. Jones (Sweden; $A c t a A+D$ )

A. Kálmán (Hungary; Acta $B+C$ )

J. Kirz (USA; JSR)

L. L. Koh (Singapore; Acta C)

G. Kulipanov (Russia; JSR)

H. Kuroda (Japan; JSR)

C. E. P. Lecomte (France; Acta $A+B$ )

T.-n. Lee (Korea; JSR)

A. Linden (Switzerland; Acta $C$ )

P. F. Lindley (France; $A c t a A+B+C+D$; $J A C)$

Y.-c. Liu (China; JSR)

R. E. Marsh (USA; Acta C)

T. Matsushita (Japan; JSR)

D. B. McWhan (USA; JSR)

D. M. Mills (USA; JSR)

S. Mobilio (Italy; $J S R$ )

K. Moffat (USA; JAC; JSR)

K. W. Muir (UK; $A c t a A+B+C$ )

I. H. Munro (UK; JSR)

M. Nardelli (Italy; Acta $B+C$ )

L. R. Nassimbeni (South Africa; Acta B)

O. Nittono (Japan; JAC)

Y. Ohashi (Japan; Acta $A+B+C$ )

M. Ohmasa (Japan; $A$ cta $A+B+C$ )

G. Oliva (Brazil; Acta $D$ )

$\AA$. Oskarsson (Sweden; JAC) 
D. Pandey (India; $J A C$ )

R. Parthasarathy (USA; Acta $B+C+D$ )

C. Pascard (France; Acta $B+C$ )

J. S. Pedersen (Denmark; $J A C$ )

J. Penner-Hahn (USA; JSR)

C. Riekel (France; JSR)

A. R. D. Rodrigues (Brazil; JSR)

R. Rosei (Italy; JSR)

W. H. E. Saenger (Germany; Acta $B+D)$

V. Saile (USA; JSR)

M. Sauvage-Simkin (France; JSR)

D. Schwarzenbach (Switzerland; Acta $A+B$ )

A. L. Spek (The Netherlands; Acta $C$ )

J. C. H. Spence (USA; Acta A)

W. C. Stallings (USA; Acta $A+B+C+D)$

H. B. Stuhrmann (Germany; JSR)

S. Suga (Japan; JSR)

M. R. Taylor (Australia; Acta $B+C$ )

J. Vicat (France; $J A C$ )

P. A. Thomas (UK; JAC)

T. Tsukihara (Japan; Acta D)

J. Vicat (France; $J A C$ )

M. Vijayan (India; $A c t a B+C+D$ )

P. C. Weber (USA; JAC)

P. S. White (USA; JAC)

Z. Zhang (China; Acta A)

H. Zimmermann (Germany; JAC)

Book-Review Editors

R. F. Bryan (USA; Acta, JAC)

I. H. Munro (UK; JSR)

\section{COMMISSION ON INTERNATIONAL} TABLES

Chairman and Editor of Volume A

Th. Hahn

Institut für Kristallographie,

RWTH Aachen,

D-52056 Aachen,

Germany

Editor of Volume $B$

U. Shmueli (Israel)

Editor of Volume $C$

E. Prince (USA)

Editor of Volume $D$

A. Authier (France)

Editors of Volume $E$

V. Kopsky (Czech Republic)

D. B. Litvin (USA)

Editors of Volume $F$

E. Arnold (USA)

M. G. Rossmann (USA)

Editors of Volume $G$

S. R. Hall (Australia)

B. McMahon (UK)

Editor of Volume $H$

H. Wondratschek (Germany)
COMMISSION ON APERIODIC

\section{CRYSTALS}

\section{Chairman}

G. C. Chapuis

Institut de Cristallographie,

Université de Lausanne,

BSP - Dorigny,

CH-1015 Lausanne,

Switzerland

Elected members

J. M. Dubois (France)

M. Farkas-Jahnke (Hungary)

D. Pandey (India)

J. M. Pérez-Mato (Spain)

M. L. Senechal (USA)

W. Steurer (Switzerland)

$S$. Van Smaalen (Germany)

A. Yamamoto (Japan)

\section{COMMISSION ON BIOLOGICAL MACROMOLECULES}

\section{Chairman}

W. H. E. Saenger

Institut für Kristallographie,

Freie Universität Berlin,

Takustrasse 6 ,

D-14195 Berlin,

Germany

Elected members

M. Bolognesi (Italy)

W.-r. Chang (China)

J. K. Dattagupta (India)

A. Liljas (Sweden)

Y. Mitsui (Japan)

J. Sevcik (Slovakia)

J. L. Smith (USA)

I. Wilson (USA)

COMMISSION ON CHARGE, SPIN AND MOMENTUM DENSITIES

Chairman

K. Schwarz

Institute for Technical Electro-

chemistry,

Vienna University of Technology,

Getreidemarkt 9/158,

A-1060 Vienna,

Austria

Elected members

A. K. Bansil (USA)

F. Itoh (Japan)

G. H. Lander (Germany)

C. Lecomte (France)

F. Sacchetti (Italy)

M. Sakata (Japan)

M. A. Spackman (Australia)

V. G. Tsirelson (Russia)

Y. Wang (China)
Ex officio member

J. W. White (Australia) (as Chairman of the Commission on Neutron Scattering)

COMMISSION ON CRYSTAL GROWTH AND CHARACTERIZATION OF MATERIALS

\section{Chairman}

H. Klapper

Mineralogisch-Petrologisches

Institut,

Universität Bonn,

Poppelsdorfer Schloss,

D-53115 Bonn,

Germany

Elected members

P. Bennema (The Netherlands)

P. M. Dryburgh (UK)

F. Licci (Italy)

N.-B. Ming (China)

T. Nishinaga (Japan)

F. Rosenberger (USA)

P. Rudolph (Germany)

I. Smolsky (Russia)

Ex officio members

P. M. Dryburgh (UK) (as Representative of the International Organization of Crystal Growth)

A. M. Glazer (UK) (as Editor of the Journal of Applied Crystallography)

COMMISSION ON CRYSTALLO-

GRAPHIC APPARATUS

This Commission has been replaced by the Commission on High Pressure.

\section{COMMISSION ON CRYSTALLO-} GRAPHIC COMPUTING

Chairman

P. E. Bourne

San Diego Supercomputer Center, PO Box 85608 ,

San Diego,

CA 92186-5608, USA

Elected members

G. L. Cascarano (Italy)

T. Higashi (Japan)

M. Kjeldgaard (Denmark)

T. Koritsanszky (Germany)

M. Ramanadham (India)

J. Simpson (New Zealand)

A. L. Spek (The Netherlands)

D. J. Watkin (UK)

\section{COMMISSION ON CRYSTALLO-} GRAPHIC DATA

This Commission has been terminated. 
COMMISSION ON CRYSTALLOGRAPHIC NOMENCLATURE

Chairman

S. C. Abrahams

Physics Department,

Southern Oregon State College, Ashland, OR 97520,

USA

Ex officio members

J. R. Helliwell (UK) (as Editor-in Chief of Acta Crystallographica)

A. Authier (France) (as Section Editor of Acta Cryst. Section A and Editor of Volume D of International Tables for Crystallography)

F. H. Allen (UK) (as Section Editor of Acta Cryst. Section B)

S. R. Hall (Australia) (as Section Editor of Acta Cryst. Section $C$ and an Editor of Volume $\mathrm{G}$ of International Tables for Crystallography)

J. P. Glusker (USA) (as Section Editor of Acta Cryst. Section D)

A. M. Glazer (UK) (as Editor of the Journal of Applied Crystallography)

S. S. Hasnain (UK) (as a Main Editor of the Journal of Synchrotron Radiation)

H. Kamitsubo (Japan) (as a Main Editor of the Journal of Synchrotron Radiation)

Th. Hahn (Germany) (as Editor of Volume A of International Tables for Crystallography)

U. Shmueli (Israel) (as Editor of Volume B of International Tables for Crystallography)

E. Prince (USA) (as Editor of Volume $\mathrm{C}$ of International Tables for Crystallography)

V. Kopsky (Czech Republic) (as an Editor of Volume E of International Tables for Crystallography)

D. B. Litvin (USA) (as an Editor of Volume E of International Tables for Crystallography)

M. G. Rossmann (USA) (as an Editor of Volume F of International Tables for Crystallography)

E. Arnold (USA) (as an Editor of Volume $\mathrm{F}$ of International Tables for Crystallography)

B. McMahon (UK) (as an Editor of Volume F of International Tables for Crystallography)

H. Wondratschek (Germany) (as Editor of Volume $\mathrm{H}$ of International Tables for Crystallography)

P. Coppens (USA) (as Chairman of the IUCr/OUP Book Series Committee)

C. M. Gramaccioli (Italy) (as
Chairman of the Commission on Crystallographic Teaching)

I. D. Brown (Canada) (as Chairman of CIF Management Committee)

\section{COMMISSION ON CRYSTALLO- GRAPHIC TEACHING}

\section{Chairman}

C. M. Gramaccioli

Dipartimento di Scienze della Terra,

Università di Milano.

Via Botticelli 23,

I-20133 Milano,

Italy

Elected members

L. A. Aslanov (Russia)

C. P. Brock (USA)

I. D. Brown (Canada)

P. N. Kasai (Japan)

E. Makovicky (Denmark)

Y. P. Mascarenhas (Brazil)

$\AA$. Oskarsson (Sweden) (Secretary)

P. Phavanantha (Thailand)

W. T. Robinson (New Zealand)

\section{COMMISSION ON ELECTRON DIFFRACTION}

\section{Chairman}

J. W. Steeds

Department of Physics,

H. H. Wills Laboratory,

University of Bristol,

Tyndall Avenue,

Bristol BS8 1TL

England

Elected members

D. L. Dorset (USA)

M. A. van Hove (USA)

A. Ichimiya (Japan)

F.-h. Li (China)

J. C. H. Spence (USA)

M. Tanaka (Japan)

D. Van Dyck (Belgium)

\section{COMMISSION ON HIGH PRESSURE}

Chairman

R. J. Nelmes

ISIS Facility, R3,

Rutherford Appleton Laboratory,

Chilton, Didcot,

Oxon OX11 0QX,

England

Elected members

Y. Fujii (Japan)

I. N. Goncharenko (Russia)

D. Hausermann (France)

R. J. Hemley (USA)

A. Katrusiak (Poland)

W. F. Kuhs (Germany)

J. B. Parise (USA)

O. Shimomura (Japan)
COMMISSION ON NEUTRON SCATTERING

\section{Chairman}

J. W. White

Research School of Chemistry,

The Australian National University, Canberra, ACT 0200,

Australia

Elected members

A. M. Balagurov (Russia)

C. J. Carlile (UK)

J. B. Forsyth (UK)

Y. Fujii (Japan)

P. S. Goyal (India)

G. Heger (Germany)

J. D. Jorgensen (USA)

J. S. Pedersen (Denmark)

E. Prince (USA)

\section{COMMISSION ON POWDER} DIFFRACTION

Chairman

R. J. Cernik

CLRC, Daresbury Laboratory,

Warrington,

Cheshire WA4 4AD,

England

Elected members

R. Delhez (The Netherlands)

L. B. McCusker (Switzerland) (Secretary)

J. Pannetier (France)

P. Scardi (Italy)

S. P. Sen Gupta (India)

D. K. Smith (USA)

I. G. R. Tellgren (Sweden)

H. Toraya (Japan)

R. B. Von Dreele (USA)

Ex officio member

R. L. Snyder (USA) (as Representative of the ICDD)

COMMISSION ON SMALL-ANGLE SCATTERING

Chairman

J. D. Barnes

Polymer Mechanics and Structure Group,

Bldg 224, Rm A209,

NIST, Gaithersburg,

Gaithersburg,

USA

Elected members

A. Craievich (Brazil)

E. Kaler (USA)

G. Kostorz (Switzerland)

K. Osamura (Japan)

J. Penfold (UK)

T. M. Sabine (Australia)

D. Svergun (Russia) 


\section{COMMISSION ON STRUCTURAL CHEMISTRY}

Chairman

C. Krüger

$\mathrm{X}$-ray Department,

Max-Planck-Institut für Kohlen-

forschung,

Kaiser-Wilhelm-Platz 1,

D-45470 Mülheim an der Ruhr, Germany

Elected members

V. K. Belsky (Russia)

G. Desiraju (India)

J. Flippen-Anderson (USA)

G. Gilli (Italy)

K. Hagen (Norway)

B. Kojić-Prodić (Croatia)

B. Krebs (Germany)

Y. Ohashi (Japan)

G. Punte (Argentina)
COMMISSION ON SYNCHROTRON

\section{RADIATION}

Chairman

Y. Amemiya

Photon Factory,

KEK, Oho 1-1 Tsukuba, Ibaraki 305, Japan

Elected members

R. Feidenhans'l (Denmark)

A. Fontaine (France)

K. K. Kannan (India)

A. H. Kvick

D. P. Siddons (USA)

K. D. Watenpaugh (USA)

S. W. Wilkins (Australia)

A. Yonath (Israel)
COMMISSION ON XAFS

Chairman

E. A. Stern

Physics Department,

Box 351560,

University of Washington, Seattle, WA 98195-1560, USA

Elected members

K. Baberschke (Germany)

A. Fontaine (France)

K. P. Garg (India)

B. Hedman (USA)

S. Mobilio (Italy)

T. Murata (Japan)

J. Penner-Hahn (USA)

\section{Regional Associates}

\section{AMERICAN CRYSTALLOGRAPHIC ASSOCIATION}

\section{Representative}

P Coppens

Department of Chemistry,

732 Natural Sciences \&

Mathematics Complex,

State University of New York,

University at Buffalo

Buffalo, NY 14260-3000

USA

\section{ASIAN CRYSTALLOGRAPHIC ASSOCIATION}

Representative

R. Chidambaram

Department of Atomic Energy,

Anushakti Bhavan,

CSM Marg,

Bombay 400039 ,

India

EUROPEAN CRYSTALLOGRAPHIC COMMITTEE

\section{Representative}

H. Schenk

Laboratory for Crystallography,

University of Amsterdam,

Nieuwe Achtergracht 166,

1018 WV Amsterdam,

The Netherlands

\section{Scientific Associates}

\section{INTERNATIONAL CENTRE FOR DIFFRACTION DATA}

Representative

R. J. Cernik (UK) (ex officio as Chairman of the Commission on Powder Diffraction)
INTERNATIONAL ORGANIZATION OF CRYSTAL GROWTH

Representative

H. Klapper (Germany) (ex officio as Chairman of the Commission on Crystal Growth and Characterization of Materials) 


\section{Representatives on bodies not belonging to the Union}

INTERDIVISIONAL COMMITTEE ON NOMENCLATURE AND SYMBOLS OF THE INTERNATIONAL UNION OF PURE AND APPLIED CHEMISTRY

Representative

S. C. Abrahams (USA) (ex officio as Chairman of the Commission on Crystallographic Nomenclature)

INTERNATIONAL COUNCIL FOR SCIENTIFIC AND TECHNICAL INFORMATION

Representative

E. N. Maslen†

Crystallography Centre,

University of Western Australia,

Nedlands 6009, WA,

Australia

$†$ Deceased 2 February 1997.
INTERNATIONAL COUNCIL OF SCIENTIFIC UNIONS (ICSU)

Representative

P. Coppens (USA) (ex officio as Immediate Past President of the IUCr)

\section{ICSU COMMITTEE ON DATA FOR SCIENCE AND TECHNOLOGY}

Representative

\section{H. D. Flack}

Laboratoire de Cristallographie, 24 quai Ernest Ansermet, $\mathrm{CH}-1211$ Genève 4 , Switzerland
ICSU COMMITTEE ON SCIENCE AND TECHNOLOGY IN DEVELOPING COUNTRIES \& INTERNATIONAL BIOSCIENCES NETWORK

Representative

P. Coppens (USA) (ex officio as Immediate Past President of the IUCr)

ICSU COMMITTEE ON SPACE RESEARCH

Representative

H. Klapper (Germany) (ex officio as Chairman of the Commission on Crystal Growth and Characterization of Materials)

ICSU COMMITTEE ON CAPACITY BUILDING IN SCIENCE

Representative

C. M. Gramaccioli (Italy) (ex officio as Chairman of the Commission on Crystallographic Teaching) 


\section{ANNEX IV}

\section{Adhering Bodies}

\begin{tabular}{|c|c|c|}
\hline Country & Category* & Adhering Body \\
\hline Argentina & I & $\begin{array}{l}\text { Consejo Nacional de } \\
\text { Investigaciones Científicas y } \\
\text { Tecnícas }\end{array}$ \\
\hline Australia & III & Australian Academy of Science \\
\hline Austria & I & $\begin{array}{l}\text { Österreichische Akademie der } \\
\text { Wissenschaften }\end{array}$ \\
\hline Belgium & II & $\begin{array}{l}\text { Académie Royale des Sciences, } \\
\text { des Lettres et des Beaux-Arts } \\
\text { de Belgique }\end{array}$ \\
\hline Brazil & III & $\begin{array}{l}\text { Conselho Nacional de } \\
\text { Desenvolvimento Científico } \\
\text { e Tecnológico }\end{array}$ \\
\hline Bulgaria & I & Bulgarian Academy of Sciences \\
\hline Canada & III & National Research Council \\
\hline Chile & I & $\begin{array}{l}\text { Comision Nacional de } \\
\text { Investigación Cientifica y } \\
\text { Tecnologia }\end{array}$ \\
\hline $\begin{array}{l}\text { China, } \\
\text { People's } \\
\text { Republic of }\end{array}$ & IV & Academia Sinica \\
\hline $\begin{array}{l}\text { China, } \\
\text { Taipei }\end{array}$ & II & $\begin{array}{l}\text { The Academy of Sciences } \\
\text { Located in Taipei }\end{array}$ \\
\hline Croatia & I & $\begin{array}{l}\text { Croatian Crystallographic } \\
\text { Association (under the auspices } \\
\text { of the Croatian Academy } \\
\text { of Science and Arts) }\end{array}$ \\
\hline $\begin{array}{l}\text { Czech and Slovak } \\
\text { Republics }\end{array}$ & I & $\begin{array}{l}\text { Regional Committee of Czech } \\
\text { and Slovak Crystallographers }\end{array}$ \\
\hline Denmark & I & $\begin{array}{l}\text { Royal Danish Academy of } \\
\text { Sciences and Letters }\end{array}$ \\
\hline $\begin{array}{l}\text { Egypt, Arab } \\
\text { Republic of }\end{array}$ & I & $\begin{array}{l}\text { Academy of Scientific Research } \\
\text { and Technology }\end{array}$ \\
\hline Finland & I & $\begin{array}{l}\text { Suomen Tiedeakatemiain } \\
\text { Valtuuskunta }\end{array}$ \\
\hline France & IV & $\begin{array}{l}\text { Académie des Sciences (Institut } \\
\text { de France) }\end{array}$ \\
\hline Germany & IV & $\begin{array}{l}\text { Deutsche Gesellschaft für } \\
\text { Kristallographie }\end{array}$ \\
\hline Hungary & I & Magyar Tudományos Akadémia \\
\hline India & II & $\begin{array}{l}\text { Indian National Science } \\
\text { Academy }\end{array}$ \\
\hline Israel & I & $\begin{array}{l}\text { Israel Academy of Sciences and } \\
\text { Humanities }\end{array}$ \\
\hline Italy & III & $\begin{array}{l}\text { Consiglio Nazionale delle } \\
\text { Ricerche }\end{array}$ \\
\hline Japan & IV & Science Council of Japan \\
\hline
\end{tabular}

G. Punte, Laboratorio Nacional de Difracción, Universidad Nacional de La Plata, CC 67, 1900 La Plata

T. NiCHOLLS, National Relations Officer, Australian Academy of Science, GPO Box 783, Canberra, ACT 2601

A. Preisinger, Institut für Mineralogie, Kristallographie und Strukturchemie, Technische Universität Wien, Getriedemarkt 9/171, A-1060 Vienna

J.-P. DECLERCQ, Laboratoire de Cristallographie, Unité CPMC, UCL, Place Louis Pasteur 1, B-1348 Louvain-la-Neuve

S. CATICha Ellus, DESCM, Instituto de Física, Universidade Estadual de Campinas, Campinas, São Paulo 13083-970

J. MACIČEK, Bulgarian Academy of Sciences, Institute of Applied Mineralogy, Rakovsky str. 92, 1000 Sofia

J. D. SCHRAG, Biotechnology Research Institute, National Research Council, 6100 Royalmount Avenue, Montreal, Quebec H4P 2R2

D. BoYs, Departamento de Física, Universidad de Chile, Casilla 487-3, Santiago

X. JiN, Department of Chemistry, Peking University, Beijing 100871

S. M. PenG, Department of Chemistry, National Taiwan University, Taipei

S. Popović, Ruđer Bošković Institute, PO Box 1016, 41001 Zagreb

M. Koman, Department of Inorganic Chemistry, Faculty of Chemical Technology, Slovak Technical University, Radlinského 9, SK-812 37 Bratislava, Slovakia

R. Feidenhans'L, Physics Department, Risø National Laboratory, PO Box 49, DK-4000 Roskilde

S. A. ABdEL-HADY, Physics Department, Faculty of Science, Cairo Higher Institute of Technology, Helwan, Cairo

A. M. VAhVASElKä, Department of Physics, University of Helsinki, PO Box 9, Siltavuorenpenger 20 D, FIN-00014 Helsinki

B. CAPElle, Association Française de Cristallographie, Tour 16, 4 place Jussieu, F-75252 Paris Cedex 05

P. PAUFLER, Institut für Kristallographie und Festkörperphysik, TU Dresden, D-01069 Dresden

P. Bombicz, Central Research Institute for Chemistry, Hungarian Academy of Sciences, POB 17, H-1525 Budapest

D. PANDEY, School of Material Science \& Technology, Banaras Hindu University, Varanasi-221 005

M. Harel, Department of Structural Biology, The Weizmann Institute of Science, Rehovot 76100

G. FILIPPINI, CS per le Relazioni tra Struttura e Reattività Chimica, CNR, Via Golgi 19, I-20133 Milano

Y. MitSUI, Department of Bio Engineering, Nagaoka University of Technology, Nagaoka, Niigata 940-21

* Adherence to the Union is in one of five Categories I-V, with corresponding voting powers and contributions as set out in Statutes $3.6,5.5$ and 9.4 . 


\begin{tabular}{|c|c|c|}
\hline Country & Category* & Adhering Body \\
\hline $\begin{array}{l}\text { Korea, } \\
\text { Republic of }\end{array}$ & I & $\begin{array}{l}\text { Korean Federation of Science and } \\
\text { Technology Societies }\end{array}$ \\
\hline Mexico & I & $\begin{array}{l}\text { Consejo Nacional de Ciencia y } \\
\text { Tecnologia }\end{array}$ \\
\hline Netherlands & II & $\begin{array}{l}\text { Stichting voor Fundamenteel } \\
\text { Onderzoek der Materie met } \\
\text { Röntgen- en Elektronenstralen }\end{array}$ \\
\hline New Zealand & I & $\begin{array}{l}\text { The Royal Society of New } \\
\text { Zealand }\end{array}$ \\
\hline Norway & I & Det Norske Videnskaps-Akademi \\
\hline Poland & I & Polska Akademia Nauk \\
\hline Portugal & I & Sociedade Portuguesa de Física \\
\hline Russia & IV & Russian Academy of Sciences \\
\hline Serbia & I & $\begin{array}{l}\text { Serbian Ministry for Science and } \\
\text { Technology }\end{array}$ \\
\hline Slovenia & I & $\begin{array}{l}\text { Slovenian Ministry of Science and } \\
\text { Technology }\end{array}$ \\
\hline South Africa & II & $\begin{array}{l}\text { Foundation for Research } \\
\text { Development }\end{array}$ \\
\hline Spain & III & $\begin{array}{l}\text { Comisión Interministerial de } \\
\text { Ciencia y Tecnología }\end{array}$ \\
\hline Sweden & II & Kungliga Vetenskapsakademien \\
\hline Switzerland & II & $\begin{array}{l}\text { Schweizerische Gesellschaft für } \\
\text { Kristallographie }\end{array}$ \\
\hline Ukraine & I & $\begin{array}{l}\text { Ukranian Crystallographic } \\
\text { Committee }\end{array}$ \\
\hline UK & V & The Royal Society \\
\hline USA & V & $\begin{array}{l}\text { National Academy of Sciences- } \\
\text { National Research Council }\end{array}$ \\
\hline Venezuela & I & $\begin{array}{l}\text { Venezuelan Crystallography } \\
\text { Association }\end{array}$ \\
\hline
\end{tabular}

Secretary of National Committee
S. K. SonG, Department of Physics, Myongji University, 38 Nam-Dong, Yongin, Kyonggi-Do 449-728

A. E. CORDERo-BorboA, Instituto de Física, UNAM, Apartado Postal 20-364, Del. Alvaro Obregón, 01000 México, DF

H. SCHENK, Laboratory for Crystallography, University of Amsterdam, Nieuwe Achtergracht 166, 1018 WV Amsterdam

C. E. F. RICKARD, Department of Chemistry, University of Auckland, Private Bag 92019, Auckland

B. FJAERTOFT, Institute of Pharmacy, University of Oslo, PO Box 1068, Blindern, 0316 Oslo

A. PIETRASZKo, W. Trzebiatowski Institute of Low Temperature and Structure Research, Polish Academy of Sciences, PO Box 937, 50-950 Wroclaw 2

M. M. R. R. CostA, Departamento de Física, Universidade de Coimbra, 3000 Coimbra

N. I. SOROKINA, Institute of Crystallography, Academy of Sciences of Russia, Leninsky prospekt 59, Moscow 117333

LJ. Karanović, Faculty of Mining and Geology, Djušina 7 , 11000 Belgrade

I. LEBAN, Department of Chemistry, University of Ljubljana, PO Box 537, SLO-61001 Ljubljana

M. PILLAY, FRD, South African ICSU Secretariat, PO Box 2600, Pretoria 0001

M. Martínez Ripoll, Instituto Rocasolano, CSIC, Serrano 119, E-28006 Madrid

R. NoRrestam, Department of Structural Chemistry, Arrhenius Laboratory, University of Stockholm, S-106 91 Stockholm

V. GRAMLICH, Institut für Kristallographie und Petrographie, ETH Zürich, ETH-Zentrum, CH-8092 Zürich

B. YA. KOTUR, Department of Inorganic Chemistry, Lviv State University, Kyryla i Mefodiya Str. 6, 290005 Lviv

The Executive Secretary, The Royal Society, 6 Carlton House Terrace, London SW1Y 5AG

A. ClearfiEld, Department of Chemistry, Texas A \& M University, College Station, TX 77843

O. V. GonZÁleZ, Departamento de Física, Escuela de Ciencias, Universidad de Oriente, Nucleo Sucre, Av. Universidad, Cerro Colorado, Cumaná Edo, Sucre

* See footnote on preceeding page.

\section{National Committees for Crystallography}

\section{Argentina}

S. BAGGIO (Chairman), M. E. J. DE ABELEDO, L. N. BECKA, D. BEDLIVY, A. BONFIGLIOLI, M. BUTSCHOWSKI, E. E. GALLONI, M. IPOHORSKI, A. PODJARNY.

Australia

J. W. WHITE (Chairman), D. C. CREAGH, I. E. GREY, M. GUSS, C. J. HOWARD, B. O'CONNOR, M. A. SPACKMAN.

\section{Belgium}

L. DUPONT (Chairman), J.-P. DECLERCQ, M. DOSIERE, G. H. EVRARD, L. V. A. FIERMANS, J.-M. GILLES, R. M. DE GRYSE, G. S. D. KING, A. T. H. LENSTRA, K. H. J. MICHEL, J. F. MOREAU, F. POORTMANS, H. L. REYNAERS, B. G. A. F. TINANT, G. G. R. VAN DEN BOSSCHE, J. F. VAN LANDUYT.

\section{Brazil}

R. RODRIGUES DA SILVA (Chairman), S. CATICHA ELLIS, J. M. CORREIA NEVES, C. CUSATIS, Y. P. MASCARENHAS.

\section{Bulgaria}

A. APOSTOLOV (Chairman), I. BONEV, I. GUTZOW, J. MACIČEK, M. MALEEV, S. PENEVA, K. PETROV. 
Canada

S. FORTIER (Chairman), I. C. BASSIGNANA, F. R. BRISSE, T. S. CAMERON, J.-P. CHARLAND, F. C. HAWTHORNE, R. J. READ

\section{Chile}

O. WITTKE (Chairman), E. BESOAÍN, D. BOYS, H. CID, J. A. COSTAMAGNA, J. GARIN, M. SUWALSKY, R. VERA.

\section{China, People's Republic of}

TANG YOU-QI (Chairman), FAN HAI-FU, FU HENG, GU XIAO-CHENG, GUO KE-XIN, HUANG JIN-LING, JIN XIANGLIN, LIANG DONG-CAI, LIANG JING-KUI, MIAO FANG-MING, MIN NAI-BEN, SHAO MEI-CHENG, XIAN DING-CHANG, XU XIAO-JIE.

\section{China, Taipei}

YU WANG (Chairman), S. L. CHANG, C. H. LEE, Y. C. LIAW, K. H. LII, L. K. LIU, C. P. TANG, S. C. YU, S. H. YUAN.

\section{Croatia}

B. KAMENAR (Chairman), B. GRŽETA, B. KOJIĆ-PRODIĆ, A. NAGL, V. NOVOSEL-RADOVIĆ, S. POPOVIĆ, S. ŠĆAVNIČAR.

Czech and Slovak Republics

M. DUNAJ-JURC̆O (Chairman), J. FIALA, V. HOLÝ, D. HRIVŇÁKOVÁ, M. KOMAN, P. MRAFKO, V. VALVODA, Z. ŽÁK.

\section{Denmark}

N. THORUP (Chairman), J. ALS-NIELSEN, A. N. CHRISTENSEN, R. FEIDENHANS'L, L. GERWARD, B. JENSEN, S. LARSEN, B. LEBECH, E. MAKOVICKY, O. SIMONSEN, T. B. ZUNIC.

\section{Egypt, Arab Republic of}

M. S. AHMED (Chairman), Y. M. ABBAS, S. A. ABDELHADY, A. M. ABDEL-RAHMAN, N. A. AHMED, S. A. A. ARAFA, F. A. DEIF, K. EL-SAYED, I. S. A. FARAG, M. A. GAFFAR, F. M. HELMI, K. H. A. MADY, M. RADWAN, A. A. RAMADAN, A. H. RASMY.

\section{Finland}

K. V. J. KURKI-SUONIO (Chairman), V. K. LINDROOS, T. L. P. PAAKKARI, A. V. PAJUNEN, J. U. VALKONEN, M. K. LEHTINEN.

\section{France}

M. MAREZIO (Chairman), B. CAPELLE, M. FREY, J. PROTAS

\section{Germany}

P. PAUFLER (Chairman), J. BOHM, U. HEINEMANN, H. R. HÖCHE, W. JEITSCHKO, G. MULLER.

\section{Hungary}

A. KÁLMÁN (Chairman), P. BOMBICZ, Z. BOCSKEI, I. DÓDONY, G. FAIGEL, I. HARGITTAI, L. MALICSKÓ, G. RADNOCZZI, I. SAJÓ, K. SIMON, E. SVÁB, T. UNGAR.
India

K. LAL (Chairman), R. CHIDAMBARAM, J. K. DATTAGUPTA, K. K. KANNAN, D. PANDEY, V. PATTABHI.

Israel

J. BERNSTEIN (Chairman), M. HAREL, M. KAPON.

Italy

E. CANNILLO (Chairman), C. BOCCHI, S. CANDELORO DE SANCTIS, A. CODA, M. COLAPIETRO, G. FERRARIS, G. FILIPPINI, C. MEALLI, S. MERLINO, C. PETRILLO, L. RANDACCIO, E. SCANDALE, D. TSERNOGIOU, P. ZANAZZI, L. ZANOTTI.

\section{Japan}

Y. OHASHI (Chairman), J. CHIKAWA, Y. FUJII, J. HARADA, H. INOKUCHI, F. IWASAKI, H. IWASAKI, Y. KAI, S. KIKUTA, Y. MITSUI, O. NITTONO, T. OHACHI, M. OHMASA, K. OHSUMI, N. SAKABE, H. TORAYA, K. YAGI.

$$
\text { Republic of Korea }
$$

J. S. SUH (Chairman), J. T. AHN, U. U. CHI, H. T. CHUN, S. J. CHUNG, H. S. KIM, M. Y. KIM, Y. H. KIM, C. H. KOO, Y. H. PARK, Y. J. PARK, S. K. SONG.

\section{Mexico}

A. E. CORDERO-BORBOA (Chairman), L. BAÑOS-LOPEZ, J. L. BOLDU-OLAIZOLA, O. CANO-CORONA, M. A. CASTELLANOS ROMAN, G. PACHECO-MALAGON, J. REYES GASGA, D. RIOS-JARA, D. ROMEU-CASAJUANA, H. TERRONES-MALDONADO, A. TOSCANO.

\section{Netherlands}

H. SCHENK (Chairman), P. T. BEURSKENS, J. DRENTH, D. FEIL, R. A. G. DE GRAAF, R. B. HELMHOLDT, F. TH. HESSELINK, A. M. KROON, E. J. MITTEMEIJER, M. G. NORTHOLT, F. TUINSTRA, J. W. VISSER.

New Zealand

J. M. WATERS (Chairman), E. N. BAKER, G. J. GAINSFORD, B. K. NICHOLSON, C. E. F. RICKARD.

\section{Norway}

C. RØMMING (Chairman), T. DAHL, B. FJAERTOFT, S. B. FURUSETH, J. K. GJØNNES, F. MO, J. SLETTEN, T. G. STRAND.

\section{Poland}

K. ŁUKASZEWICZ (Chairman), Z. GALDECKI, E. LAGIEWKA, M. LEFELD-SOSNOWSKA, J. LIPKOWSKI, A. PIETRASZKO, J. ŻMIJA.

\section{Portugal}

M. A. FORTES (Chairman), M. M. R. R. COSTA, M. O. V. DE FIGUEIREDO, J. LIMA-DE-FARIA, R. A. QUADRADO. 


\section{Russia}

YU. A. OSSIPYAN (Chairman), V. L. AKSENOV, K. S. ALEKSANDROV, E. V. ANTIPOV, L. A. ASLANOV, S. V. BORISOV, A. A. CHERNOV, S. K. FILATOV, E. H. HARUTYUNYAN, D. M. KHEIKER, V. SH. SHEKHTMAN, R. P. SHIBAEVA, V. I. SIMONOV, YU. I. SMOLIN, N. I. SOROKINA, S. M. STISHOV, V. S. URUSOV, B. B. ZVYAGIN.

\section{Serbia}

S. STANKOVIĆ (Chairman), S. JANJIC, L. KARANOVIĆ, D. POLETI, D. RODIC, D. STOJANOVIĆ.

\section{Slovenia}

L. GOLIC̆ (Chairman), V. KAUČIC MARINKOVIĆ, A. PRODAN.

\section{South Africa}

G. J. KRUGER (Chairman), J. C. A. BOEYENS, S. BOURNE, J. P. R. DE VILLIERS, M. J. LAING, L. R. NASSIMBENI, J. J. RETIEF.

$$
\text { Spain }
$$

C. MIRAVITLLES TORRAS (Chairman), M. I. ARRIORTUA MARCAIDA, A. CONDE AMIANO, F. HERNANDEZ CANO, M. MARTÍNEZ RIPOLL, F. SANZ RUIZ, X. SOLANS HUGUET.

$$
\text { Sweden }
$$

I. OLOVSSON (Chairman), J. ALBERTSSON, U. HÅLENIUS, L. KIHLBORG, $\AA$. KVICK, A. LILJAS, Y. LINDQVIST,
R. McGREEVY, R. NORRESTAM, A. OSKARSSON, M. SANDSTRÖM, E. SAUER-ERIKSSON, R. TELLGREN, J. O. THOMAS.

Switzerland
G. C. CHAPUIS (Chairman), V. GRAMLICH, H. STÖCKLIEVANS.

\section{Ukraine}

E. I. GLADYSHEVSKY (Chairman), Z. BARTOSHYNSKY, O. BODAK, O. CHERNEGA, M. GAMARNIK, B. KHAENKO, B. KOTUR, O. KURDYUMOV, B. NIKOLIN, L. PALATNIK, O. VLOKH, Y. VOROSHILOV.

$$
U K
$$

A. M. GLAZER (Chairman), F. H. ALLEN, P. BARNES, A. J. BLAKE, R. L. BRADY, K. M. CRENNELL, J. B. FORSYTH, C. J. GLMORE, S. HARRIS, J. A. K. HOWARD, E. H. KELLY, S. J. MAGINN, A. M. MOORE, H. MUIRHEAD, P. A. THOMAS, M. M. WOOLFSON.

USA

C. E. BUGG (Chairman), C. W. CARTER, A. K. CHEETHAM, C. CHIDESTER, A. CLEARFIELD, D. L. DORSET, D. S. EGGLESTON, P. M. D. FITZGERALD, J. L. FLIPPENANDERSON, J. D. JORGENSEN, J. A. KADUK, M. E. KASTNER, M. L. RIVERS, I. K. ROBINSON, J. L. SMITH.

\section{Venezuela}

M. V. CAPPARELLI (Chairman), D. GÓMEZ DE ANDÉREZ, O. V. GONZÁLEZ, J. L. MICHINEL MACHADO. 